University of South Florida

DIGITAL COMMONS

Digital Commons @ University of

@ UNIVERSITY OF SOUTH FLORIDA

South Florida

Research Reports

National Center for Transit Research (NCTR)

Archive (2000-2020)

$10-1-2015$

\title{
Technology Application among Florida Community Transportation Coordinators
}

CUTR

Follow this and additional works at: https://digitalcommons.usf.edu/cutr_nctr

\section{Recommended Citation}

"Technology Application among Florida Community Transportation Coordinators," National Center for Transit Research (NCTR) Report No. CUTR-NCTR-RR-2015-06, Center for Urban Transportation Research, University of South Florida, 2015.

DOI: https://doi.org/10.5038/CUTR-NCTR-RR-2015-06

Available at: https://scholarcommons.usf.edu/cutr_nctr/74

This Technical Report is brought to you for free and open access by the National Center for Transit Research (NCTR) Archive (2000-2020) at Digital Commons @ University of South Florida. It has been accepted for inclusion in Research Reports by an authorized administrator of Digital Commons @ University of South Florida. For more information, please contact digitalcommons@usf.edu. 

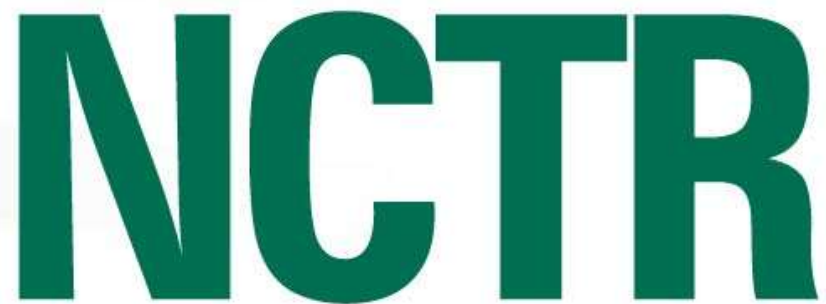

NATIONAL CENTER for TRANSIT RESEARCH

\title{
Technology Application among Florida Community Transportation Coordinators
}

Final Report

\author{
October 2015 \\ FDOT Research Report \\ BDV26-977-06
}

PREPARED FOR

Florida Department of Transportation and Florida Commission for the Transportation Disadvantaged
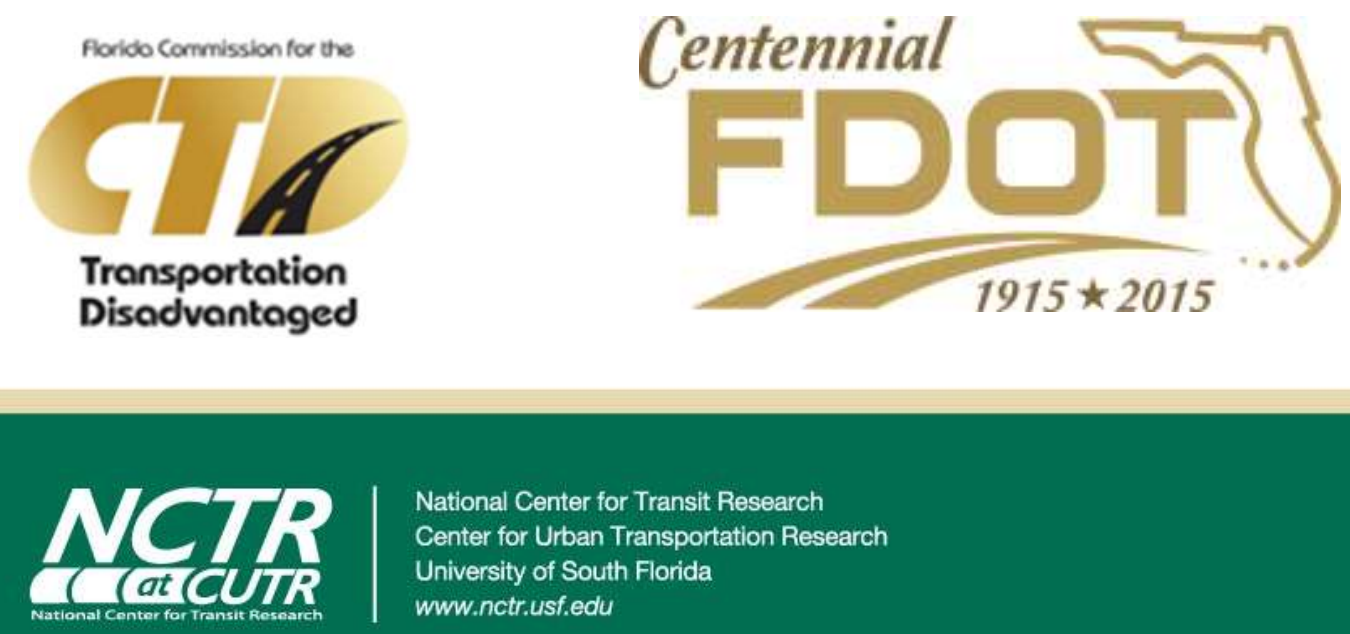


\section{Disclaimer}

The contents of this report reflect the views of the authors, who are responsible for the facts and the accuracy of the information presented herein. This document is disseminated under the sponsorship of the Department of Transportation University Transportation Centers

Program and the Florida Department of Transportation, in the interest of information exchange. The U.S. Government and the Florida Department of Transportation assume no liability for the contents or use thereof.

The opinions, findings, and conclusions expressed in this publication are those of the authors and not necessarily those of the State of Florida Department of Transportation.

The authors do not endorse products from any vendors. Products illustrated in the report are used as examples of available technology. 


\section{Metric Conversion}

\begin{tabular}{|c|c|c|c|c|}
\hline SYMBOL & WHEN YOU KNOW & MULTIPLY BY & TO FIND & SYMBOL \\
\hline \multicolumn{5}{|c|}{ LENGTH } \\
\hline in & inches & 25.4 & millimeters & $\mathrm{mm}$ \\
\hline ft. & feet & 0.305 & meters & $\mathrm{m}$ \\
\hline yd. & yards & 0.914 & meters & $\mathrm{m}$ \\
\hline mi & miles & 1.61 & kilometers & $\mathrm{km}$ \\
\hline \multicolumn{5}{|c|}{ VOLUME } \\
\hline fl. oz. & fluid ounces & 29.57 & milliliters & $\mathrm{mL}$ \\
\hline gal & gallons & 3.785 & liters & $\mathrm{L}$ \\
\hline $\mathbf{f t}^{3}$ & cubic feet & 0.028 & cubic meters & $\mathrm{m}^{3}$ \\
\hline$y^{3}$ & cubic yards & 0.765 & cubic meters & $\mathrm{m}^{3}$ \\
\hline \multicolumn{5}{|c|}{ NOTE: volumes greater than $1000 \mathrm{~L}$ shall be shown in $\mathrm{m}^{3}$} \\
\hline \multicolumn{5}{|c|}{ MASS } \\
\hline oz. & ounces & 28.35 & grams & $\mathrm{g}$ \\
\hline lb. & pounds & 0.454 & kilograms & $\mathrm{kg}$ \\
\hline $\mathbf{T}$ & Short tons (2000 lb.) & 0.907 & $\begin{array}{c}\text { megagrams } \\
\text { (or "metric ton") }\end{array}$ & $\mathrm{Mg}$ (or "t") \\
\hline \multicolumn{5}{|c|}{ TEMPERATURE (exact degrees) } \\
\hline${ }^{\circ} \mathbf{F}$ & Fahrenheit & $\begin{array}{c}5(F-32) / 9 \\
\text { or }(F-32) / 1.8\end{array}$ & Celsius & ${ }^{\circ} \mathrm{C}$ \\
\hline
\end{tabular}




\section{Technical Report Documentation Page}

\begin{tabular}{|c|c|c|c|c|c|}
\hline \begin{tabular}{|l|} 
1. Report No. \\
NCTR 211779700
\end{tabular} & \multicolumn{2}{|c|}{ 2. Government Accession No. } & \multicolumn{3}{|c|}{ 3. Recipient's Catalog No. } \\
\hline & \multicolumn{3}{|c|}{ 5. Report Date } \\
\hline \multicolumn{3}{|c|}{$\begin{array}{l}\text { Technology Application among Florida Community Transportation } \\
\text { Coordinators }\end{array}$} & \multicolumn{3}{|c|}{ 6. Performing Organization Code } \\
\hline \multicolumn{3}{|c|}{$\begin{array}{l}\text { Nevine Labib Georggi } \\
\text { Contributors: Casey Jarrell, Jay Goodwill, and Joel Volinski }\end{array}$} & \multicolumn{3}{|c|}{$\begin{array}{l}\text { 8. Performing Organization Report No. } \\
211779700\end{array}$} \\
\hline \multicolumn{3}{|c|}{ 9. Performing Organization Name and Address } & \multicolumn{3}{|c|}{ 10. Work Unit No. (TRAIS) } \\
\hline \multicolumn{3}{|c|}{$\begin{array}{l}\text { National Center for Transit Research } \\
\text { Center for Urban Transportation Research } \\
\text { University of South Florida } \\
4202 \text { East Fowler Ave., CUT100 } \\
\text { Tampa, FL } 33620\end{array}$} & \multicolumn{3}{|c|}{$\begin{array}{l}\text { 11. Contract or Grant No. } \\
\text { BDV26-977-06 }\end{array}$} \\
\hline \multirow{2}{*}{\multicolumn{3}{|c|}{$\begin{array}{l}\text { 12. Sponsoring Agency Name and Address } \\
\text { Florida Department of Transportation Research Center } \\
\text { Office of Public Transportation Transit Planning Program } \\
605 \text { Suwannee Street, MS } 30 \\
\text { Tallahassee, FL 32399-0450 }\end{array}$}} & \multicolumn{3}{|c|}{$\begin{array}{l}\text { 13. Type of Report and Period Covered } \\
\text { Final Report } \\
\text { (May 2014-October 2015) }\end{array}$} \\
\hline & & & \multicolumn{3}{|c|}{ 14. Sponsoring Agency Code } \\
\hline \multicolumn{6}{|c|}{ 15. Supplementary Notes } \\
\hline \multicolumn{6}{|c|}{$\begin{array}{l}\text { Project Manager: Sheri Powers, Area } 5 \text { Project Manager } \\
\text { William Hearndon, Area } 4 \text { Project Manager } \\
\text { Florida Commission for the Transportation Disadvantaged } \\
605 \text { Suwannee Street, MS } 49 \\
\text { Tallahassee, FL 32399-0450 } \\
\text { sheri.powers@dot.state.fl.us }\end{array}$} \\
\hline \multirow{2}{*}{\multicolumn{6}{|c|}{$\begin{array}{l}\text { Efficiently providing transit service to individuals who are considered to be, "transportation disadvantaged," } \\
\text { including people who are older, have disabilities, or are low-income, is a goal of the Federal Transit } \\
\text { Administration, the Florida Department of Transportation, and the Florida Commission for the Transportation } \\
\text { Disadvantaged. As demand for paratransit services continues to increase in many communities, transit agencies } \\
\text { must find innovative, creative, and cost-efficient ways to meet increasing demand, even when resources are not } \\
\text { increasing at the same pace. This report will help agencies apply effective practices that have been successful in } \\
\text { solving challenges with the application of new innovative technologies that are available to the industry. } \\
\text { An online survey of paratransit providers in Florida and visits to seven sites were conducted to gather case } \\
\text { examples and lessons learned from the deployment of reservation, scheduling, and dispatching software; mobile } \\
\text { data computers or terminals; global positioning systems; automatic vehicle location; advanced telephone } \\
\text { systems; and vehicle security cameras. Practical lessons learned can inform agencies seeking to deploy similar } \\
\text { technologies in the areas of vendor selection, system selection, and transitioning. The study recommends a } \\
\text { follow-up survey because a majority of agencies deployed these technologies only a few months prior to the } \\
\text { survey and interviews, rendering assessment of the return on investment premature. }\end{array}$}} \\
\hline & & & & & \\
\hline \multicolumn{4}{|l|}{ 17. Key Words } & 18. D & ution Statement \\
\hline \multicolumn{4}{|c|}{$\begin{array}{l}\text { Paratransit, automatic vehicle location, AVL, global positioning systems, GPS, } \\
\text { mobile data terminal, MDT, mobile data computer, MDC, vehicle security camera, } \\
\text { passengers per hour, productivity, on-time performance, no-shows }\end{array}$} & No $P$ & ctions \\
\hline $\begin{array}{r}\text { 19. Security Classi } \\
\text { Unclass }\end{array}$ & is report) & $\begin{array}{c}\text { 20. Security Classif. (of this page) } \\
\text { Unclassified }\end{array}$ & 21. No & $\begin{array}{l}\text { ages } \\
01\end{array}$ & 22. Price \\
\hline
\end{tabular}




\section{Tables of Contents}

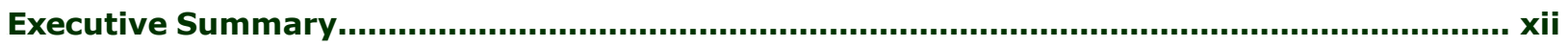

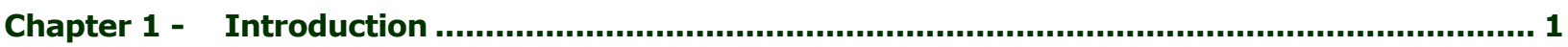

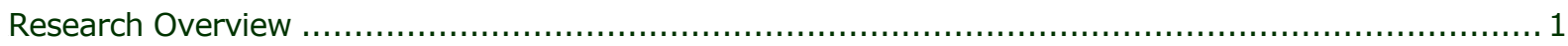

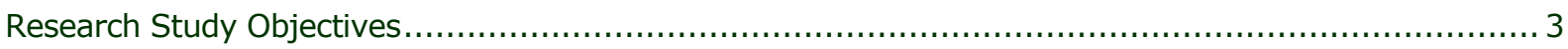

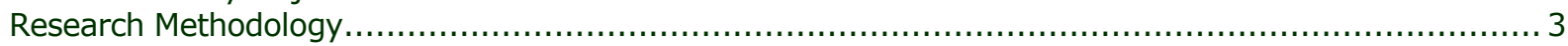

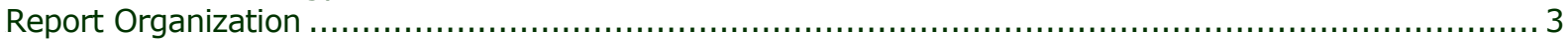

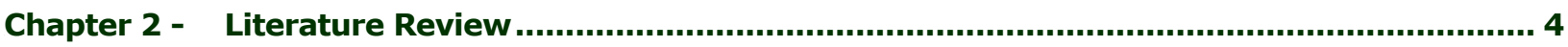

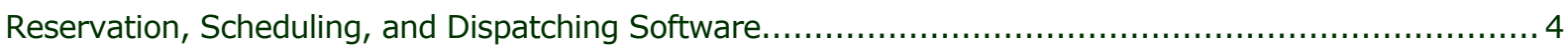

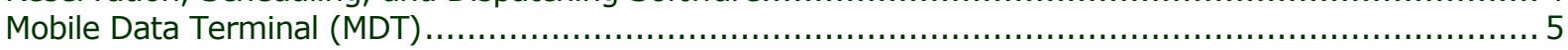

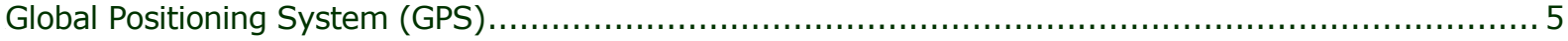

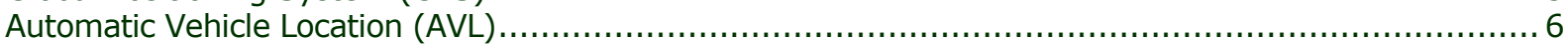

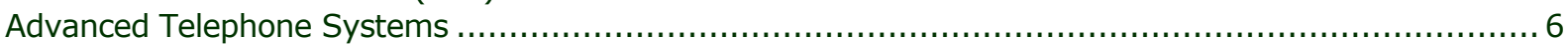

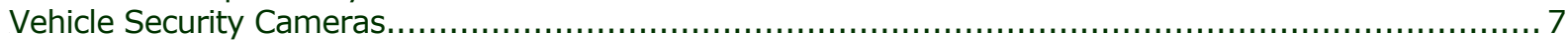

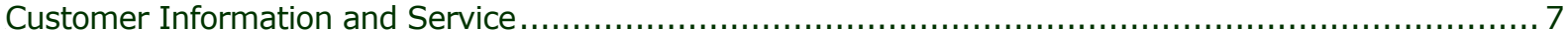

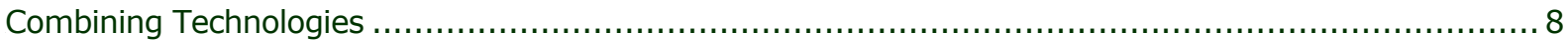

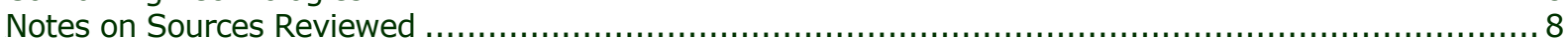

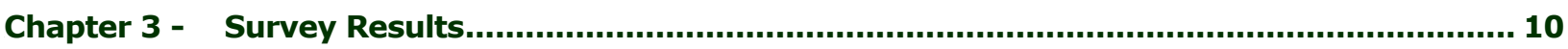

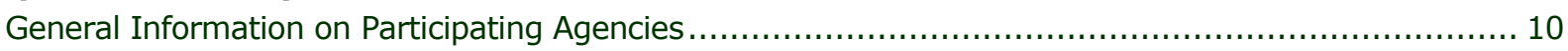

Overview of Technology Types Used by Agencies.................................................... 10

Funding Sources of Paratransit Services Provided by Agencies Surveyed .............................. 11

Reservation, Scheduling, and Dispatching Software............................................................ 13

Impacts of Using Reservation, Scheduling, and Dispatching Software on Decreasing "No-Shows".... 13

Impacts of Using Reservation, Scheduling, and Dispatching Software on Reducing Labor Costs....... 15

Impacts of Using Reservation, Scheduling, and Dispatching Software on Improving Customer

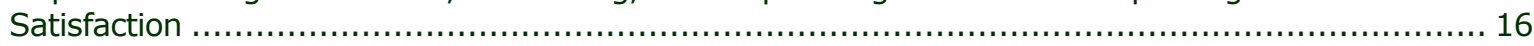

Impacts of Using Reservation, Scheduling, and Dispatching Software on On-Time Performance ....... 17

Impacts of Using Reservation, Scheduling, and Dispatching Software on Driver Performance.......... 18

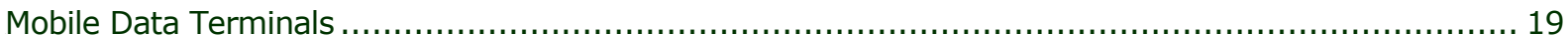

Impacts of MDT Deployment on On-Time Performance................................................. 20

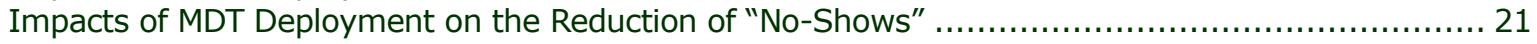

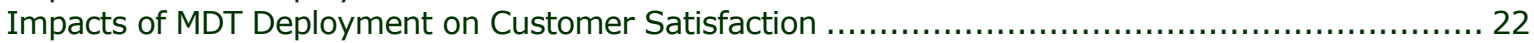

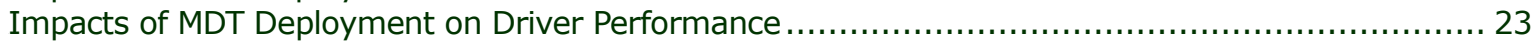

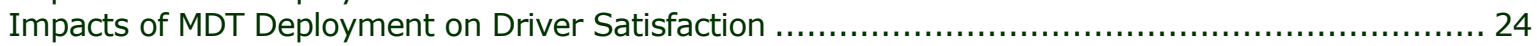

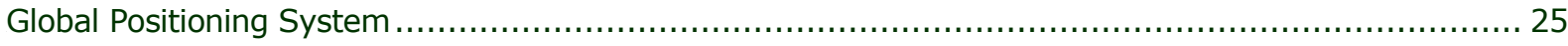

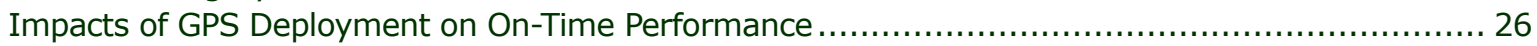

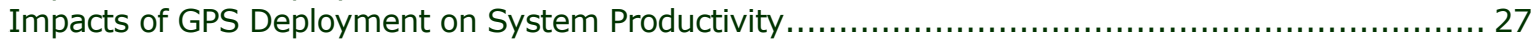

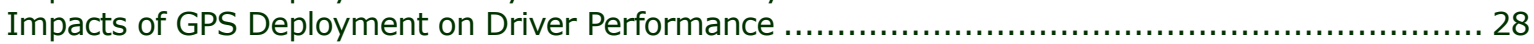

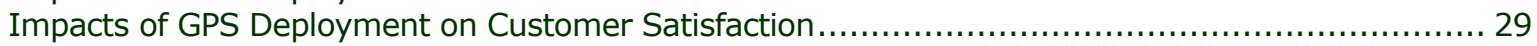

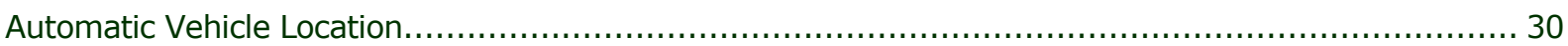

Impacts of AVL Deployment on On-Time Performance ................................................ 31

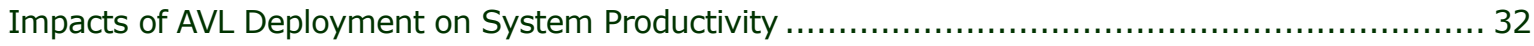

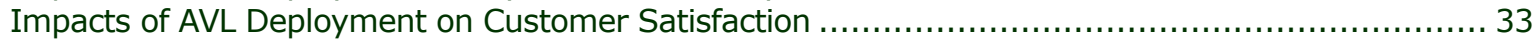

Impacts of AVL Deployment on Driver Performance..................................................... 34

Impacts of Using Advanced Telephone System on Productivity .......................................... 36

Impacts of Using Advanced Telephone System on the Reduction of "No-Shows"......................... 37

Impacts of Using Advanced Telephone System on Customer Satisfaction............................... 38

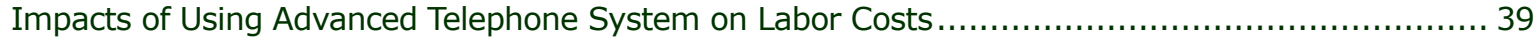




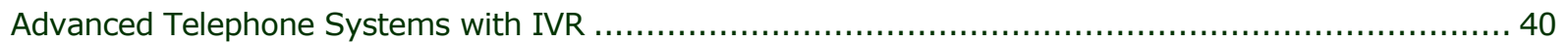

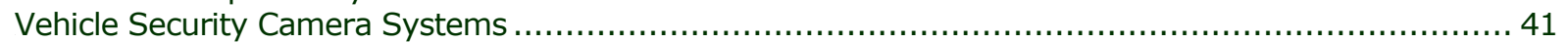

Impacts of Using Vehicle Security Camera Systems on Productivity or Performance................... 42

Impacts of Using Vehicle Security Camera Systems on Customer Satisfaction ............................4 43

Impacts of Using Vehicle Security Camera Systems on Driver Performance ........................... 44

Chapter 4 - Case Examples and Lessons Learned ................................................................... 45

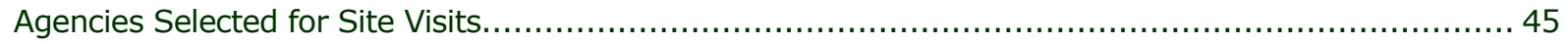

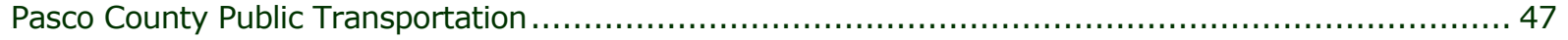

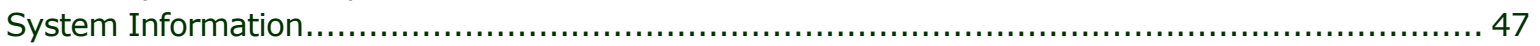

Description of Technology, Costs, and Funding Sources ................................................ 47

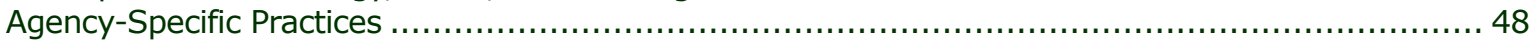

Technology Benefits as Experienced by the Agency...................................................... 48

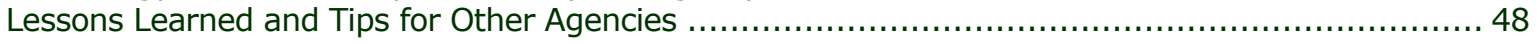

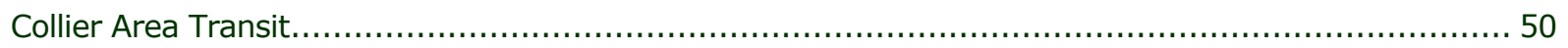

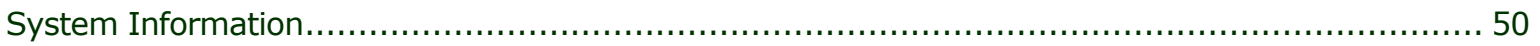

Description of Technology, Costs, and Funding Sources ................................................ 50

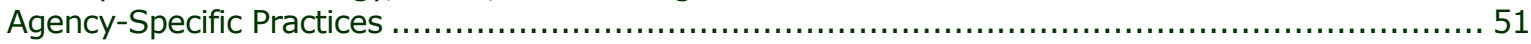

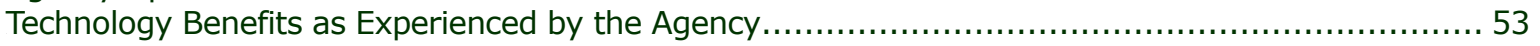

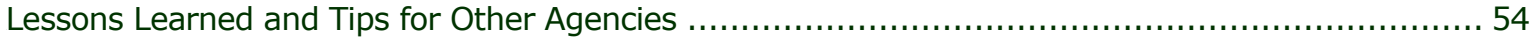

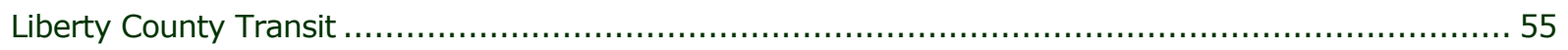

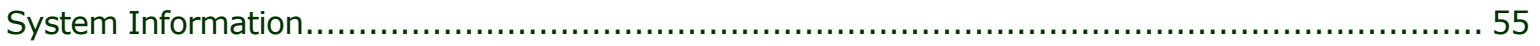

Description of Technology, Costs, and Funding Sources ................................................. 55

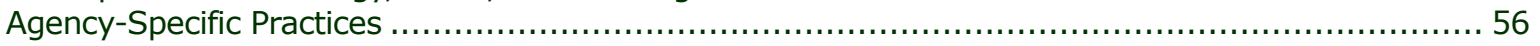

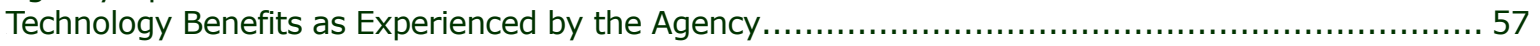

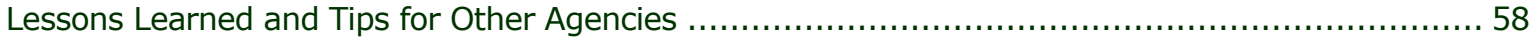

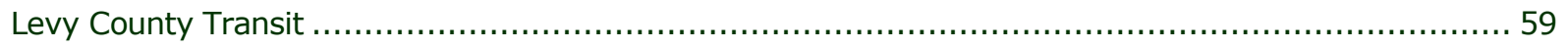

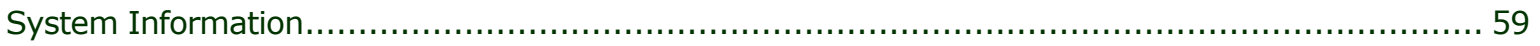

Description of Technology, Costs, and Funding Sources ................................................. 59

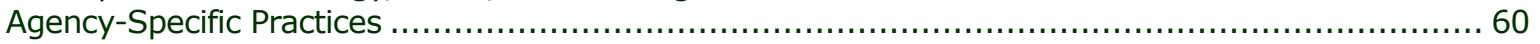

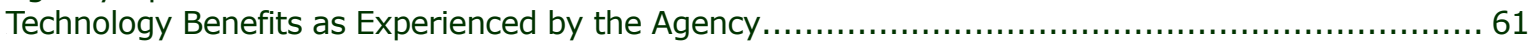

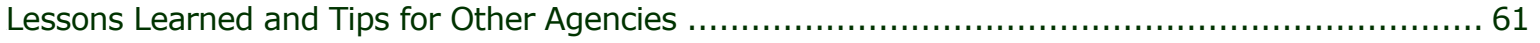

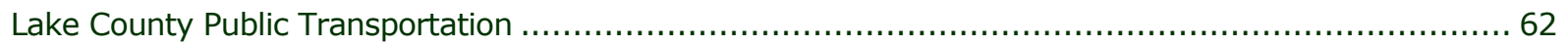

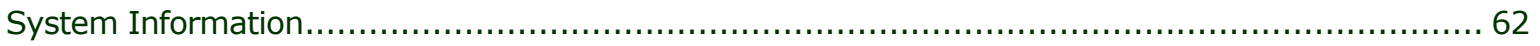

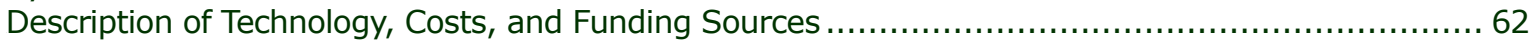

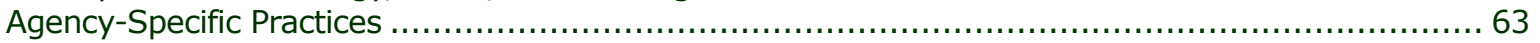

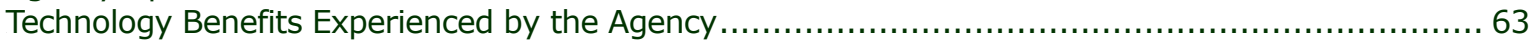

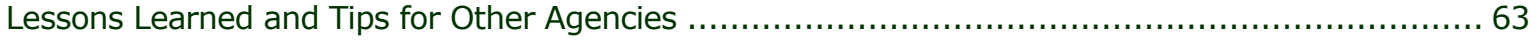

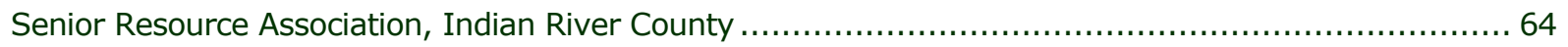

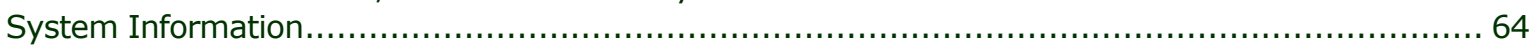

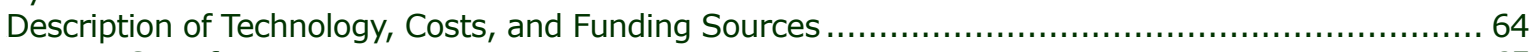

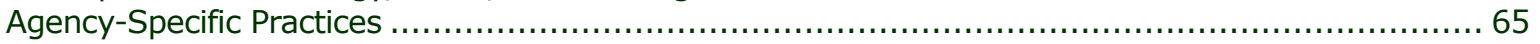

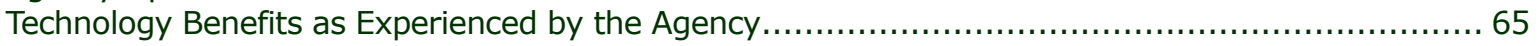

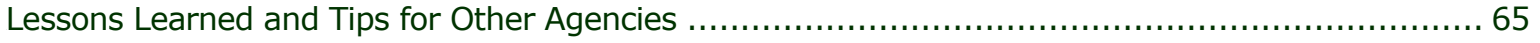

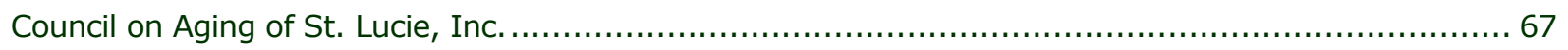

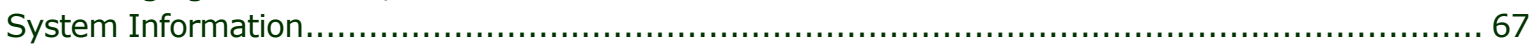

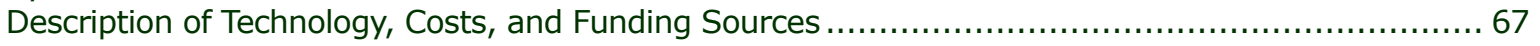

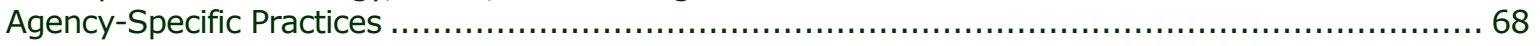

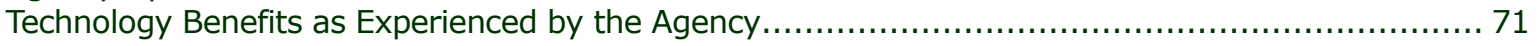

Lessons Learned and Tips for Other Agencies ............................................................. 72 
Chapter 5 - Conclusions and Recommendations........................................................ 73

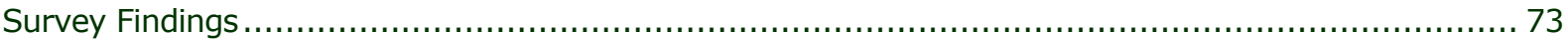

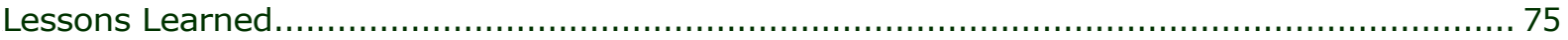

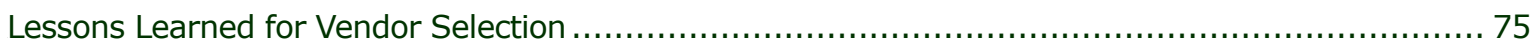

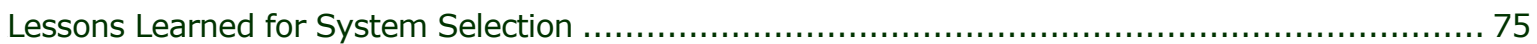

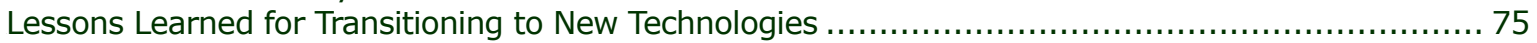

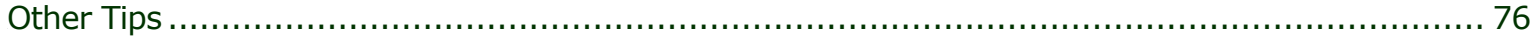

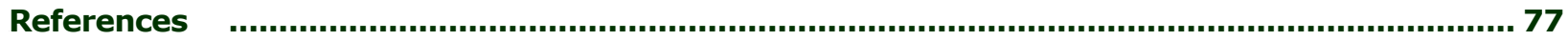

Appendix A - Survey Instrument............................................................................... 79 


\section{List of Figures}

Figure 1-1: Overview of General Concept of Paratransit Process and Potential

Technologies Deployed.

Figure 2-1: Tablet Serving as an MDT/AVL/GPS Unit Exchanges Real-Time Data with

Dispatcher using the Reservation, Scheduling, and Dispatching Software $\ldots \ldots \ldots \ldots \ldots \ldots \ldots . \ldots$

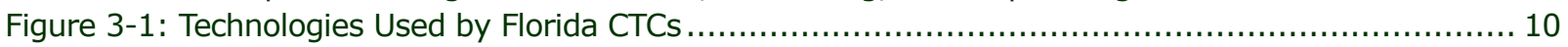

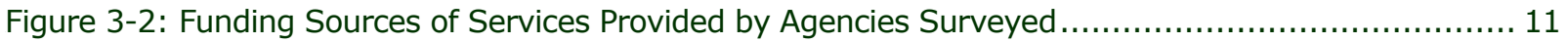

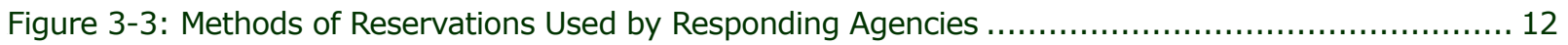

Figure 3-4: Reservation, Scheduling, and Dispatching Software Package Selection

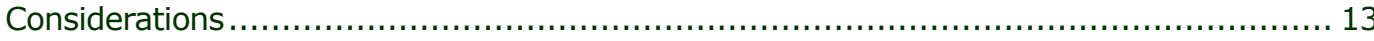

Figure 3-5: Impacts of Using Reservation, Scheduling, and Dispatching Software on "No-

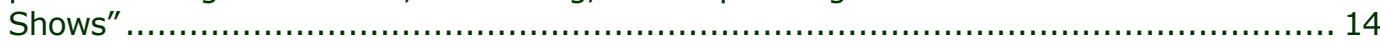

Figure 3-6: Impacts of Using Reservation, Scheduling, and Dispatching Software on

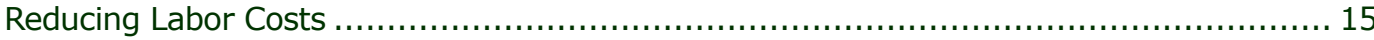

Figure 3-7: Impacts of Using Reservation, Scheduling, and Dispatching Software on

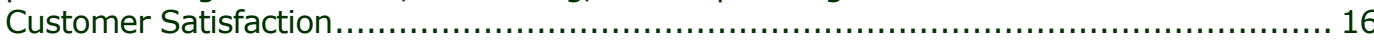

Figure 3-8: Impacts of Reservation, Scheduling, and Dispatching Software on On-Time

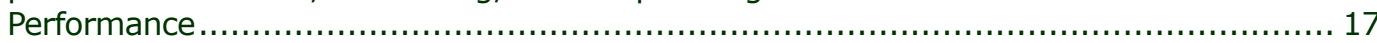

Figure 3-9: Impacts of Using Reservation, Scheduling, and Dispatching Software on

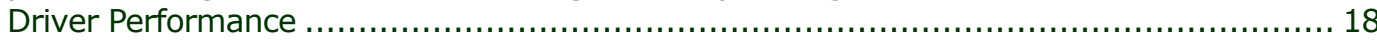

Figure 3-10: Impacts of MDT Deployment on On-Time Performance..................................... 20

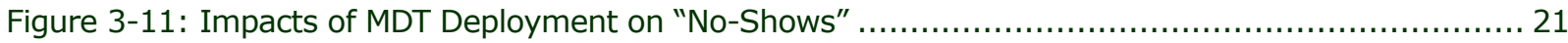

Figure 3-12: Impacts of MDT Deployment on Customer Satisfaction ................................... 22

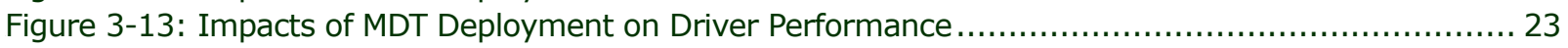

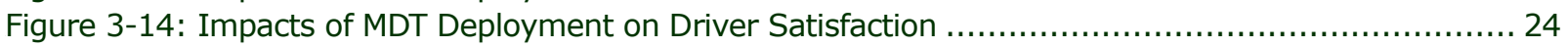

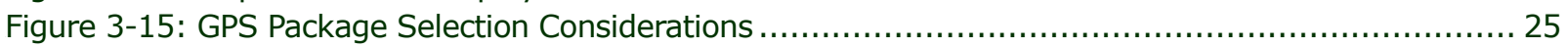

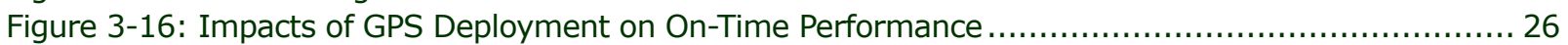

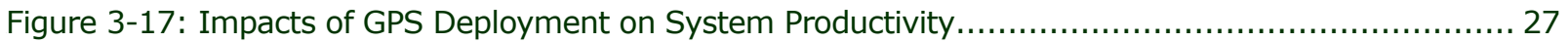

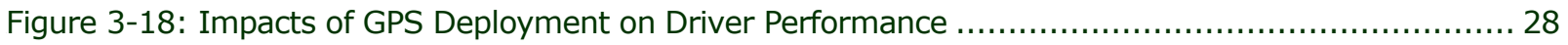

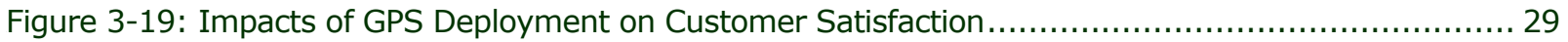

Figure 3-20: AVL Package Selection Considerations..................................................... 30

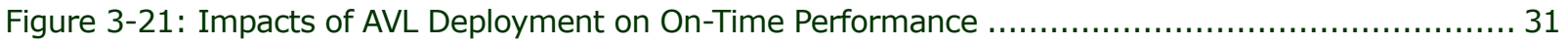

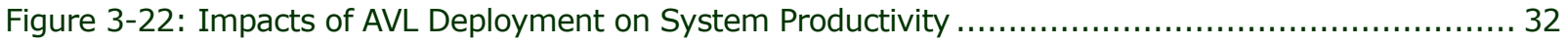

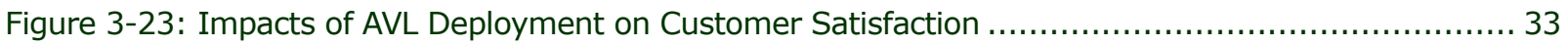

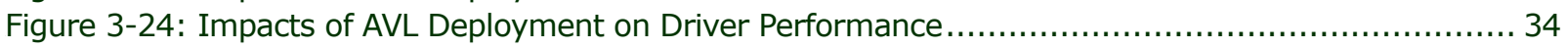

Figure 3-25: Advanced Telephone System Package Selection Considerations................................ 35

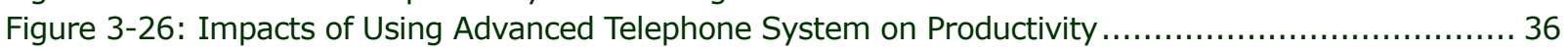

Figure 3-27: Impacts of Using Advanced Telephone System on Reduction of "No-Shows" ..................... 37

Figure 3-28: Impacts of Using Advanced Telephone System on Customer Satisfaction ..................... 38

Figure 3-29: Impacts of Using Advanced Telephone System on Labor Costs .............................. 39

Figure 3-30: Vehicle Security Camera Package Selection Consideration ...................................... 41

Figure 3-31: Impacts of using Vehicle Security Camera Systems on Productivity or

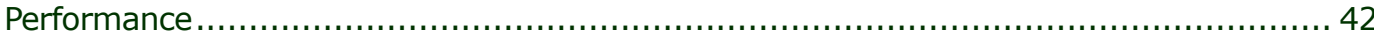

Figure 3-32: Impacts of Using Vehicle Security Camera Systems on Customer Satisfaction................. 43

Figure 3-33: Impacts of Using Vehicle Security Camera Systems on Driver Performance .................. 44

Figure 4-1: MDT (AVAIL Vector 9000) Mounted on Front of Dashboard on Collier Area

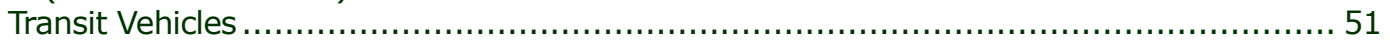

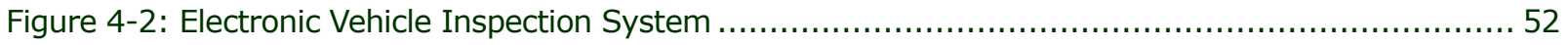

Figure 4-3: Vehicle Security Camera System on Collier Area Transit Fleet Vehicle........................... 52

Figure 4-4: New M-Slate MDT from AVAIL on a Collier Area Transit Fleet Vehicle.......................... 53

Figure 4-5: Tablets in Liberty County Transit Assigned to Drivers, Not Vehicles ............................. 56

Figure 4-6: Scheduling and Dispatching Staff Can View Real-Time Locations and Speeds

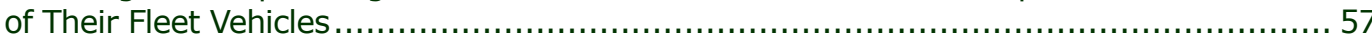


Figure 4-7: Big Screen Displaying Locations of Fleet Vehicles in Real-Time for At-a-Glance Tracking by Schedulers and Dispatchers in Same Office at Levy County Transit

Figure 4-8: Fixed-Route and Demand Response Vehicle Locations and Speeds Monitored

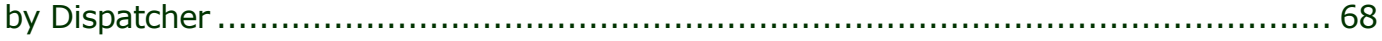

Figure 4-9: Electronic Manifest Displayed on Tablet on Council on Aging of St. Lucie Fleet Vehicle.

Figure 4-10: New MDT Tablet Mounted on Stand Secured to Floor of Vehicle and Old MDT Ranger Unit Mounted on the Dashboard....

Figure 4-11: V-TRACK AVL System Unit and Screen Output Displaying Location of Vehicles in System

Figure 4-12: Council on Aging of St. Lucie, Inc., hosts RouteMatch and V-TRACK AVL on

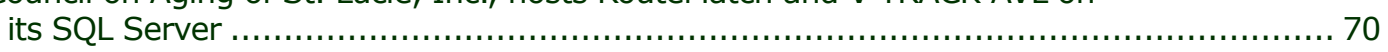

Figure 4-13: Vehicle Security Cameras Mounted Facing Wheelchair Lift ...................................... 71

Figure 4-14: Security Camera Mounted on Outside of Transit Vehicle at Council on Aging of St. Lucie, Inc. 


\section{List of Tables}

Table ES-1: Impacts of Deploying Different Technologies on Selected Performance

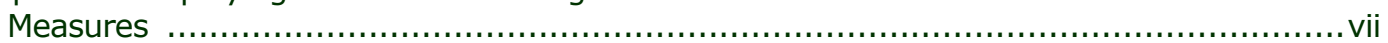

Table 4-1: Agencies Selected for Further Documentation of Impacts ....................................... 46

Table 4-2: 2014 Pasco County Public Transportation Information as Reported to Florida

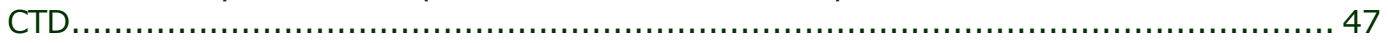

Table 4-3: 2014 Collier Area Transit Information as Reported to Florida CTD ............................... 50

Table 4-4: 2014 Liberty County Transit Information as Reported to Florida CTD ................................ 55

Table 4-5: 2014 Levy County Transit Information as Reported to Florida CTD .............................. 59

Table 4-6: 2014 Lake County Public Transportation Information as Reported to Florida

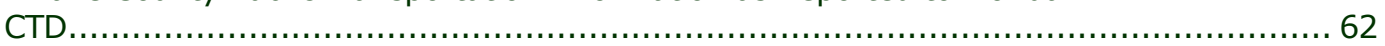

Table 4-7: 2014 Senior Resource Association, Indian River County, Information as

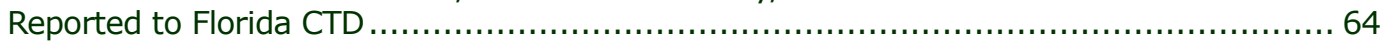

Table 4-8: 2014 Council on Aging of St. Lucie, Inc., Information as Reported to Florida

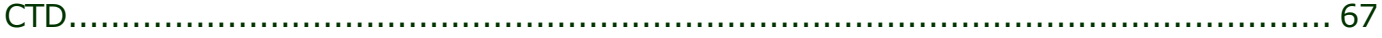

Table 5-1: Impacts of Deploying Different Technologies on Selected Performance

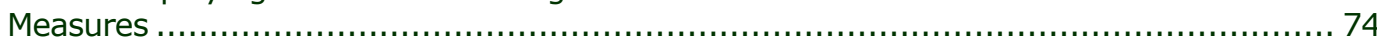




\section{Acknowledgments}

The research team recognizes and appreciates the contribution of Rosemary Gerty, General Manager, Regional Accessibility at the Regional Transportation Authority, Greater Chicago Area. Thanks are expressed to Boyd Thompson, Director of Operations at Ride Solution, Putnam County, Florida, and Lisa C. Love, former Director of Transportation Services, St. Johns County Council on Aging, Inc.

The research team is appreciative of the responsiveness of the Florida Community Transportation Coordinators and the staffs of transit agencies that participated in the online survey conducted as part of this project. The team also thanks the following staff members who discussed their agency's experiences with deployed technologies during site visit interviews and who provided the opportunity to take the photographs shared in this report.

Pasco County Public Transportation: Mike Carroll, Public Transportation Director Joseph L. DeGeorge, Operations Manager

Collier Area Transit:

Liberty County Transit:

Levy County Transit:

Lake County Public Transportation:

Senior Resource Association:

Council on Aging of St. Lucie, Inc.:

The NCTR Research Team

Principal Investigator:

Co-Principal Investigator:

Reviewers:

Graduate Research Assistant:
Yousi Cardeso, Operations Coordinator Omar Deleon, Planning Manager/Revenue Omar Lopez, Paratransit Manager

Monica Welles, Program Coordinator

Connie Conley, Director

Amy Bradford, Transportation Representative, Community Services Department

Karen B. Rose Deigl, CEO/President Chris Stephenson, Operations Manager Mary Pierce, Paratransit Supervisor Jennifer Johnson, Chief Financial Officer Ashley Bennete, Dispatcher

Marianne Arbore, Transit Director, VP/CTO Bruce Walker, Software System Analyst

Nevine Labib Georggi, Senior Research Associate, CUTR

Joel Volinski, Director, NCTR

Jay Goodwill, Senior Research Associate, CUTR Phil Winters, Director, TDM Program, CUTR

Casey Jarrell, Engineer I, HNTB Corporation 


\section{Executive Summary}

\section{Research Overview}

Individuals who are considered "transportation disadvantaged" may include people who are older, have disabilities, or are low-income. A survey of transit agencies by the U. S. Government Accountability Office (GAO) found that demand for paratransit trips increased $7 \%$ from 2007 to 2010 . About $73 \%$ of agencies surveyed experienced an increase of approximately $12 \%$ in the number of individuals registered to use Americans with Disabilities Act (ADA) paratransit service ${ }^{1}$.

The pressure to provide adequate transit service for people who are transportation disadvantaged while containing costs is and will continue to be a balancing act as long as demand continues to increase. All aspects of the cost-effectiveness of operations are constantly being studied to find case examples that would help provide quality service even with funding limitations. Providing efficient transit service to the transportation disadvantaged and to persons with disabilities is a goal of the Federal Transit Administration (FTA), the Florida Department of Transportation (FDOT), and the Florida Commission for the Transportation Disadvantaged (CTD).

This study defines paratransit services as complimentary ADA services and door-to-door services, including those provided by the CTD's Community Transportation Coordinators (CTCs). In Florida, the number of passenger trips provided in 2014 by Florida CTCs was $29,243,177$, which is projected to grow annually as the general and older adult populations continue the growth pattern currently observed.

This research study investigated the impacts of applying various technologies to paratransit systems. Based on a survey of Florida agencies and interviews with several of them during site visits, lessons learned are presented to help agencies apply effective practices that have been successful in solving challenges with the application of new innovative technologies that are available to the industry. The report also provides data from survey responses that indicate reasons that prompted the application of these technologies, the costs of the technologies deployed, and the funding sources that were used for the purchases. In addition, the report sheds light on the ability of the studied technologies to increase system performance.

\section{Survey Findings}

The scarcity of information sources that address the impacts of new technologies on the performance measures in the paratransit field became clear during the literature review phase of this study. Although some publications document the impacts on transit in general, the nature of paratransit operations is different from fixed-route transit. Operators of paratransit vehicles get a daily manifest that lists the stops they will make that day, including riders' names, addresses, and drop-off locations, whereas transit operators have fixed schedules and static stops. This research study addressed the gap by conducting an online survey of all Florida CTCs in February 2015 and in-person interviews with seven of the agencies that cited significant impacts in the survey. The mailing list of all Florida CTCs was obtained from the Florida CTD and 78 percent responded to the survey. Survey questions are included in Appendix A of this report.

\footnotetext{
1 "Demand has increased, but little is known about compliance," GAO-13-17, Nov. 15, 2012. Accessed June 23, 2015, at http://gao.gov/assets/660/650079.pdf
} 
Based on the information found in the literature review, the following technologies were the focus of this research. The survey indicated the following percentages of responding Florida CTCs using these technologies:

- Reservation, scheduling, and dispatching software (100\%)

- Mobile data computer (MDC) or mobile data terminal (MDT) (74\%)

- Automatic vehicle location (AVL) (71\%)

- Global positioning system (GPS) (69\%)

- Vehicle security cameras (66\%)

- Advanced telephone systems (63\%)

Also based on the literature review, the following performance measures were selected as the major elements for evaluating the technologies listed above:

- System productivity (passengers served per revenue hour)

- On-time performance

- Reduction of no-shows

- Driver performance and satisfaction

- Customer satisfaction

Table ES-1 presents an overview of the findings of the survey in which participants were asked how each technology affected the performance of their system.

To put some of the statistics of Table ES-1 in perspective, two items of interest must be kept in mind. First, several of these technologies were implemented in late 2014 or early 2015, and the CTCs remarked that it was too early to assess any impacts. For example, the majority of the respondents (83\%) updated their reservation, scheduling, and dispatching software in late 2014 or early 2015 . Second, several agencies had recently deployed the Samsung tablet as their MDT/AVL/GPS all-in-one unit; separating the impacts of one unit that functions as three is not easily expressed. Six of the seven agencies interviewed during site visits were using a tablet as their MDT unit.

Notable from Table ES-1 are the following:

- On-time performance was most impacted by deploying MDTs (64\%), and by use of reservation, scheduling, and dispatching software (63\%). These two technologies work in sync to track important times such as arrival and departure from the origin and dropoff at destination. Knowledge of these times is beneficial in generating reports and pointing to the need for improvements or training.

- Deploying MDTs scored the highest in moderate-to-significant improvements on driver performance, with $83 \%$ percent of the agencies recognizing that improvement. The improved driver performance was tied to the use of tablets, which were easier read than previous MDTs that had smaller screens. Also, an electronic manifest replacing a paper manifest was an added time-saver for drivers as paperwork was reduced.

- The second most cited improvement in driver performance was realized from deploying vehicle security cameras (69\%). Some agencies expressed that the drivers initially were uncomfortable with being video- and audio-recorded but soon realized that cameras protected them in case of an incident or false complaint. Drivers generally forgot they were being recorded all the time. 
- The most-cited technologies affecting customer satisfaction were MDTs (60\%) and vehicle security cameras (59\%). MDTs made the system more efficient, as electronic manifests make it possible for dispatchers to communicate changes with drivers, which made return trips more efficient. In addition to feeling more secure with cameras on board, customers experienced faster complaint resolution because the recordings show the agency exactly what happened.

Table ES-1: Impacts of Deploying Different Technologies on Selected Performance Measures

\begin{tabular}{|c|c|c|c|c|}
\hline \multirow[b]{2}{*}{$\begin{array}{l}\text { Performance Measures of Selected } \\
\text { Technologies }\end{array}$} & \multicolumn{4}{|c|}{ Impacts } \\
\hline & $\begin{array}{l}\text { Significant } \\
\text { Impacts (\%) }\end{array}$ & $\begin{array}{c}\text { Moderate } \\
\text { Impacts }(\%)\end{array}$ & $\begin{array}{c}\text { No } \\
\text { Impacts } \\
(\%)\end{array}$ & $\begin{array}{l}\text { Unknown } \\
\qquad(\%)\end{array}$ \\
\hline \multicolumn{5}{|c|}{ Reservation, Scheduling, and Dispatching Software } \\
\hline Customer satisfaction & 22 & 33 & 15 & 30 \\
\hline Reduction of "no shows" & 8 & 19 & 42 & 31 \\
\hline Driver performance & 30 & 33 & 15 & 22 \\
\hline On-time performance & 37 & 26 & 15 & 22 \\
\hline Agency labor costs & 14 & 29 & 25 & 32 \\
\hline \multicolumn{5}{|l|}{ Mobile Data Terminals } \\
\hline Customer satisfaction & 16 & 44 & 12 & 28 \\
\hline Reduction of "no shows" & 12 & 4 & 56 & 28 \\
\hline Driver performance & 29 & 54 & 8 & 9 \\
\hline On-time performance & 28 & 36 & 16 & 20 \\
\hline Driver satisfaction & 24 & 40 & 20 & 16 \\
\hline \multicolumn{5}{|l|}{ Global Positioning System } \\
\hline Customer satisfaction & 11 & 16 & 26 & 47 \\
\hline Driver performance & 26 & 32 & 10 & 32 \\
\hline On-time performance & 5 & 42 & 16 & 37 \\
\hline System productivity & 16 & 21 & 21 & 42 \\
\hline \multicolumn{5}{|l|}{ Automatic Vehicle Location } \\
\hline Customer satisfaction & 20 & 27 & 20 & 33 \\
\hline Driver performance & 20 & 33 & 13 & 34 \\
\hline On-time performance & 25 & 12 & 19 & 44 \\
\hline System productivity & 0 & 29 & 21 & 50 \\
\hline \multicolumn{5}{|l|}{ Advanced Telephone System } \\
\hline Customer satisfaction & 10 & 40 & 20 & 30 \\
\hline Reduction of "no shows" & 18 & 27 & 27 & 28 \\
\hline System productivity & 27 & 37 & 9 & 27 \\
\hline Labor costs & 10 & 30 & 40 & 20 \\
\hline \multicolumn{5}{|l|}{ Vehicle Security Camera System } \\
\hline Customer satisfaction & 19 & 44 & 25 & 12 \\
\hline Driver performance & 19 & 50 & 12 & 19 \\
\hline System productivity & 25 & 19 & 31 & 25 \\
\hline
\end{tabular}


To get a thorough understanding of how new technologies are helping Florida CTCs meet the challenges of providing the necessary services as well as working within their means, the research team asked them to identify the impacts of new technologies. CTC staff knows the challenges well, as trips have to be completed with no delays and customers have to be satisfied.

\section{Lessons Learned}

To document case examples and lessons learned, seven Florida CTCs were selected for site visits, during which in-person interviews were conducted. The methodology used to select agencies was based on distilling the survey responses from all the agencies and identifying those that experienced moderate and/or significant impacts when deploying each technology. The research team selected agencies with a minimum of three moderate-to-significant impacts on performance measures to justify the site visit. The systems visited are the following, listed in the order of the site visits conducted:

- Pasco County Public Transportation

- Collier Area Transit

- Liberty County Transit

- Levy County Transit

- Lake County Public Transportation

- Senior Resource Association, Indian River County

- Council on Aging of St. Lucie County, Inc.

\section{Lessons Learned for Vendor Selection}

- Vendors should be able to provide references, and agencies should take the time to interview these references. Building upon the research presented in this report, peer agencies should be asked about their experiences with vendor technical support, training, and availability via phone or in person and their timely responsiveness to issues/challenges that come up during transition from old to new system, updates, and customer service beyond the transition. A vendor's timely response to peer agencies is a good indication of its availability.

- Hands-on training provided by the vendor is key to the success of transitioning to new systems. Agencies should make sure many opportunities are provided for training of staff and operators. In addition, agencies should set up train-the-trainer sessions so staff are confident in training new operators on the system even after transitioning is completed. Agencies can make sure that the contract includes training and/or online educational sessions for their staff.

\section{Lessons Learned for System Selection}

- Before specifications of a new system are decided upon, agencies should seek the input of all agency staff involved in the paratransit operation. Upper management may know in general what all staff jobs entail but may not be as familiar with the intricate data needs required for performing day-to-day tasks, particularly report generation.

- Each agency should recognize the unique features of its system, including their specific needs. Since software is usually standardized, it is recommended that agencies make sure to convey their specific needs during the planning process before the procurement package is developed. Data fields that have been used for years in old software may not correspond to the new software, so adjustments or customizations may be needed. 
Agencies are better off making this customization up front than trying to retrofit the software during the transion or post deployment.

\section{Lessons Learned for Transitioning to the New Technologies}

- New and old systems should run in parallel for at least a month until all "glitches" are worked out. Even if it means the agency will be paying two vendors simultaneously, it is well worth the cost so as not to fall behind in reporting and billing of trips.

- Some resistance to new technology should be expected from staff and operators. With training, attitudes towards change will be more positive once benefits are realized and trust is built.

\section{Other Tips}

- Investing in a vehicle security camera system was cited by several agencies as providing the "best bang for the buck." The benefits of video cameras included protection of drivers and passengers, incident management, risk reduction, conflict mitigation, and eliminating unfounded liability payouts.

- Some agencies pull videos for random inspection to make sure operators properly follow all procedures. This policy could reduce the tasks of field inspectors.

- In case of Internet or cellular communications failure, agencies must have a backup plan such as paper manifests, two-way radio communications, and cell phone access to the software system, etc.

- The deployments have shown that the technologies are helping in increasing overall system efficiency. The effectiveness of these technologies may take time to be realized in full, but money will be saved in the long run from efficiency and performance improvements. Patience is key. 


\section{Chapter 1 - Introduction}

\section{Research Overview}

The pressure on transit agencies to provide effective services, although challenging, provides opportunities for creative and innovative solutions to meet growing demand even when resources are not increasing at the same pace [1]. Providing efficient transit service to the transportation disadvantaged and to persons with disabilities is a goal of the Federal Transit Administration (FTA), the Florida Department of Transportation (FDOT), and the Florida Commission for the Transportation Disadvantaged (CTD). This research study investigated the impacts of applying various technologies to paratransit systems. Based on a survey of Florida agencies and interviews with several of them during site visits, lessons learned are presented to help agencies apply effective practices that have been successful in solving challenges with the application of new technologies that are available to the industry. The report also provides data from survey responses that indicate the reasons that prompted the application of these technologies, the costs of the technologies deployed, and the funding sources that were used for the purchases. In addition, the report sheds light on the ability of the studied technologies to increase system performance.

Figure 1-1 is a broad overview of the process to reserve, schedule, and complete a paratransit trip with the technology applications that have been applied to increase the efficiency of the process. Depending on the agency, the process may be fully or partially automated. From the literature reviewed, it is noted that, in this industry, each agency has unique circumstances that may differ from the general concept illustrated in Figure 1-1.

In a recent article [2], Ron Brooks, Manager of Accessible Transit Services at Valley Metro in Phoenix, Arizona, addressed the challenges facing paratransit as demand increases and costs are rising. He emphasized that technology is playing an even greater role in the delivery of paratransit services. This research focused on several technologies that have been used in the paratransit industry to improve both the user experience and the operations of a system. Those technologies include:

- Reservation, scheduling, and dispatching software

- Mobile Data Terminal (MDT) or Mobile Data Computer (MDC)

- Global Positioning System (GPS)

- Automatic Vehicle Location (AVL)

- Advanced Telephone Systems

- Vehicle security cameras 


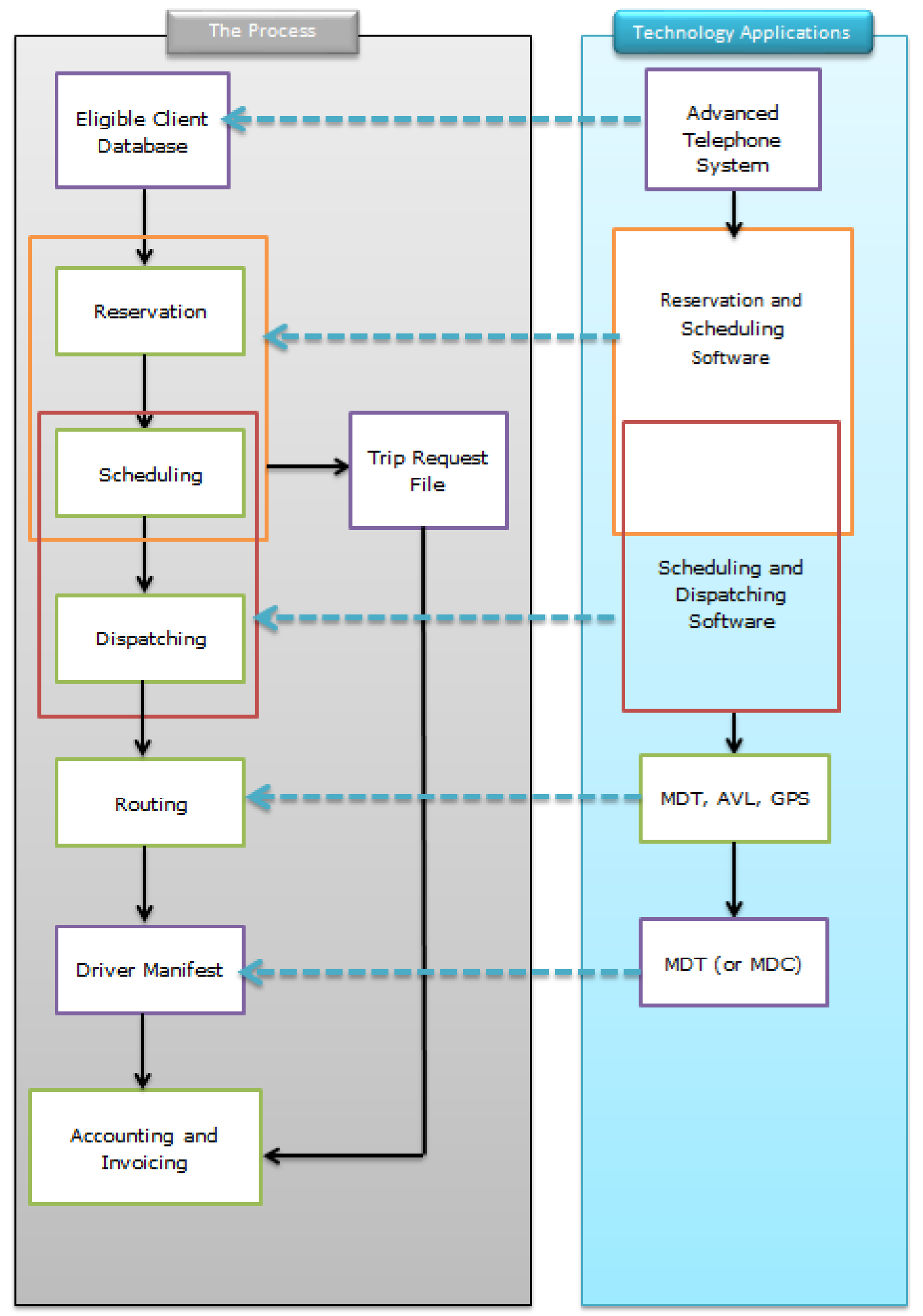

Figure 1-1: Overview of General Concept of Paratransit Process and Potential Technologies Deployed 


\section{Research Study Objectives}

The objective of this study was to gather and disseminate information on case examples in the application of technology in the paratransit field. The research purposes were to inform the industry of the state of the practice and to initiate an exchange among providers in Florida on successful practices.

\section{Research Methodology}

An online survey of all Florida Community Transportation Coordinators (CTCs) was conducted in February 2015. Based on the survey responses, seven paratransit providers representing rural, urban, and small- and medium-size agencies were selected for site visits, at which indepth interviews were conducted. The selection of these agencies was based on the reporting of significant impacts on performance measures due to deployment of the various technologies. Based on information from the selected agencies, lessons learned and tips for future deployments are presented in this report.

The following performance measures were the focus of the questions presented to Florida CTCS and staff of systems interviewed during site visits:

- System productivity (passengers served per revenue hour)

- On-time performance

- Reduction of no-shows

- Driver performance and satisfaction

- Customer satisfaction

\section{Report Organization}

Chapter 2 presents a summary of the literature review conducted under Task 1 of the project.

Chapter 3 includes the survey findings and documents the results of the in-depth interviews conducted during site visits to the seven Florida agencies. It also presents the justification and methodology for selecting these agencies. The questionnaire used as the online survey instrument is included in Appendix A.

Chapter 4 provides the findings of this study and offers practical recommendations based on lessons learned.

Chapter 5 presents conclusions and recommendations. 


\section{Chapter 2 - Literature Review}

The following sections focus on several technologies that have been used in the paratransit industry to improve both the user experience and the operational efficiency of paratransit systems. Based on sources reviewed, the technologies selected as the focus of the project are discussed separately in the next sections.

\section{Reservation, Scheduling, and Dispatching Software}

Paratransit software packages are capable of managing databases of eligible passengers, determining eligibility, scheduling trips, developing trip manifests, monitoring past trips, and producing invoices. In 2008, 94\% of Florida transit agencies used reservation, scheduling, and dispatching software for their paratransit system [3].

Paratransit services can offer different types of reservations. Same-day service can accommodate requests made the same day, depending on availability. Immediate service has obvious advantages for paratransit users; however, these trips can be difficult operationally for a variety of reasons. Advance service is prescheduled to arrive a day or more after the reservation is originally made. Subscription reservations are a form of advance reservations for trips that occur on a regular basis, usually for work trips or recurring medicals trips such as dialysis treatment. Most trip reservations are made the previous day or up to two weeks in advance, depending on system policies.

There are four levels of Computer Aided Dispatch (CAD) software:

1. Generic software, which includes word processing, data management, and spreadsheets.

2. Customized generic software, which can meet specific needs of the agency.

3. Semi-automated CAD software used for zone-to-zone transit operations.

4. Fully-automated CAD software, which has greater Advanced Public Transportation System (APTS) compatibilities and full Geographic Information System (GIS) compatibility [4].

Generic software generally costs $\$ 100-\$ 500$. Specialty software can be used for tasks that are more specific. Trip order-taking software, which is offered by many vendors, generally costs less than $\$ 1,000$. However, if scheduling software is necessary for a paratransit service, ordertaking capability is included within that software.

Customized database applications cost $\$ 1,000-\$ 10,000$ and are recommended for agencies that have 10-30 vehicles in their fleet. Semi-automated CAD software is a commercial product that costs $\$ 1,000-\$ 25,000$. Fully-automated CAD software can cost $\$ 4,000-\$ 1$ million, depending on the size of the fleet plus any training and maintenance expenses and customization [4].

According to a 2013 annual survey conducted by Metro Magazine concerning productivity, agencies that bill per hour averaged 2.34 passengers, and those that bill per trip averaged 2.15 passengers [5]. Although contracting issues are factors in this context, these figures are presented here as reported averages of productivity.

Various software providers have stated that agencies that effectively use computerized routing and scheduling software have shown $10-20 \%$ productivity improvements as a result of 
reduced mileage per trip and more efficient allocation of service hours [6]. For example, the Toledo Area Regional Transit Authority in Ohio saw significant changes after the installation of routing/scheduling software in its paratransit system. The agency reported that the number of passengers per hour increased by $25 \%$, which enabled the paratransit service to grow by nearly $25 \%$ without an increase in its budget [7, p. 52].

\section{Mobile Data Terminal (MDT)}

MDCs or MDTs and the more recent Mobile Data Tablets act as a form of communication between the operator of a paratransit vehicle and the paratransit provider's central dispatch location; usually, they are paired with AVL technology. MDTs are capable of sending vehicle location, passenger count, engine performance, and mileage to these central dispatch locations. MDTs allow operators to send and receive messages, prompt alarms, and monitor their adherence to schedules [8]. With MDTs, operators are able to record pick-up and drop-off times and locations, store time and mileage logs, and allow for automated record keeping with minimal effort. The dispatcher (located at the central location) is better able to create, delete, and reassign trips when MDT technology is available alongside AVL technology. The editing of these trips can be in response to traffic, cancellations, or other incidents [3]. MDTs are capable of having "no-shows" entered into them. In case of an Americans with Disabilities (ADA) trip, after contact is established with a rider, the dispatcher can cancel the return trip if it is not needed, allowing for better use of vehicle hours [9].

The cost of an MDT that would be appropriate for a paratransit vehicle typically runs between $\$ 1,000$ and $\$ 4,000$ per unit, including hardware and software. Cost savings due to MDT installation comes from the elimination of manually re-writing and re-entering trip data since MDTs remove the need for paperwork related to the trip manifest process. With an electronic manifest on their MDT, vehicle operators can save up to 30 minutes per day by not having to manually enter information into paper manifests, thus allowing the provision of more trips per day. Also, the electronic transfer of data from the MDT unit to the central database results in a significant decrease in the need for a data entry clerk. The implementation of MDTs alone would save Miami-Dade Transit $\$ 125,000$ annually [10]. Accessible Services in Seattle (Washington) experienced a $7 \%$ increase in productivity after the installation of MDTs, which resulted in a cost savings that paid for the entire cost of the system within three years [9].

VIA, the public transportation agency in San Antonio (Texas) installed MDTs in its paratransit vehicles and estimated that, after installation, two-way radio communication was reduced by up to $80 \%$; allowing dispatchers to be more productive. VIA showed a productivity increase from 1.1 to 2.3 passengers per hour after installation. Because the frequency of radio use was significantly reduced, the number of VIA radio dispatchers could be reduced or reassigned to different positions, and the number of vehicles that one dispatcher could monitor increased to 35 vehicles, which was not feasible before the new MDTs were deployed. Similar productivity increases were reported in Philadelphia by WHEELS, a paratransit provider, which saw dispatchers increase the number of vehicles they were able to monitor from 25 to 45 vehicles [9].

\section{Global Positioning System (GPS)}

GPS is often used for the purpose of getting route directions and finding the shortest path to a destination. GPS devices navigate using satellites while devices broadcast signals that provide their location, status, and time based on onboard vehicle clocks. A GPS device will receive radio signals that travel through space, noting the time that the signal arrives. The time it takes for the signal to arrive can be used to calculate the distance from the satellite to the GPS device. Once the device has calculated its distance from at least four satellites, it can then use geometry to determine its location in three dimensions [11]. 
In paratransit, GPS can be used to avoid missed pick-ups due to operational errors or difficultto-locate riders [12]. The 2009 FTA report "Feasibility Study on the Use of Personal GPS Devices in Paratransit" found that GPS technologies can lead to an improved level of service and can reduce an agency's operating costs. Onboard GPS equipment cost may range from $\$ 200$ to $\$ 2,000$ per vehicle. Capital costs for a GPS system, including control center hardware, installation, and training averaged $\$ 2,800$ per vehicle in 2009 [12].

Paratransit systems of the Central Florida Regional Transportation Authority (LYNX) and Jacksonville Transportation Authority (JTA) use Mentor Rangers for their GPS. Mentor, now owned by Trapeze, does not list prices; however, JTA indicated that in FY 2013-2014, the Mentor Ranger GPS systems were purchased for $\$ 4,872$ per unit. Ranger is a mix of several technologies, including GPS, AVL, MDT, fare collection, and driver behavior monitoring (i.e., speed) [13]. These additional features result in a higher cost per unit.

\section{Automatic Vehicle Location (AVL)}

AVL technology is a computer-based system that allows vehicles to be tracked through measuring the real-time location of the vehicle by way of GPS and relaying that information back to a central database. AVL systems are either passive or active. Passive AVL systems are capable of storing GPS data, speed, and direction of the vehicle. Passive AVL system data can be uploaded when the vehicle returns to the property garage and the device is removed, connected, and then downloaded to a computer. Active AVL systems are capable of the same functions; however, they also are capable of transmitting data in real-time by cellular data communications [14].

AVL systems can benefit paratransit services through higher productivity. With the help of AVL, when a new trip is requested, the dispatcher can assign trips in real time, creating more efficient schedules, improving on-time performance, and increasing productivity.

A 12-vehicle deployment of AVL linked to traveler information for a small agency cost $\$ 60,000$ while it cost a large urban agency $\$ 70$ million to equip 5,700 buses [15].

The fixed-route transit systems in Portland (Oregon), Baltimore (Maryland), and Milwaukee (Wisconsin) all reported an improvement in on-time bus performance, ranging from $9 \%$ to $23 \%$, after the installation of AVL paired with a Computer Aided Dispatch (CAD) system. After AVL technology was added to the Tri-Met bus dispatch system in Portland, there was a decrease in both passenger wait time and in-vehicle travel time, which resulted in an annual savings of $\$ 3.5$ million [16]. After the installation of AVL, San Jose (California) was able to reduce its paratransit expenditures from $\$ 4.88$ to $\$ 3.72$ per passenger trip [17].

Although research into paratransit documentation did not offer substantial insights on how AVL and other technologies impact paratransit, these technologies have been proven effective in transit systems.

\section{Advanced Telephone Systems}

An automatic call-handling telephone system is capable of routing phone calls, storing voice messages, notifying recipients of new messages, and providing callers with information by integrated voice capabilities, including schedules, fares, and current service status [18]. Advanced telephone systems monitor and improve the task of handling incoming calls, including average waiting time (on the phone); average phone call length once the caller is connected, and dropped calls. Monitoring these performance measures can allow an agency to seek improvement where necessary. There is also the growing use of interactive voice response (IVR) systems to notify riders of scheduled pick-up times and vehicle locations. When the phone system is automated and paired with reservation software, it can send reminder or 
verification calls to the trip-requester within one day of his/her trip or a real-time alert that the vehicle is within 30-60 minutes (depending on agency policy) from the pick-up location. Use of this service resulted in a reduction in many no-shows for many agencies [3]. The cost of an IVR system is generally $\$ 3,000$ per phone line [19].

A transit agency in Canada reported that implementation of technology that calls a rider automatically when a vehicle is 10 minutes away resulted in a drop in wait times of 46 seconds, on average, at pick-ups, representing an average $40 \%$ reduction in wait times. This saved time can result in additional trips being made during the course of a day.

The Toledo Area Regional Transit Authority installed automatic callback software to work as its IVR system. The software called passengers when the vehicle was in the vicinity of their pickup addresses, allowing them time to prepare for the arrival of the vehicle. This reduced the amount of no-shows and wait times for their paratransit service [7, p. 52].

\section{Vehicle Security Cameras}

Onboard security cameras (interior and exterior) can be used to improve paratransit services by monitoring vehicle operation, operator performance, and passenger behavior. These surveillance systems are capable of both audio and video recordings that can capture evidence of altercations or injuries or causes of traffic incidents [20]. The cameras also can create a sense of safety for riders and the drivers and can provide evidence against any possible cases of unwarranted litigation.

Auditors recommended that Transit Plus in Milwaukee install security cameras on its fleet of paratransit vehicles after a complaint in 2012 by a passenger who slipped from his wheelchair on a Transit Plus van; he was left hanging by his neck from the seat belt on the van, and passed away three days after the incident [21]. The van's service officials claimed that the seat belt had not been in contact with the passenger's neck. The auditors' report suggested installing cameras on all 160 Transit Plus vans at a cost of more than $\$ 800,000$ [22]. The money saved from avoiding unwarranted litigation could vary dramatically. Security cameras also can be used for random monitoring of drivers and reporting compliance.

Although security camera systems are available from several vendors, the following is provided as an example of the application by one specific vendor. DriveCam is a type of security camera that is placed inside a vehicle, with one camera facing the driver and another facing the windshield and showing the surrounding environment. When unsafe driving behavior occurs, such as hard braking, the event is recorded in both video and data format (including speed, location, and forces on the vehicle), and the information is uploaded via a cellular connection. The video and data can be privately reviewed by operations staff who can determine whether coaching of the driver is necessary to avoid future events. Easton Coach Company's paratransit system installed DriveCam technologies on its fleet in 2006 to evaluate driver behavior. Within the first two years, the company's accident claim numbers decreased by $40 \%$, and, since the start of the DriveCam installation, cell phone use among drivers decreased $73 \%$, followingdistance events improved 70\%, and traffic violations decreased 69\% [23].

\section{Customer Information and Service}

Customer service and customer information technologies are another way to improve paratransit services and include telephone or computer surveys post-trip to gather feedback from customers about the paratransit trip that was just taken. These surveys can provide information about a paratransit trip from a user's perspective, allowing an agency to recognize where improvements need to be made, which, in turn, could save the agency money.

Paratransit, Inc., which serves the Consolidated Transportation Services Agency (CTSA) for the 
Sacramento area in California, provides its paratransit passengers with the opportunity to contact the company with ideas, complaints, or comments in relation to its services through a contact form on its website, through email, or by postal mail. The agency guarantees a reply within 30 days of receiving the feedback from the paratransit user [24].

\section{Combining Technologies}

Tablets can perform as all-in-one units for three technologies (MDT, AVL, and GPS) and are connected with reservation, scheduling, and dispatching systems (see Figure 2-1). In some systems, the three technologies plus the reservation, scheduling, and dispatching software are provided by the same vendor so data can sync in real time. It should be noted that the combination of the technologies makes it difficult to separate their impacts.

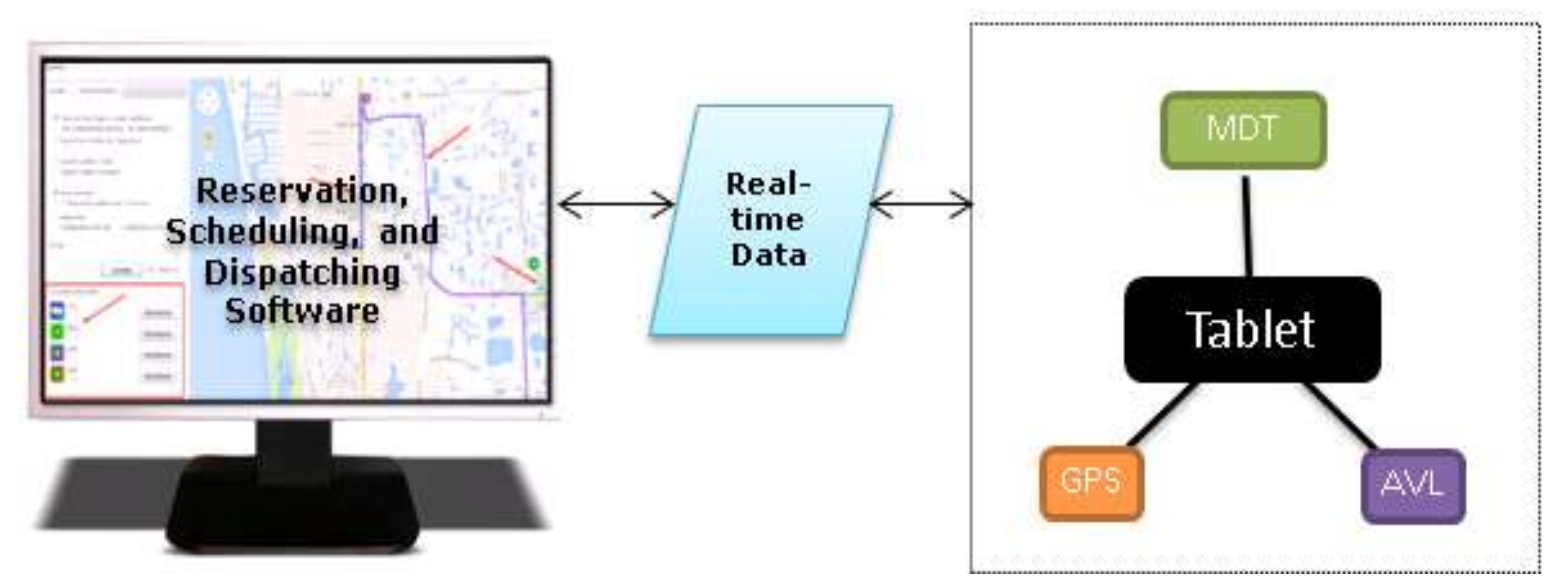

Figure 2-1: Tablet Serving as an MDT/AVL/GPS Unit Exchanges Real-Time Data with Dispatcher using the Reservation, Scheduling, and Dispatching Software

St. John's County Council on Aging in Florida installed AVL and CAD technologies on its paratransit vehicles, allowing the agency to reduce its scheduling, dispatching, and billing staff by half and also increasing productivity. The number of trips per vehicle hour increased from 0.5 to $2.5[25]$.

Optimal routing of paratransit trips can be achieved through a combination of scheduling software and MDTs; a telephone system also is necessary. An example of this is a person calling to cancel his/her paratransit trip. The dispatcher can update the schedule and the MDT for the driver. Once the trip is removed from the manifest on the MDT, the driver can continue to the next pick-up or drop-off with the newly-updated schedule shown on the MDT. Since "noshows" and late cancellations can negatively affect the efficiency of service and increase the cost for paratransit systems, it is important to be able to manage same-day cancellations in real time [26]. Technologies that provide routing software can increase efficiency in paratransit systems by maximizing ridesharing while decreasing ride time and service miles [27].

\section{Notes on Sources Reviewed}

Throughout the literature review process for this study and despite searching national publications, the information concerning impacts of technology applications on paratransit operations management and customer service was scarce. By comparison, there is far more information related to fixed-route services than paratransit. More paratransit-specific data would be beneficial for paratransit systems looking to improve their services and address challenges with the use of technology. 
This research study contributes to the body of knowledge by focusing on paratransit agencies in Florida and providing in-depth discussions on how technologies can affect operations management and customer service. Although deployment of these technologies in Florida is recent, these discussions shed light on how effective the technologies were only a few months after deployment, increasing the productivity of the systems as self-reported by the agencies. It is recommended that a follow-up survey be conducted in one or two years to conduct a quantitative assessment of the impacts these technologies will have on the performance measures selected for this research study. 


\section{Chapter 3 - Survey Results}

An online survey of paratransit providers in Florida was conducted in February 2015. A mailing list of all 49 Florida CTCs was obtained from the CTD. The response rate was $78 \%$ with 38 agencies participating. The number of observations $(\mathrm{N})$ for each survey question is included in each chart in this chapter as some respondents skipped some of the questions if they were not applicable. Survey questions are included in Appendix A of this report.

\section{General Information on Participating Agencies}

\section{Overview of Technology Types Used by Agencies}

As shown in Figure 3-1, all of the CTCs (35 agencies) responding to this question use a reservation, scheduling, and dispatching software. Only seven agencies (20\%) use advanced phone systems with IVR, and as many as $63 \%$ use advanced telephone system with automated service, voice mail, call hold, and call forward. 'Other' in the chart refers to two-way radios and pre- and post-trip inspection equipment.

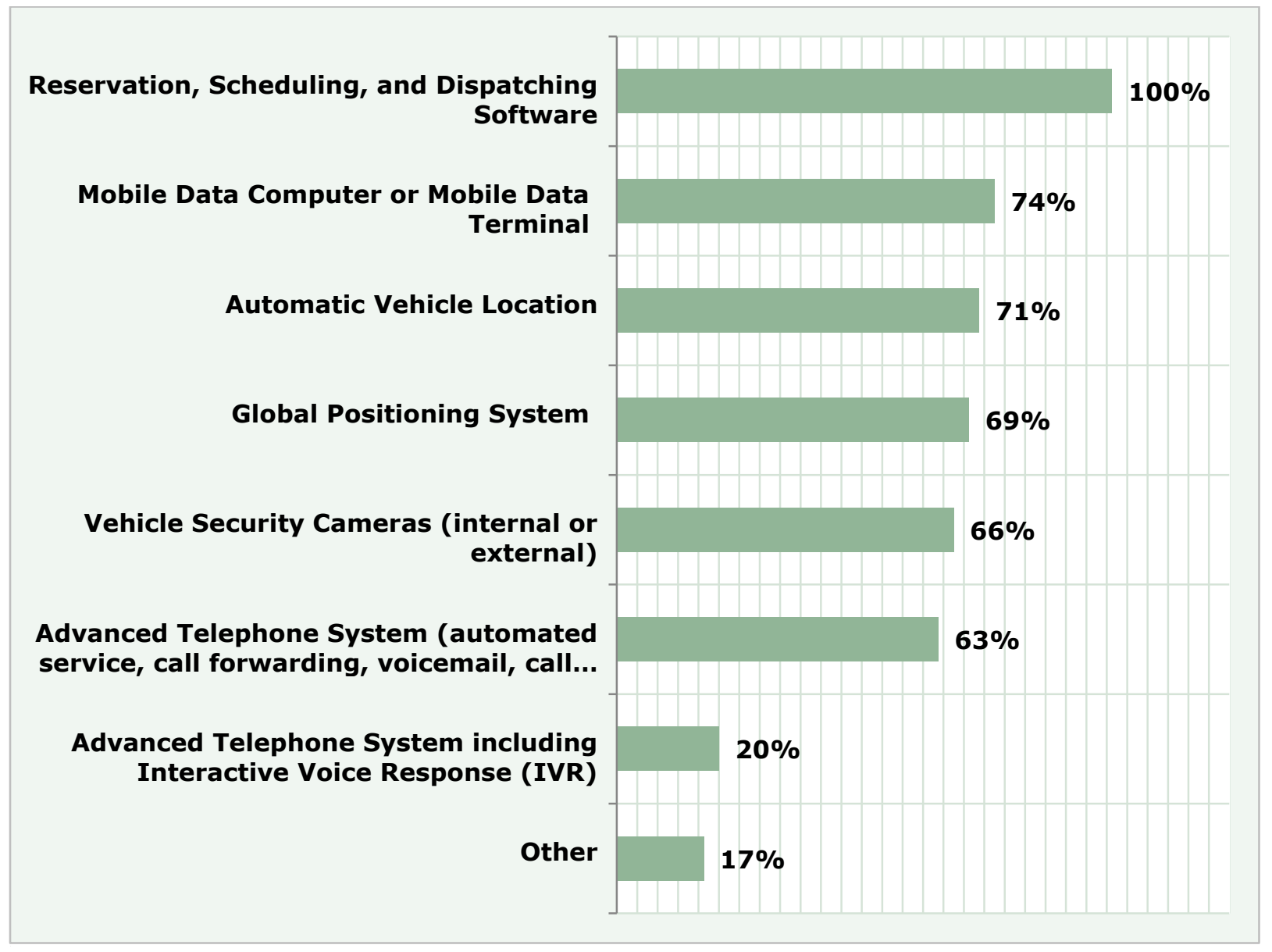

Figure 3-1: Technologies Used by Florida CTCs 


\section{Funding Sources of Paratransit Services Provided by Agencies Surveyed}

Figure 3-2 is a summary of the different funding sources of paratransit services that Florida CTCs provide to their riders. In total, 38 agencies provided information, indicating that all provide transportation disadvantaged services, 25 (66\%) provide trips for area agencies on aging $(66 \%)$, and $21(75 \%)$ provide Medicaid non-emergency transportation (75\%). A total of $13(34 \%)$ include other services such as trips related to social services, HMOs, agency coordinated transportation, Florida Department of Elder Affairs, Community Development Block Grant programs, Section 5316 Job Access and Reverse Commute programs, Veterans Affairs, and FDOT Section 5311 Public Transportation programs.

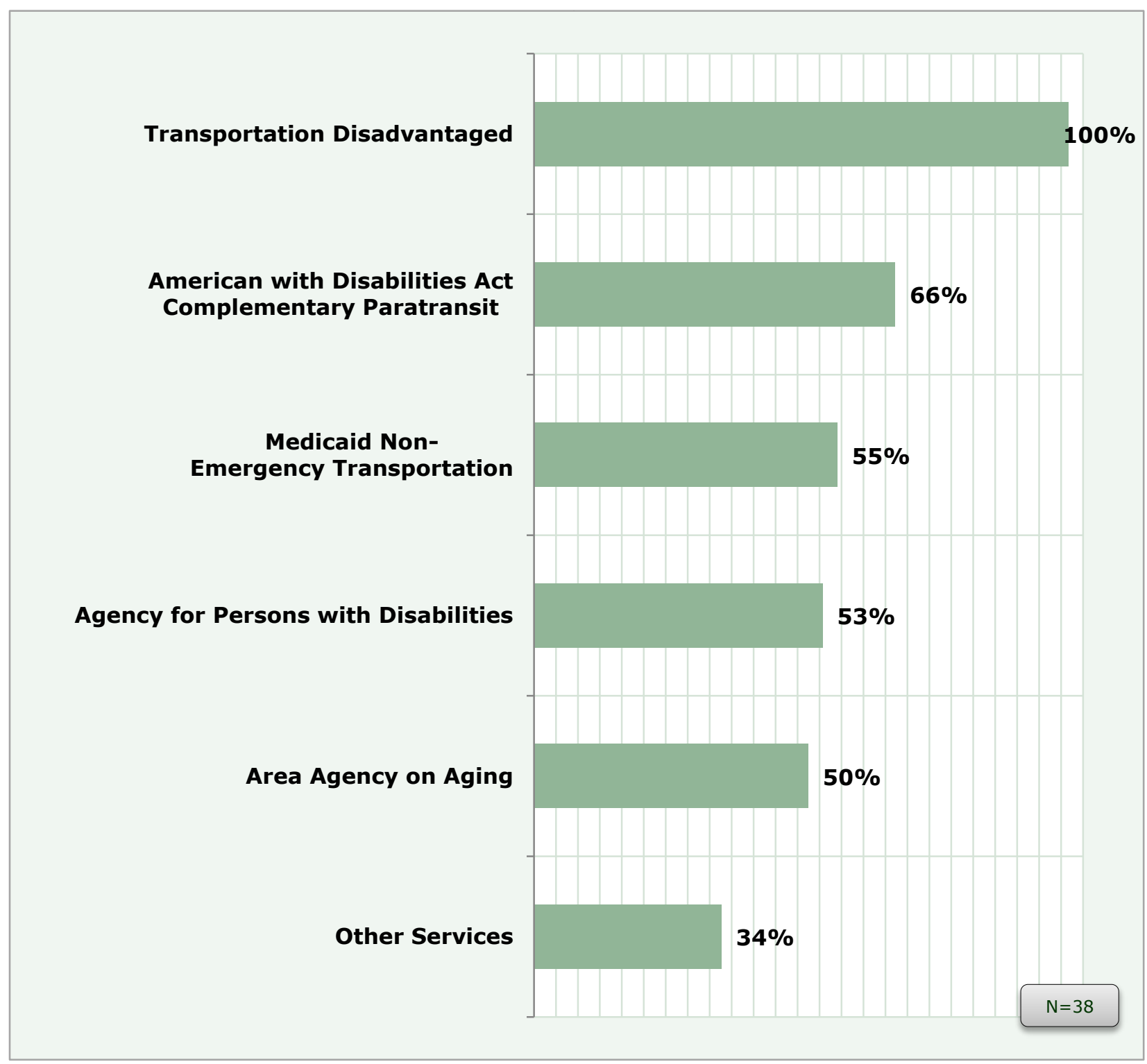

Figure 3-2: Funding Sources of Services Provided by Agencies Surveyed 
Figure 3-3 shows that all the 38 agencies surveyed use traditional telephone service for reservations. Agencies use several other methods as well, as shown in Figure 3-3. Feedback from agencies visited indicated that the main reason the telephone is the major method used for taking reservations was the preference of passengers to speak to a "live" person. Some email or website methods are not used as a reservation tool but rather are for alerting a scheduler to call the passenger on the telephone to make a reservation.

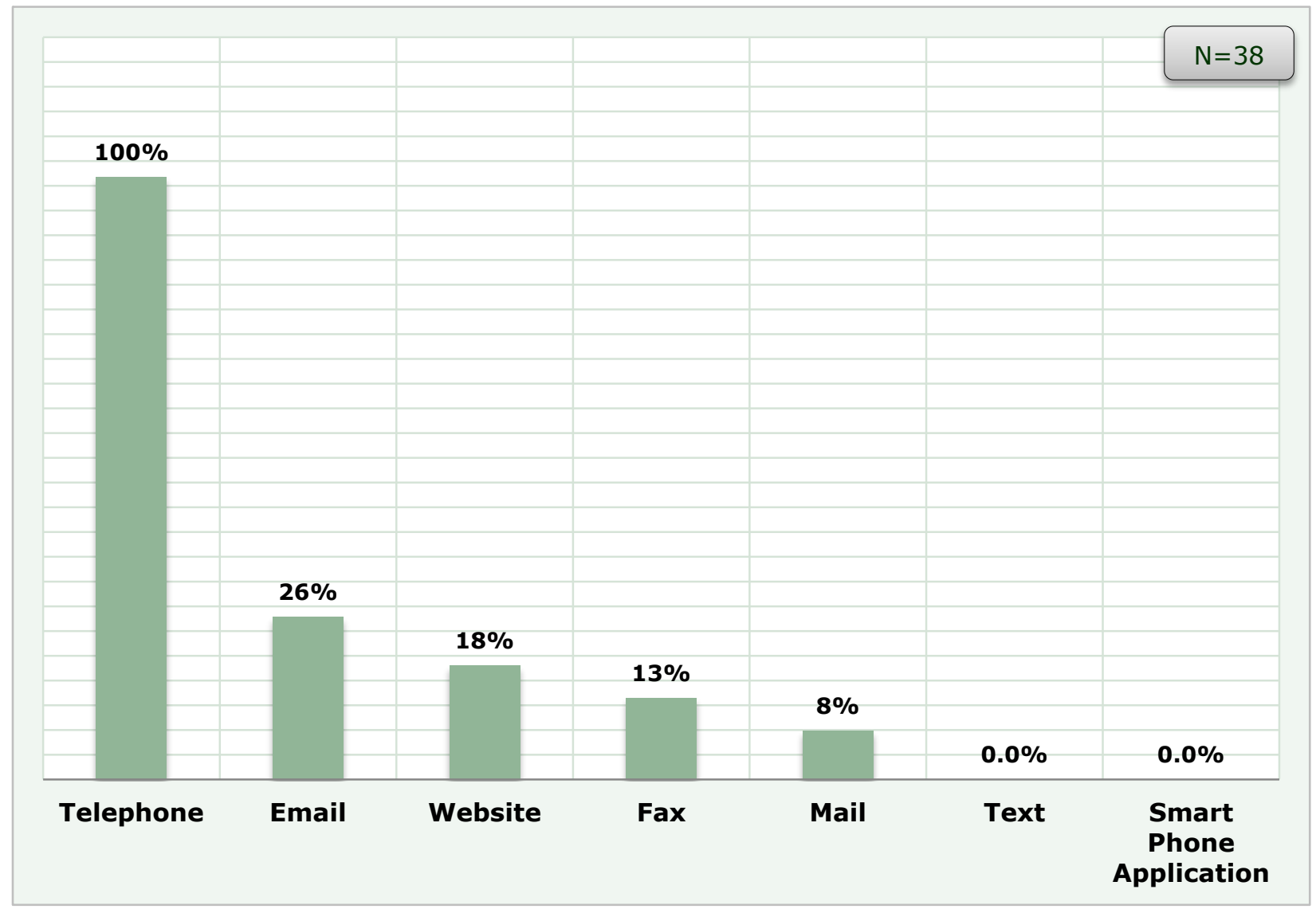

Figure 3-3: Methods of Reservations Used by Responding Agencies 


\section{Reservation, Scheduling, and Dispatching Software}

Among the 30 respondents who indicated their agencies use reservation, scheduling, and dispatching software, half use RouteMatch or CTS systems and 36\% use Trapeze; the remaining $14 \%$ use systems such as StrataGen Systems or Ecolane USA. Several software systems were installed or updated within 14 months of the survey (31\%).

Related to length of warranty agreements, $42 \%$ indicated having one-year warranty service on their software, $25 \%$ have either three or five years, and $33 \%$ have ongoing services within their contract with the vendor. The majority of the respondents $(83 \%)$ updated their software in late 2014 or early 2015.

Figure 3-4 shows that in addition to reservation, scheduling, and dispatching software, the majority of agencies (96\%) have both technical support and training as part of their software package, and 36\% included a warranty in their package. For 'Other,' one respondent indicated that the software is Web-based and another indicated maintenance as part of the package.

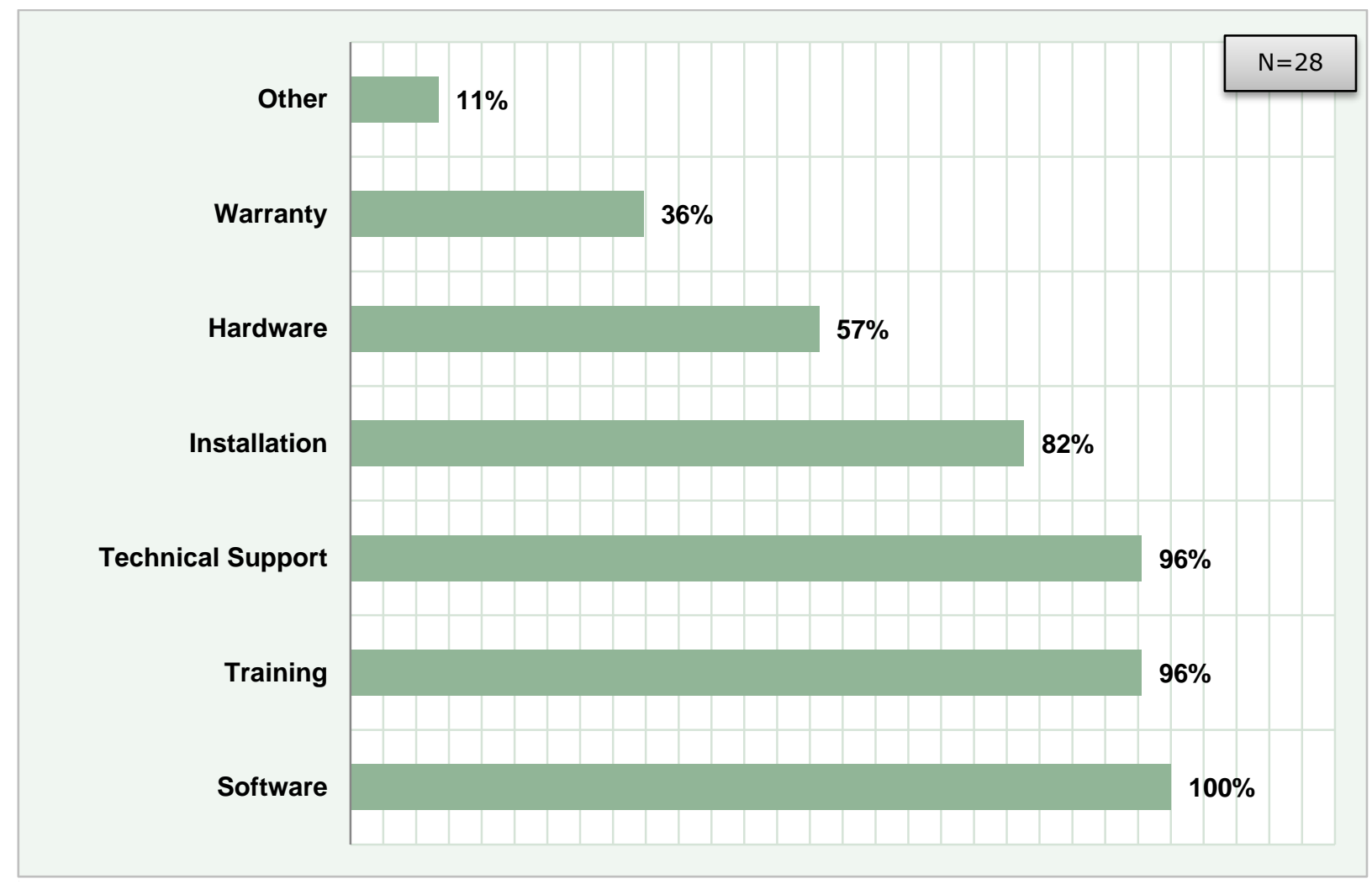

Figure 3-4: Reservation, Scheduling, and Dispatching Software Package Selection Considerations

Impacts of Using Reservation, Scheduling, and Dispatching Software on Decreasing "No-Shows"

"No-shows" are a challenging issue for paratransit providers. Some riders forget they made a reservation, and others forget to cancel after finding other means of transportation for the scheduled trip. Agencies expend time and money to dispatch a vehicle to a location and wait for a rider that does not show up. It may be that deploying this particular technology is not 
directly related to the reduction of "no-shows," as indicated in Figure 3-5, since $42 \%$ indicated no impacts detected on that performance measure. However, respondents who reported significant or moderate impacts attributed it to a reporting tool of the software that tracks repeated "no-show" occurrences from the same riders. The benefit of tracking this element in the history profile of a rider may require an inquiry of the rider to better understand the circumstances or send extra reminders. It also helps the agency when administering a policy to reduce "no-shows." One agency indicated that its Rider's Guide is educating passengers on how "no-shows" affect the services provided to the community in an effort to curb the practice.

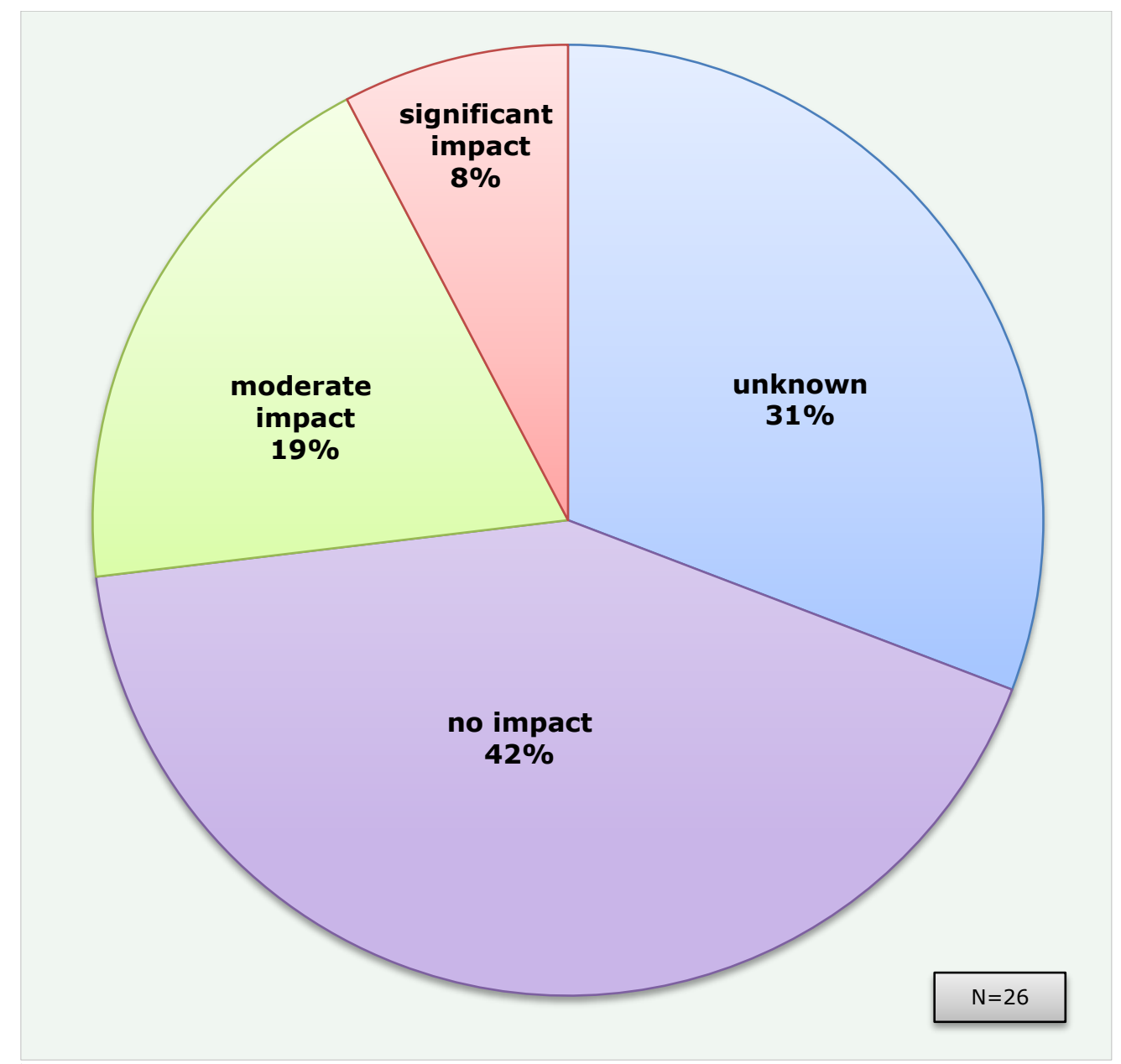

Figure 3-5: Impacts of Using Reservation, Scheduling, and Dispatching Software on "No-Shows" 


\section{Impacts of Using Reservation, Scheduling, and Dispatching Software on Reducing Labor Costs}

Some respondents indicated that their agencies have been using scheduling software for some time but recently updated it or changed vendors, which was significant because changes were implemented in Medicaid's Managed Medical Assistance (MMA) Program in Florida. With these changes, some agencies faced additional demands on their systems, and the introduction of various new and improved functions of the software made these additional tasks less burdensome. It was concluded by one respondent that it would have been impossible to keep up with the new MMA requirements without adding more personnel had it not been for their new software. Other agencies indicated the need to employ more staff or use over-time while implementation and training for the software was ongoing until glitches were all resolved.

As shown in Figure 3-6, 43\% of respondents indicated moderate to significant impacts on labor costs. It was repeatedly indicated from responses to the survey that the efficiency of the software optimized daily scheduling, which improved productivity and may have avoided the need for extra labor. Some agencies added more personnel, as their counties are growing and demand for the service is increasing as well.

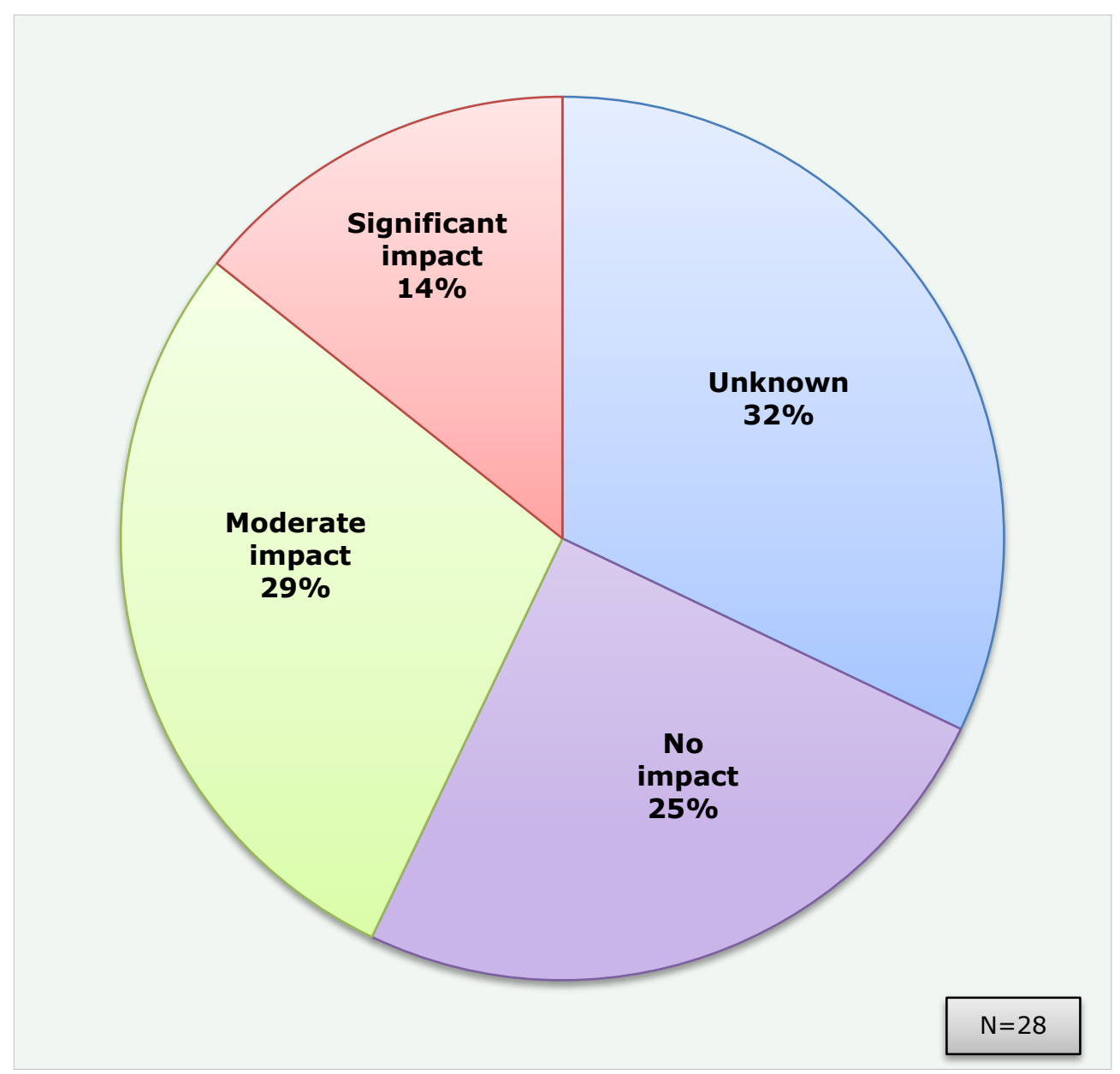

Figure 3-6: Impacts of Using Reservation, Scheduling, and Dispatching Software on Reducing Labor Costs 


\section{Impacts of Using Reservation, Scheduling, and Dispatching Software on Improving Customer Satisfaction}

Agencies experiencing moderate to significant impacts (55\%) in customer satisfaction after deploying the software attributed better customer service to the faster time it takes to reserve a trip, which means less time a passenger is on the phone (see Figure 3-7). One agency reported a $30 \%$ decrease in annual complaints because of using the new software. Setting up a comprehensive database of eligible riders with different types of funding sources listed in the passenger profiles helps in speeding up the process of trip reservation and reducing the time the customer has to be on the phone. Some agencies provide a trip confirmation number (generated by the software) to the passenger to be used for fast trip cancellation.

One of the major features of the software is the capability to optimize the scheduling process in planning efficient routes, which reduces the time the passenger is onboard the vehicle.

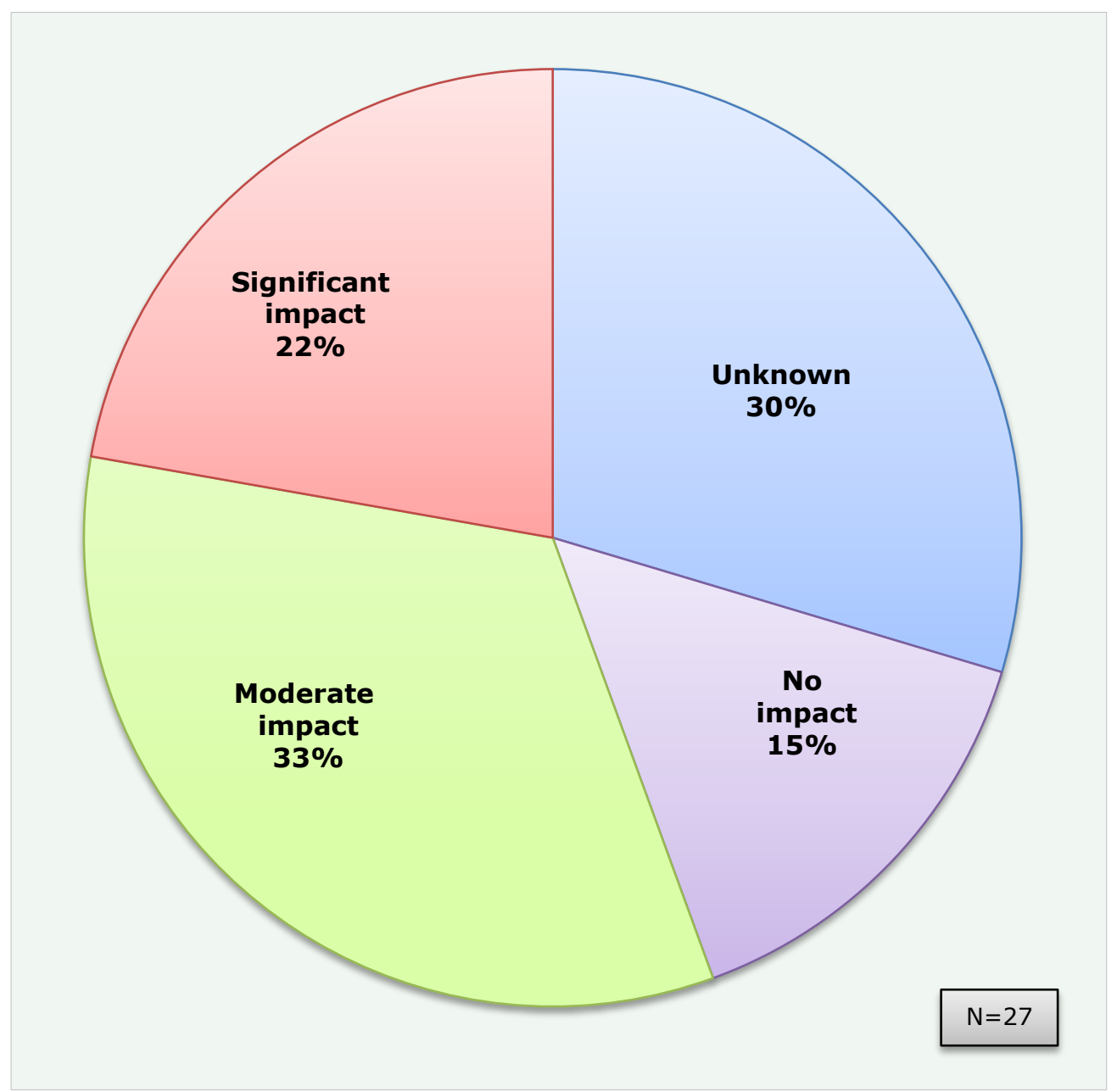

Figure 3-7: Impacts of Using Reservation, Scheduling, and Dispatching Software on Customer Satisfaction 


\section{Impacts of Using Reservation, Scheduling, and Dispatching Software on}

On-Time Performance

The overall efficiency of the operating system improves when better data quality that is more comprehensive can be collected and reported. These reports help agency staff pinpoint issues that contribute to lowered on-time performance and provide resolution of these issues, such as improved routing or grouping of passengers on the same routes.

Approximately $63 \%$ of agencies surveyed reported experiencing an increase in on-time performance (see Figure 3-8) because electronic manifests can be updated in real time to advise the operator of cancellations, which improves on-time performance through route optimization. Another reason cited was the ability to capture the time the driver arrives at and departs the location.

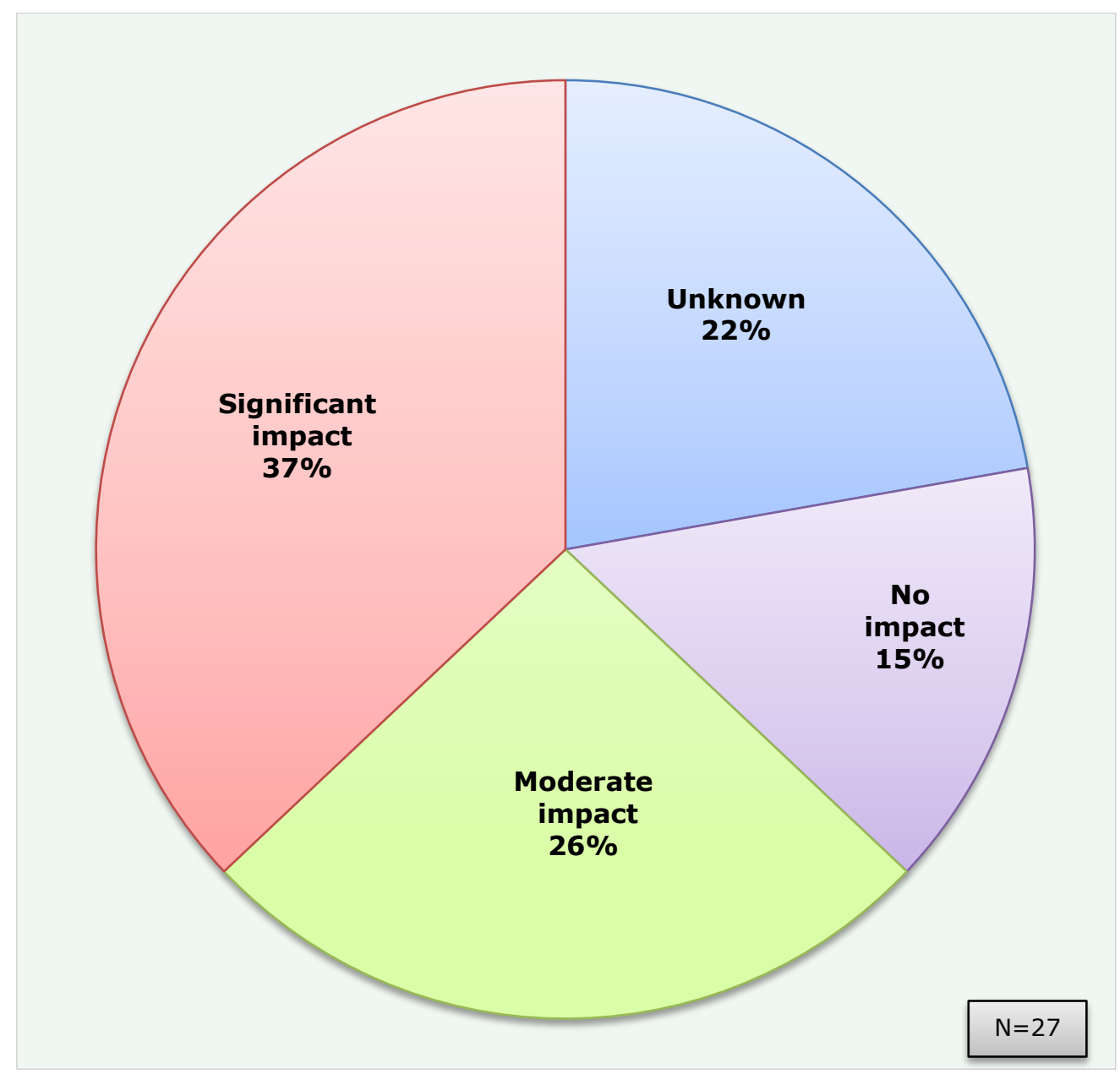

Figure 3-8: Impacts of Reservation, Scheduling, and Dispatching Software on On-Time Performance 
As shown in Figure 3-9, 63\% of respondents indicated that the deployment of this technology had moderate to significant impacts on driver performance, with one agency reporting a $25 \%$ increase in driver productivity. One agency indicated a similar increase by optimizing scheduling to improve driver productivity, although there was a learning curve involved with the scheduler coming to trust the scheduling done by the software that assigned more trips and/or more passengers per hour to the driver.

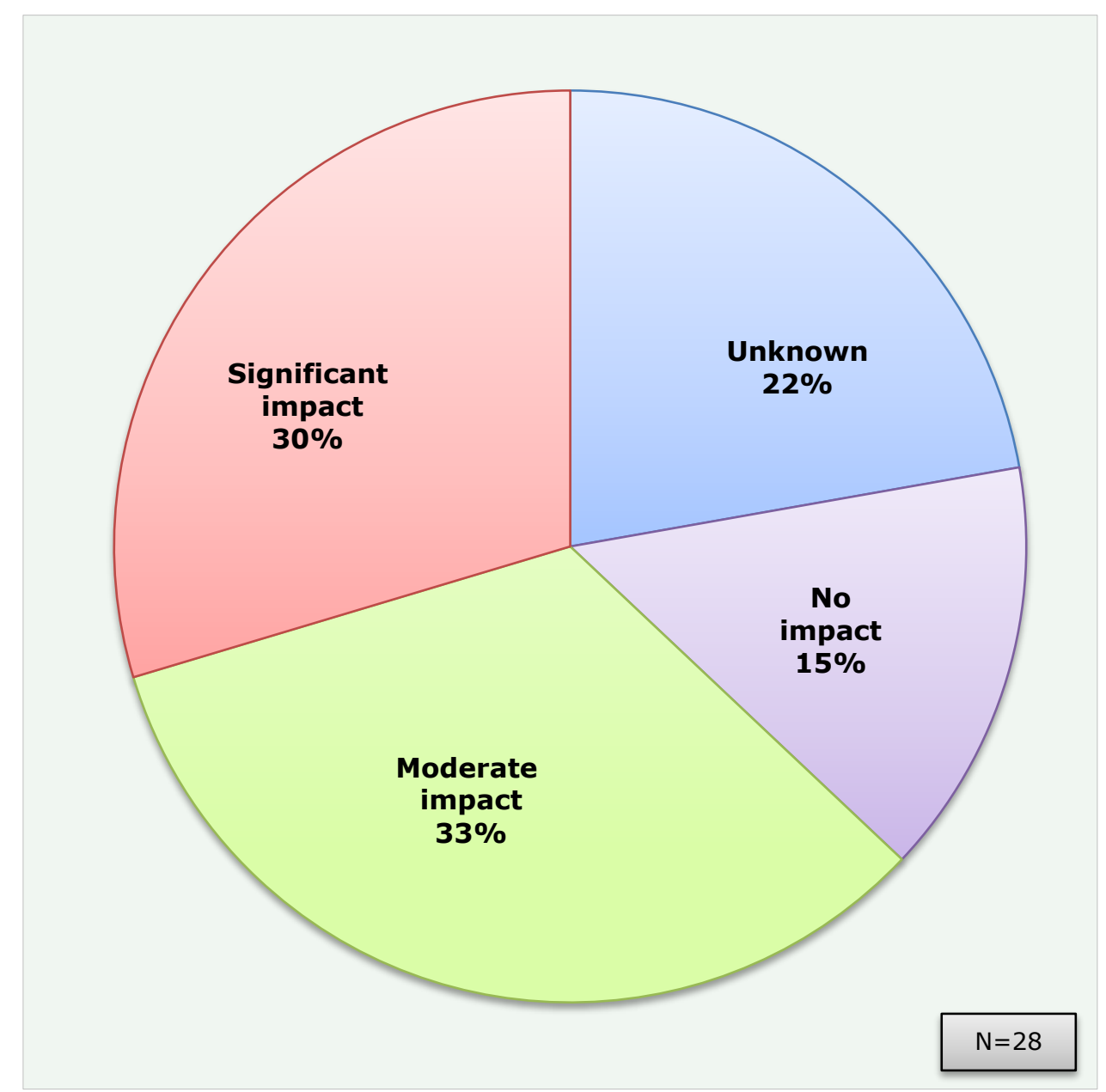

Figure 3-9: Impacts of Using Reservation, Scheduling, and Dispatching Software on Driver Performance 


\section{Mobile Data Terminals}

Among the 38 agencies responding to questions related to MDT usage, 28 (74\%) confirmed the use of MDT systems; $56 \%$ of these agencies installed their systems as recently as late 2014 or early 2015, 15\% installed their systems between 2012 and 2013, and the remaining 29\% varied between 2002 and 2011. The following manufacturers were noted among responses received:

- CTS

- Radio Satellite Integrators, Inc.

- Trapeze

- GreyHawk Technologies

- $\quad$ Digital Dispatch Systems

- Mentor Ranger (acquired by Trapeze)

- Samsung Galaxy Tablet

- RouteMatch

- Verizon

- AVAIL

Because 15 of the 27 agencies (55.5\%) reported having had their systems installed within just a few months of the survey, answering questions about the benefits/costs of the technology may have been premature, which was the main cause for citing "unknown impacts." However, it may be considered a baseline for future questionnaires that address specific impacts. 


\section{Impacts of MDT Deployment on On-Time Performance}

On-time performance is an important measure for an agency providing service. As previously stated, some agencies deployed their new technologies only a month before the survey was conducted, so impacts were yet to be determined. However, there was some consensus with experiencing an initial slight drop in on-time performance. The drop may be due to a learning curve or a better evaluation method, with the MDT being more accurate in its documentation of timeliness. To that end, a 64\% significant or moderate improvement is a step in the right direction for this major performance measure (see Figure 3-10).

Some of the justifications for noting "significant" impacts included the capability of databases to generate on-time performance reports using the arrival time of the vehicle at the rider's location as well as the time the trip started after the rider was onboard. Knowing these times gives the staff the ability to focus on solutions to delays, if reported.

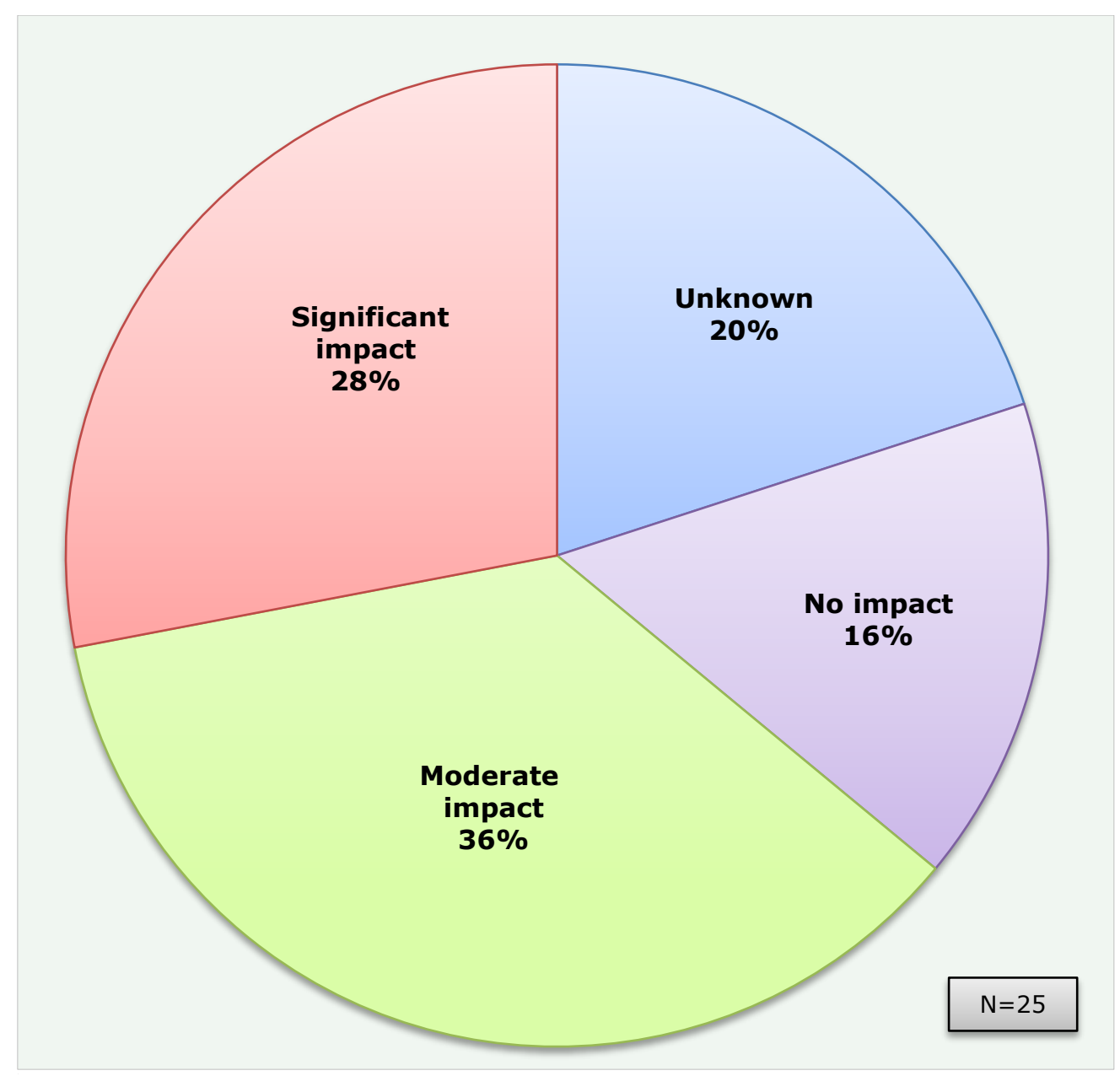

Figure 3-10: Impacts of MDT Deployment on On-Time Performance 


\section{Impacts of MDT Deployment on the Reduction of "No-Shows"}

Figure 3-11 shows that $12 \%$ of responding agencies experienced significant reductions in "noshows" after the deployment of MDTs, with one agency reporting a reduction of $11 \%$. Another agency indicated that its reduction in "no-shows" was due to the fact that trips can be cancelled immediately and that information is sent instantly to the operator via MDT, thus avoiding unnecessary trips.

It is obvious that the newness of the systems rendered many questions premature for many of the agencies. Some respondents indicated that "no-show" reduction was not due to MDT deployment but rather to other features of the system that were anticipated to reduce "noshows." For example, the notification module of the reservation, scheduling, and dispatching system in RouteMatch is linked to the AVL and will call a passenger within 30-60 minutes of estimated real-time vehicle arrival at the trip origin. This time window can be set by the agency. The probability of a passenger being ready for pick-up on-time is anticipated to reduce "no-shows." Although MDTs are used, many systems have a tablet functioning as an MDT/AVL/GPS all-in-one unit.

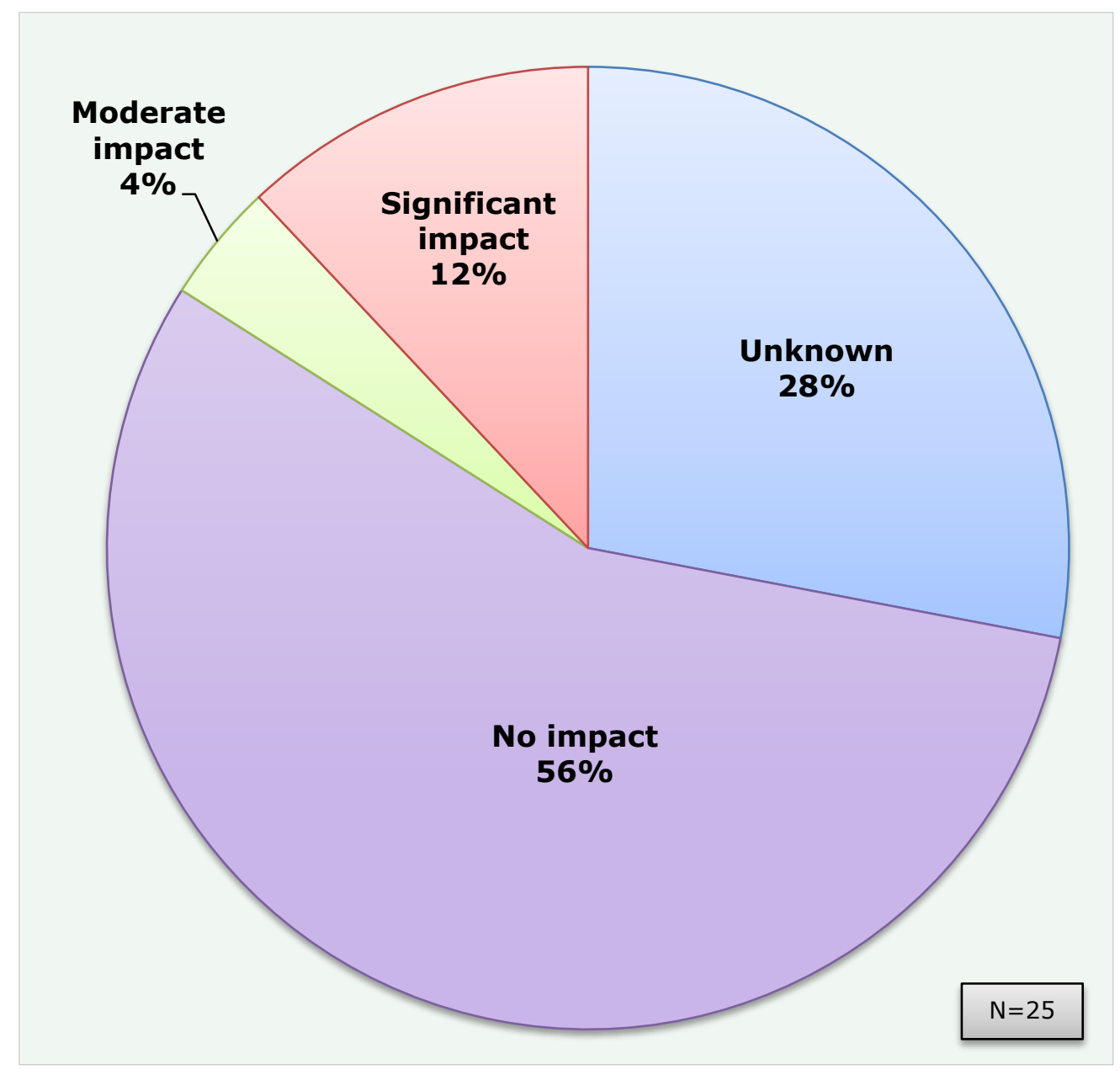

Figure 3-11: Impacts of MDT Deployment on "No-Shows" 


\section{Impacts of MDT Deployment on Customer Satisfaction}

Without conducting a "before and after" survey, the question of whether the deployment of MDTs had an impact on customer satisfaction was subjective, which is why the survey sought the reason for the assessment of that performance measure. A total of $28 \%$ of respondents indicated "unknown impacts;" reasons were that the agencies had yet to survey customers or that the agency has just started using new MDTs. The main reasons, given by $60 \%$ of participants who indicated moderate or significant impacts, were the capabilities to update the manifest directly on the MDT in real time and to see all fleet vehicles and trips scheduled at a glance. These capabilities allow dispatchers to quickly schedule return trips, a feature that customers appreciate.

In addition, MDT deployment allowed for coordination with an IVR system to generate advanced arrival notification phone calls to riders, relieving their anxiety and the need to call the agency for arrival times.

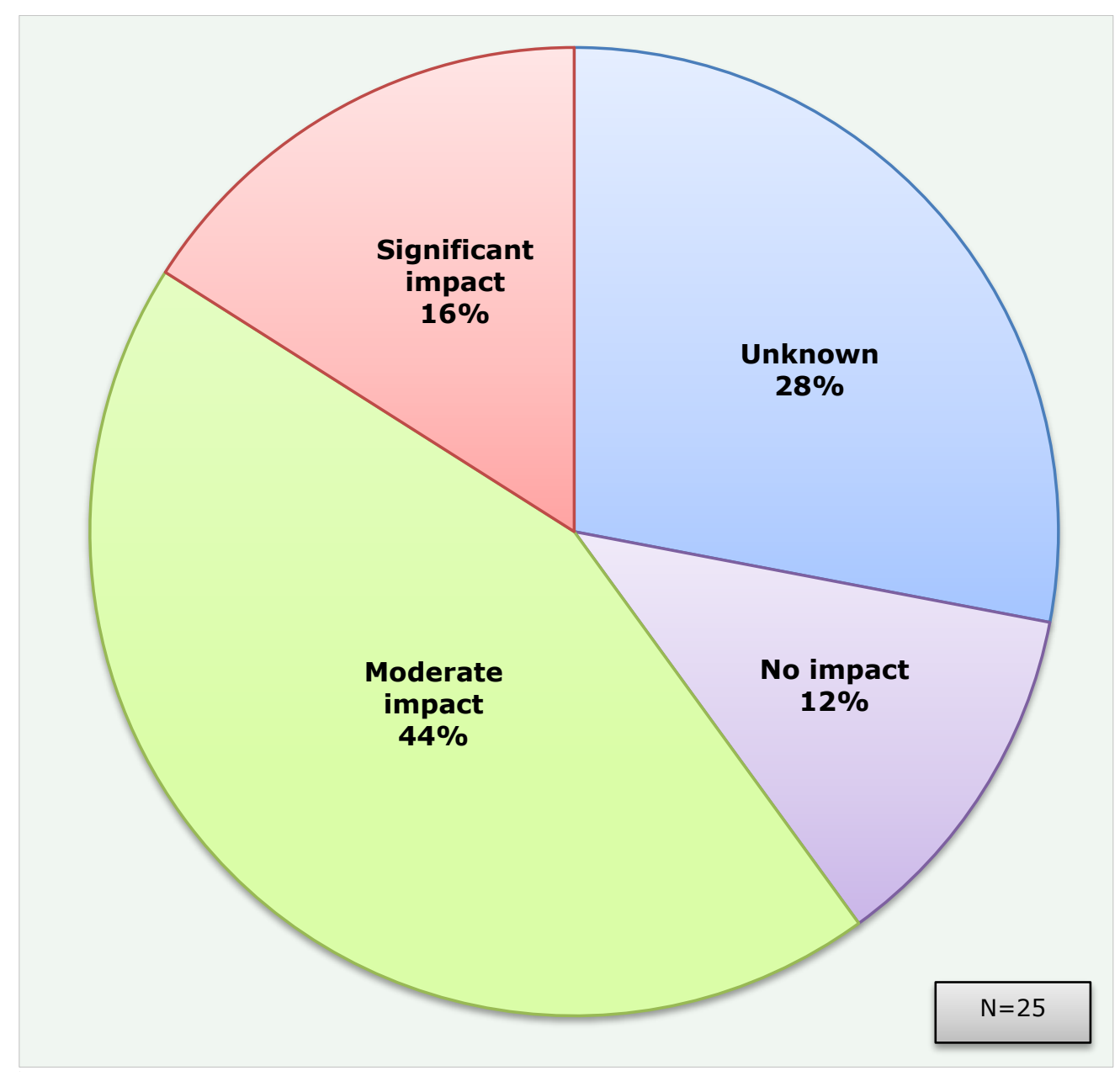

Figure 3-12: Impacts of MDT Deployment on Customer Satisfaction 


\section{Impacts of MDT Deployment on Driver Performance}

According to some respondents in the survey, the deployment of MDTs in different systems allows drivers the ability to view the trips for which they are responsible without having to search through a paper manifest. In addition to displaying speed, location, and capacity, drivers are aware that their performance is being monitored. Reasons cited by $83 \%$ of respondents (see Figure 3-13) choosing "moderate" or "significant" impacts included:

- "More accountability."

- "Has helped with timeliness, navigation, and e-mail messaging to base as well as reduction in paperwork required."

- "25\% more trips are now being performed on the demand response side."

- "Easier to update work during day, easier to find addresses, better documentation of actual times and odometer readings."

The reasons provided for "no impacts" included:

- $\quad$ "Learning curve with office staff and operators has taken some time. Operators are resistant to change as they feel more work is being placed on them."

- "There is still resistance to not having a paper manifest and a slowdown in dealing with no-shows since they have to rely on dispatch to release the MDT to move on."

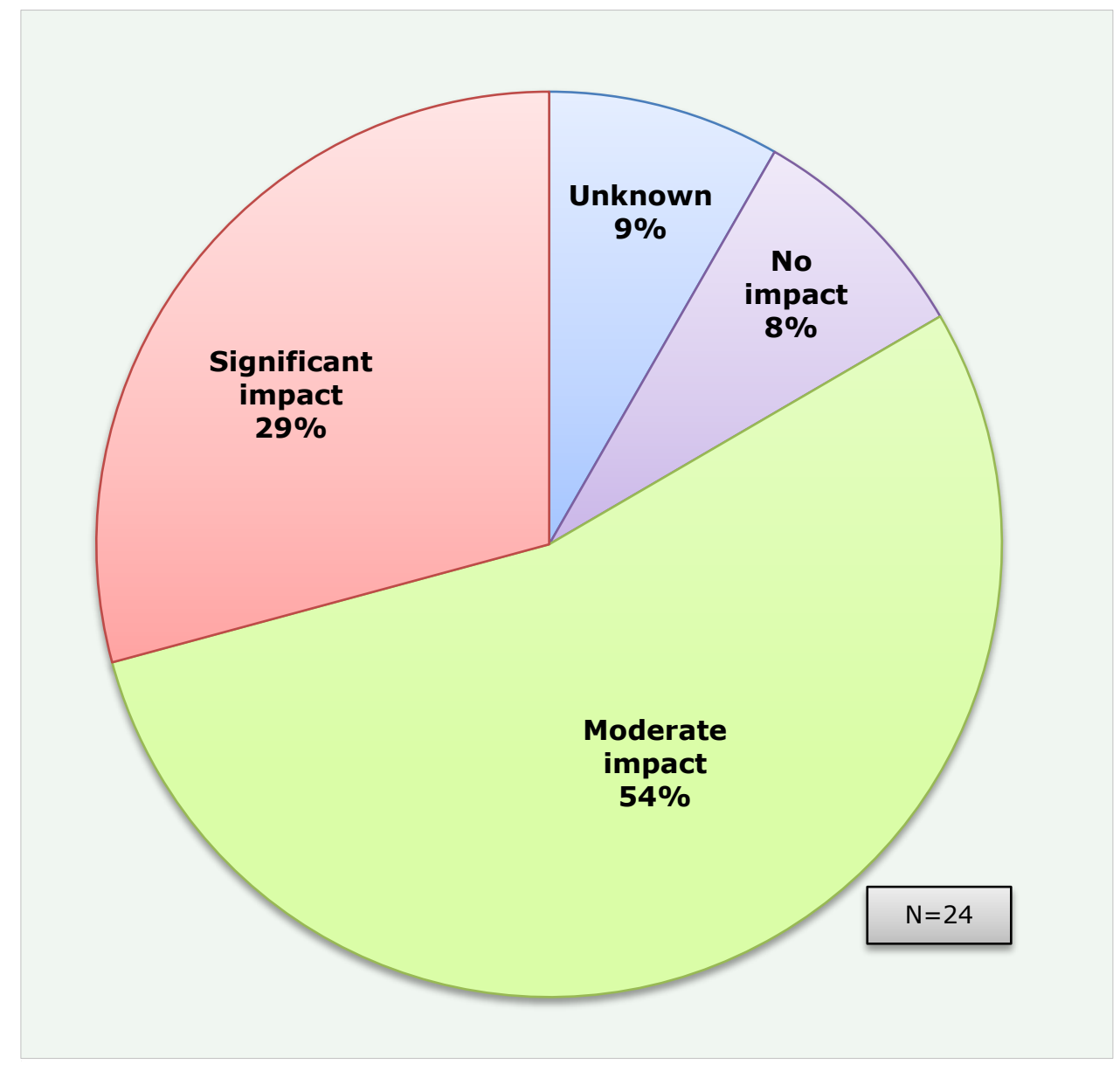

Figure 3-13: Impacts of MDT Deployment on Driver Performance 


\section{Impacts of MDT Deployment on Driver Satisfaction}

Regarding impacts of MDT deployment on driver satisfaction, Figure 3-14 shows that approximately two-thirds of the agencies surveyed (64\%) reported moderate or significant impacts for reasons including:

- The automated features made it easier for the operators to report arrival and departure times. They can show they were on time at the pick-up location and they waited the proper amount of time before a no-show was recorded.

- Drivers no longer had to do a manual manifest, therefore less paperwork.

- Updates come instantly, reducing errors between dispatchers and drivers.

- Reduced the time of having to locate the rider on paper and writing in times and mileages.

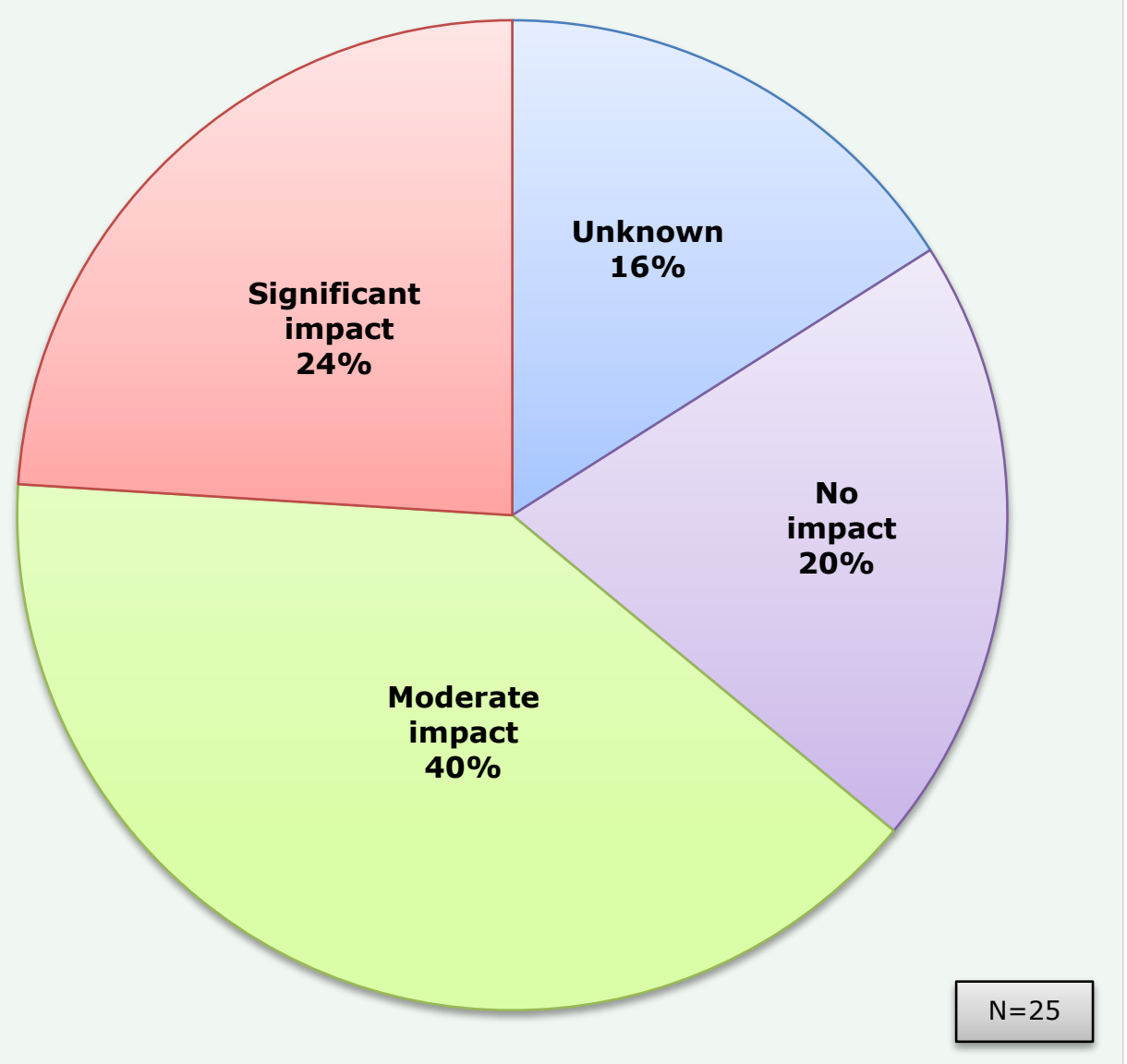

Figure 3-14: Impacts of MDT Deployment on Driver Satisfaction 


\section{Global Positioning System}

Among agencies responding to this question, more than $38 \%$ indicated that all vehicles operating in their systems were equipped with GPS; only nine indicated that GPS was not deployed on their fleet (25\%).

Some agencies had vehicles already equipped with GPS when purchased (30\%), some were installed as a part of their MDT parcel, and other systems were online with tablets used on vehicles. Manufacturers of GPS installed on vehicles included CTS, Midland, Seon, Trapeze/Mentor, and AVAIL, with Samsung tablets as part of RouteMatch software.

Figure 3-15 shows the variation in GPS packages purchased by the agencies, with many including training, warranty, and technical support; 35\% installed the units themselves. Those responding "other" (36\%) were agencies for which GPS was part of MDT system or Tablet system.

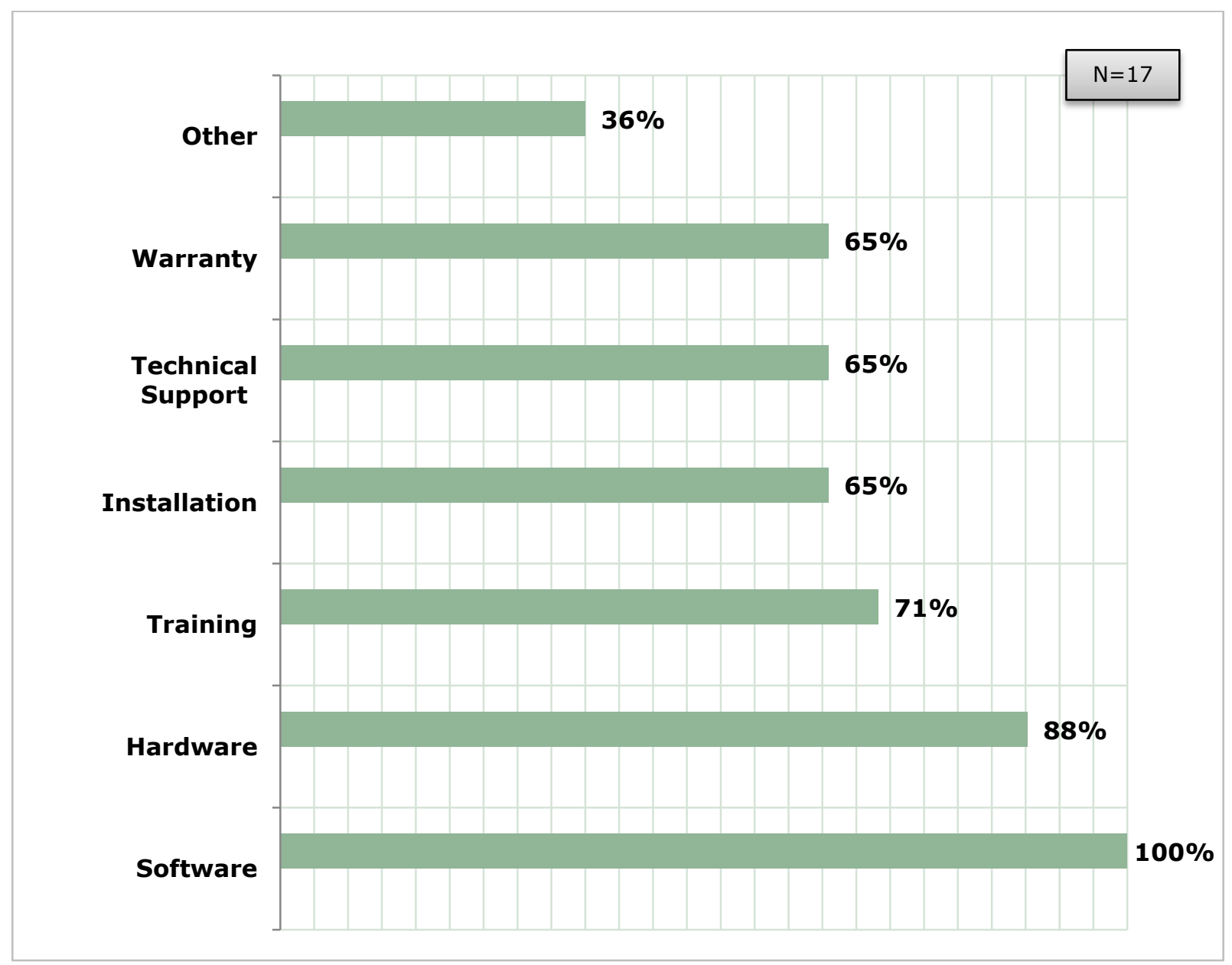

Figure 3-15: GPS Package Selection Considerations

GPS systems were installed as recently as 2014 or 2015 at $50 \%$ of the agencies responding and $37.5 \%$ installed their systems between 2011 and 2013; the remaining agencies indicated that they have had their systems since 2007. Among systems installed before $2014,76 \%$ of agencies indicated that updates to their systems were installed in 2014 or 2015. 
In total, $50 \%$ indicated having a one-year warranty and $25 \%$ had a five-year warranty. The remaining agencies indicated they had a two- or three-year warranty.

\section{Impacts of GPS Deployment on On-Time Performance}

Because some GPS systems were installed recently, many respondents indicated they were too new to assess. The $47 \%$ of agencies that indicated experiencing moderate or significant impacts attributed that to drivers being more efficient in finding locations, particularly new rider locations. The GPS turn-by-turn navigation appearing on the MDTs eliminates two-way radio communications to other drivers or the dispatcher to ask for directions.

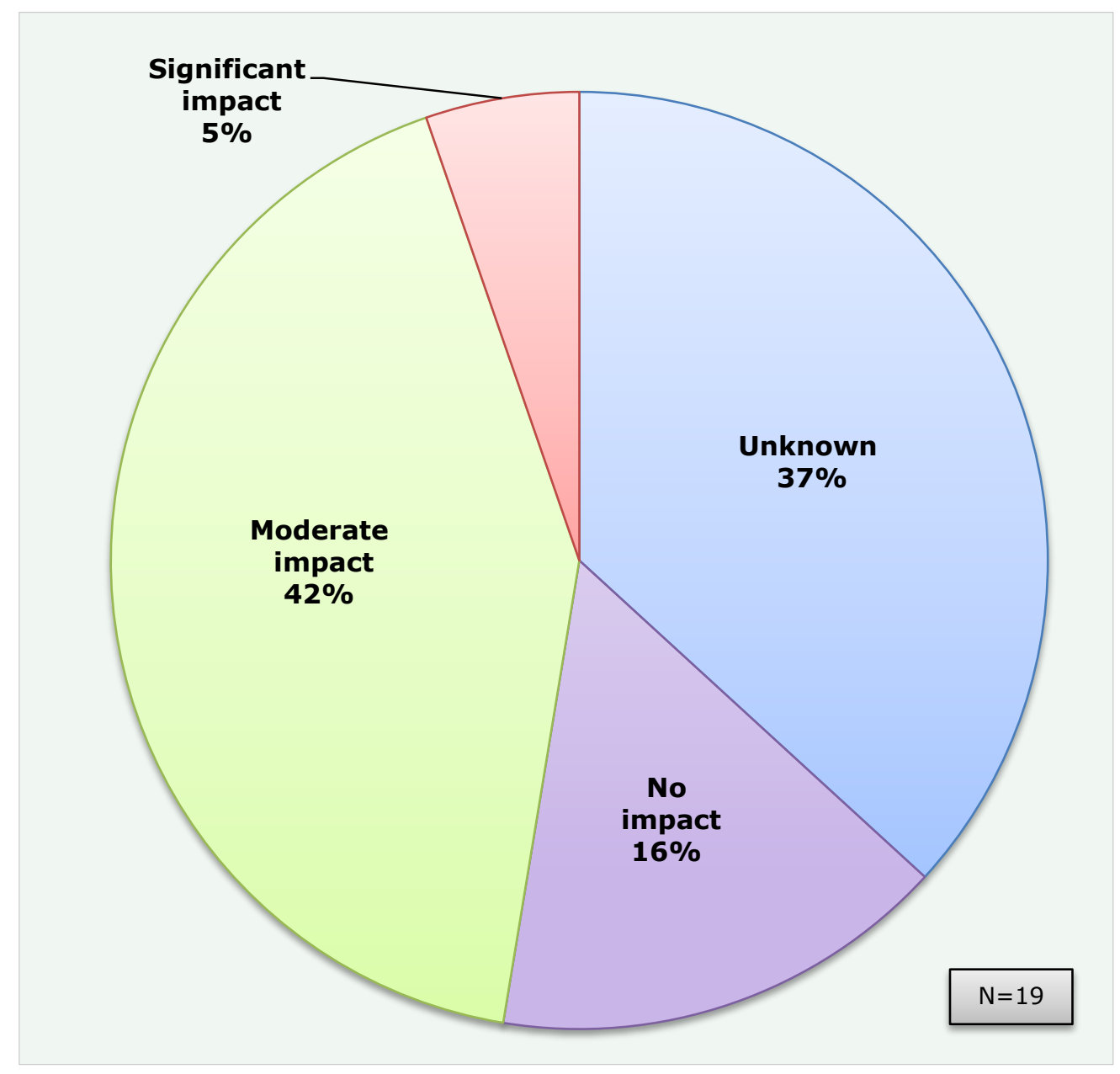

Figure 3-16: Impacts of GPS Deployment on On-Time Performance 


\section{Impacts of GPS Deployment on System Productivity}

Productivity of a system is measured in passengers per revenue hour. In this survey, $37 \%$ indicated moderate to significant impacts to passengers per revenue hour. One agency reported 2.6 passengers per revenue hour in 2014, up from 1.8 in 2009. The recent deployment of the system was the reason many participants $(42 \%)$ selected "unknown impact." Figure 3-17 shows participants' choices.

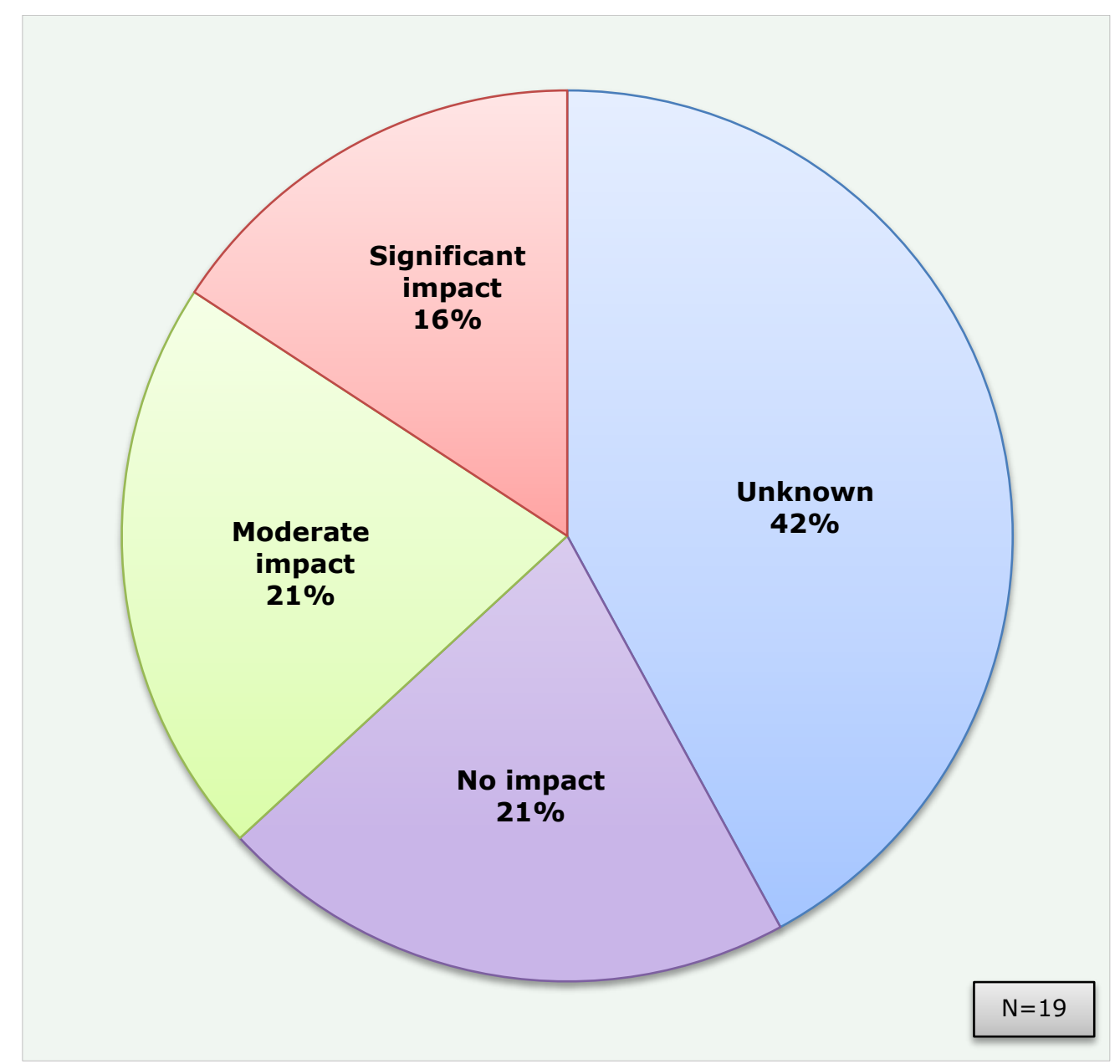

Figure 3-17: Impacts of GPS Deployment on System Productivity 


\section{Impacts of GPS Deployment on Driver Performance}

Reducing the instances of error in finding passenger locations, particularly for new passengers, and appointment locations was the main reason for $58 \%$ of agencies reporting moderate or significant impacts. The need to communicate with the dispatcher or other drivers to ask for directions was reduced.

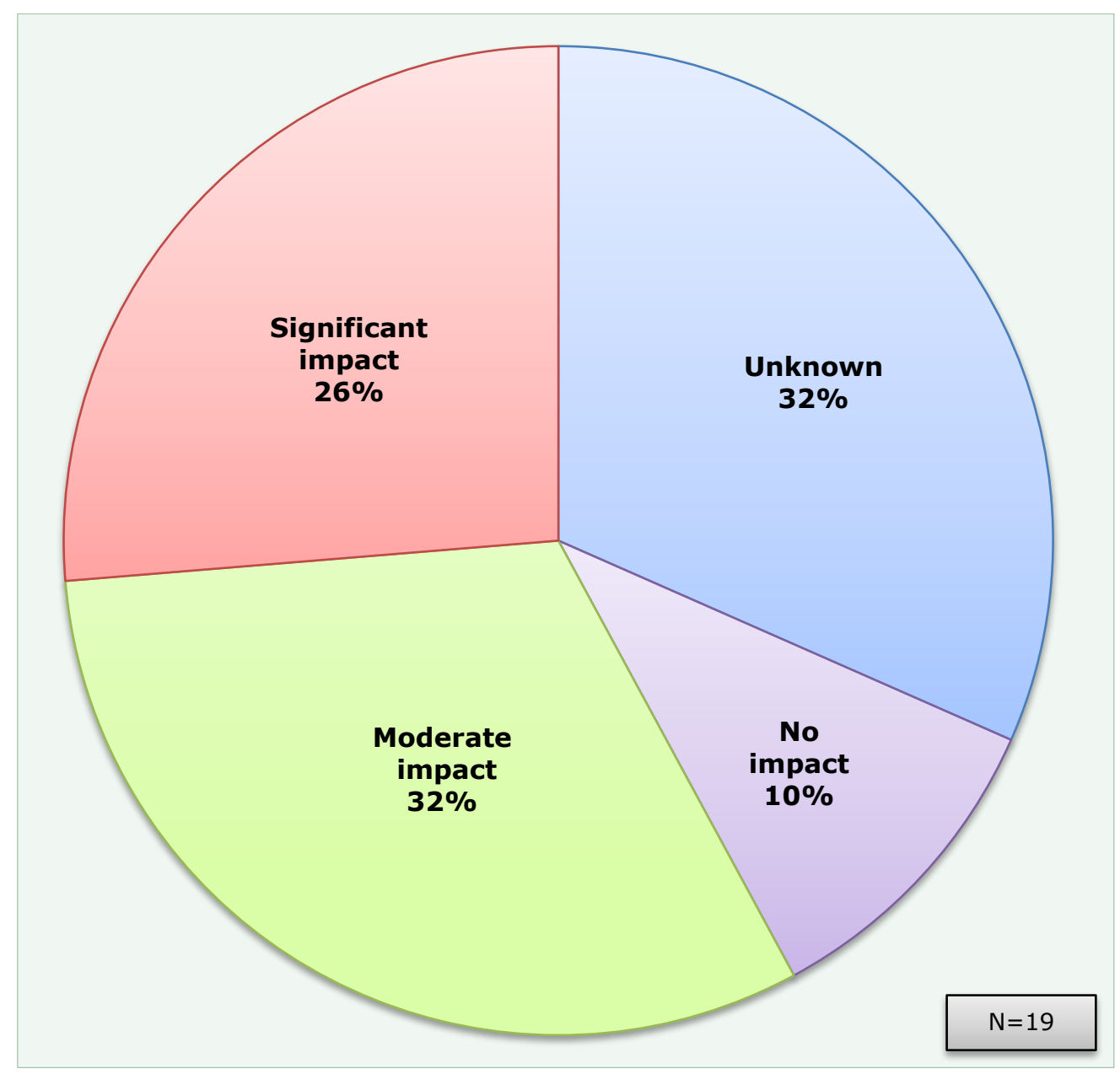

Figure 3-18: Impacts of GPS Deployment on Driver Performance 


\section{Impacts of GPS Deployment on Customer Satisfaction}

A total of $27 \%$ of respondents attributed improvements in customer satisfaction to the ability to advise customers more accurately about when their vehicle will be arriving and to assure them that the driver knows their trip destination. It is also useful in mitigating customer complaints, as the driver is tracked at all times.

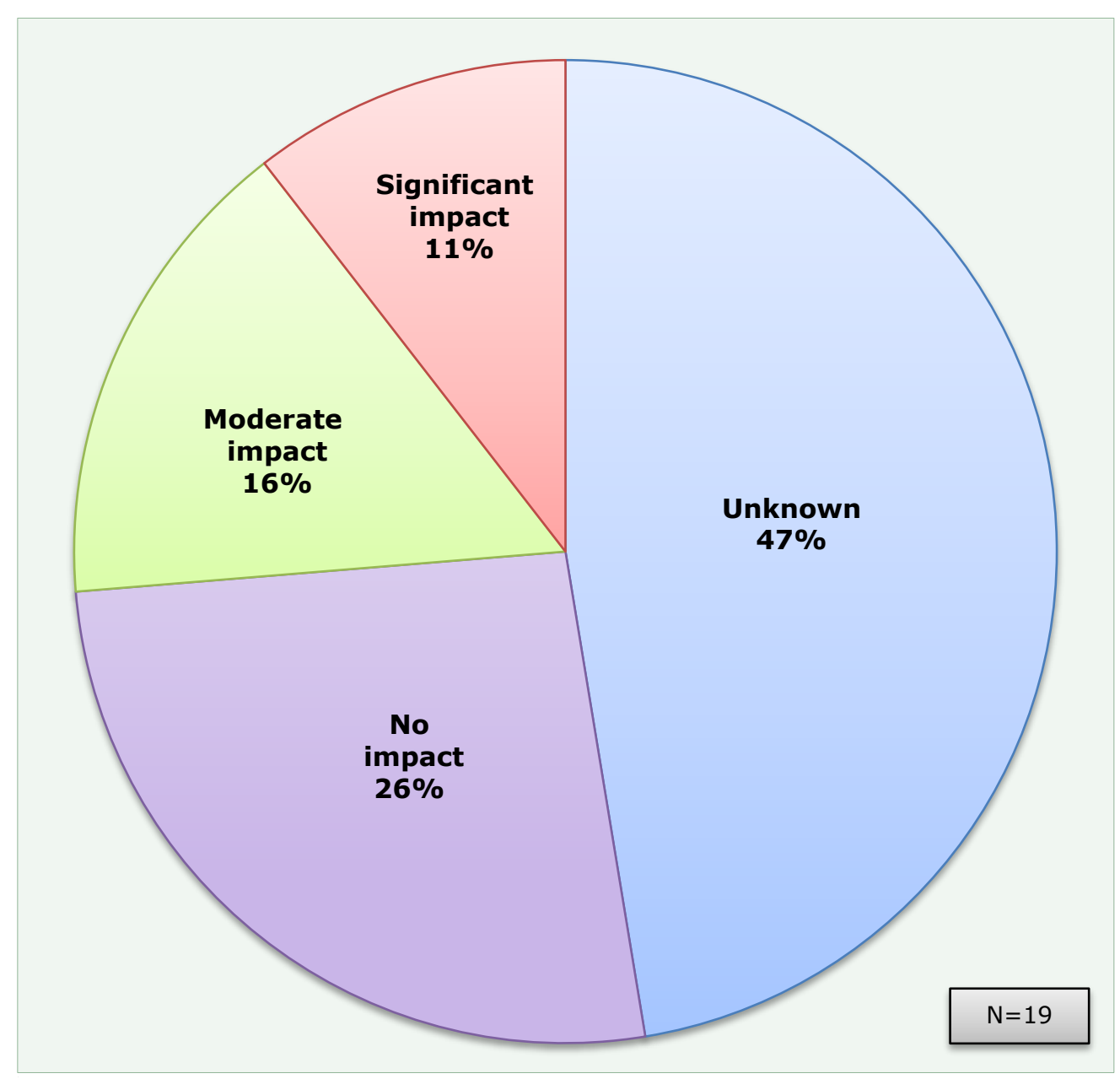

Figure 3-19: Impacts of GPS Deployment on Customer Satisfaction 


\section{Automatic Vehicle Location}

Most agencies deploying new technologies use the Samsung tablet as an MDT/AVL/GPS all-inone unit. Among responders, $65 \%$ indicated their agencies use an AVL system mainly as part of their MDT package. The following vendors were cited in the survey were CTS, Radio Satellite Integrators, Inc., Trapeze, GreyHawk Technologies (with MDT), Digital Dispatch Systems, Mentor Ranger (acquired by Trapeze), Samsung Galaxy Tablet, RouteMatch, and AVAIL.

Only $11 \%$ stated that AVL systems were not used on all their fleet vehicles. Figure 3-20 shows how agencies selected the packages of their AVL systems. The $12 \%$ indicating "other" cited AVL as part of their MDT package. A total of $25 \%$ of agencies installed their own AVL systems at their facilities.

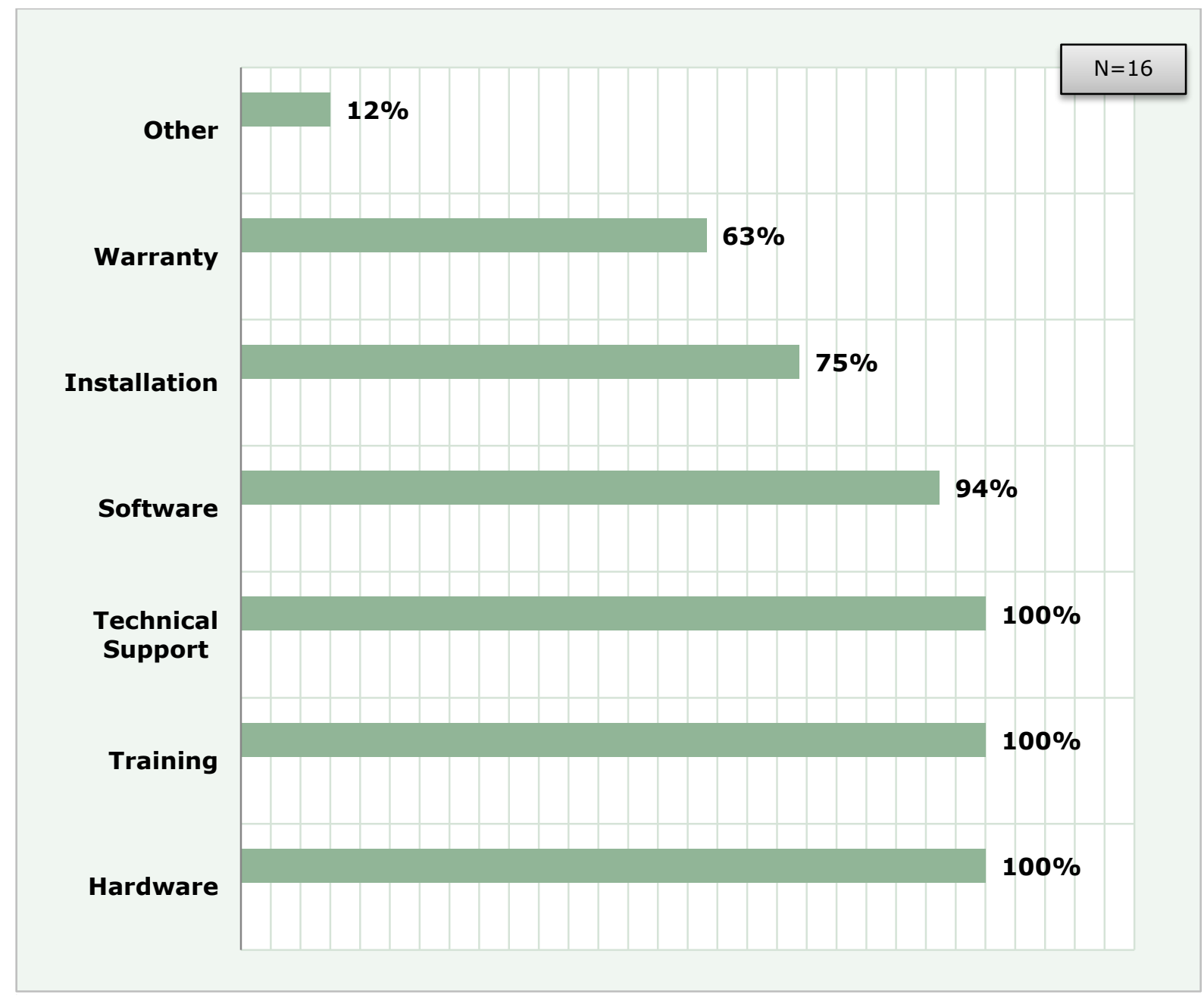

Figure 3-20: AVL Package Selection Considerations

Answers to the question related to warranty duration indicated that annual updates are part of a contract with reservation, scheduling and dispatching software, with very few responders indicating one-, two-, or five-year warranties. Approximately $44 \%$ of the agencies surveyed installed AVL systems in 2014 or $2015,60 \%$ updated their software in 2014 or 2015 , and $57 \%$ updated their hardware at the same time. 


\section{Impacts of AVL Deployment on On-Time Performance}

The majority of agencies surveyed said their systems were too new to assess; the remaining $37 \%$ attributed their moderate to significant impacts to the ability of the dispatcher to track the fleet vehicles at all times, providing the scheduler/dispatcher with reports that pinpoint where deficiencies in on-time performance occurred.

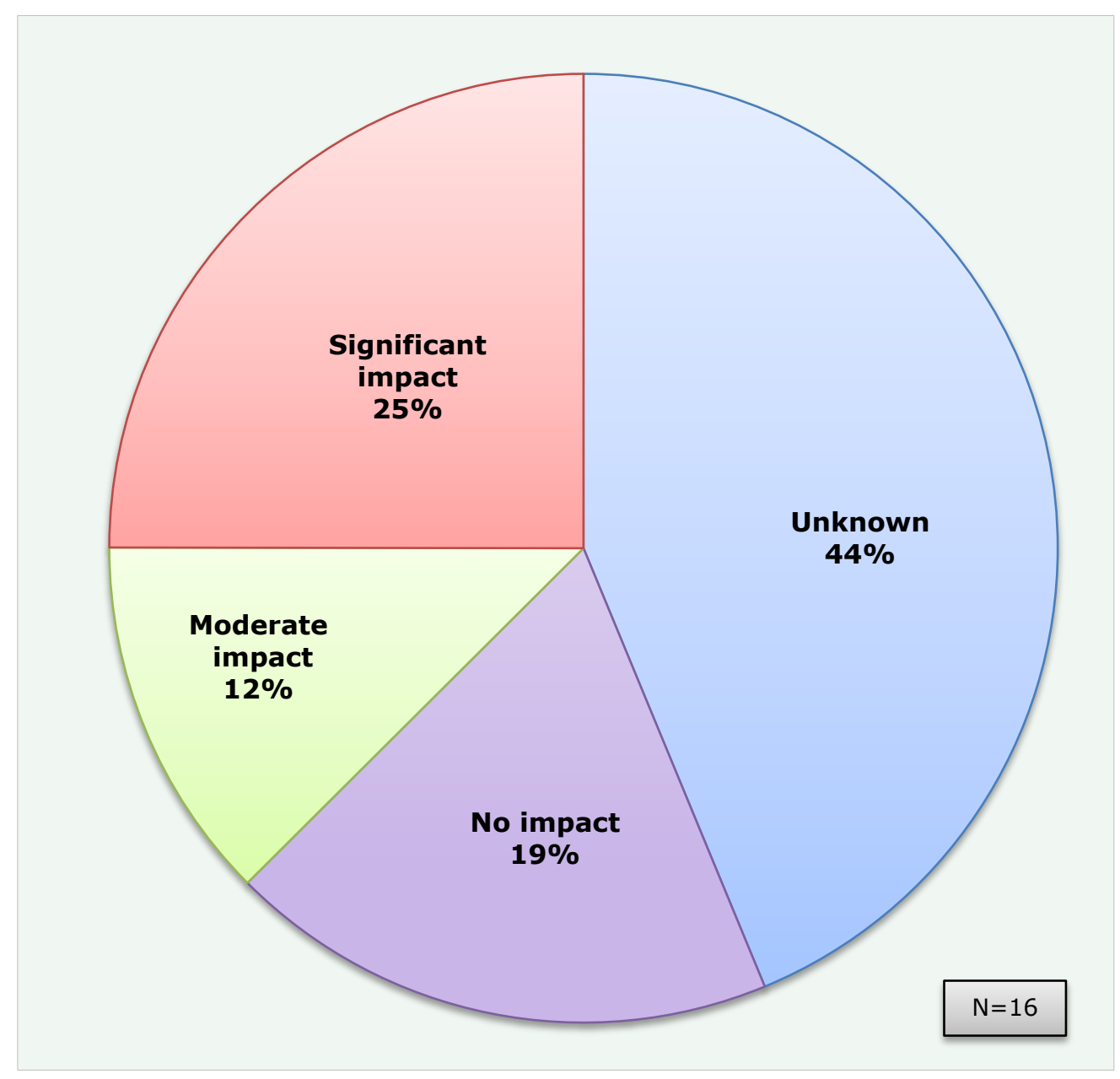

Figure 3-21: Impacts of AVL Deployment on On-Time Performance 


\section{Impacts of AVL Deployment on System Productivity}

One agency attributed its jump from 1.6 to 1.88 passengers per revenue hour to a new AVL system. Many of those who indicated moderate impacts (29\%) cited better scheduling as the reason for increased productivity (Figure 3-22). Some agencies in rural areas indicated that it is difficult to improve productivity since trip duration is lengthy. One of the reasons cited among the $21 \%$ of agencies that experienced no impacts from using AVL was the system being not yet fully operational due to fixed-route reconfiguration (AVL systems used for fixed-route transit need to have the full dataset of all routes for the system to be fully operational).

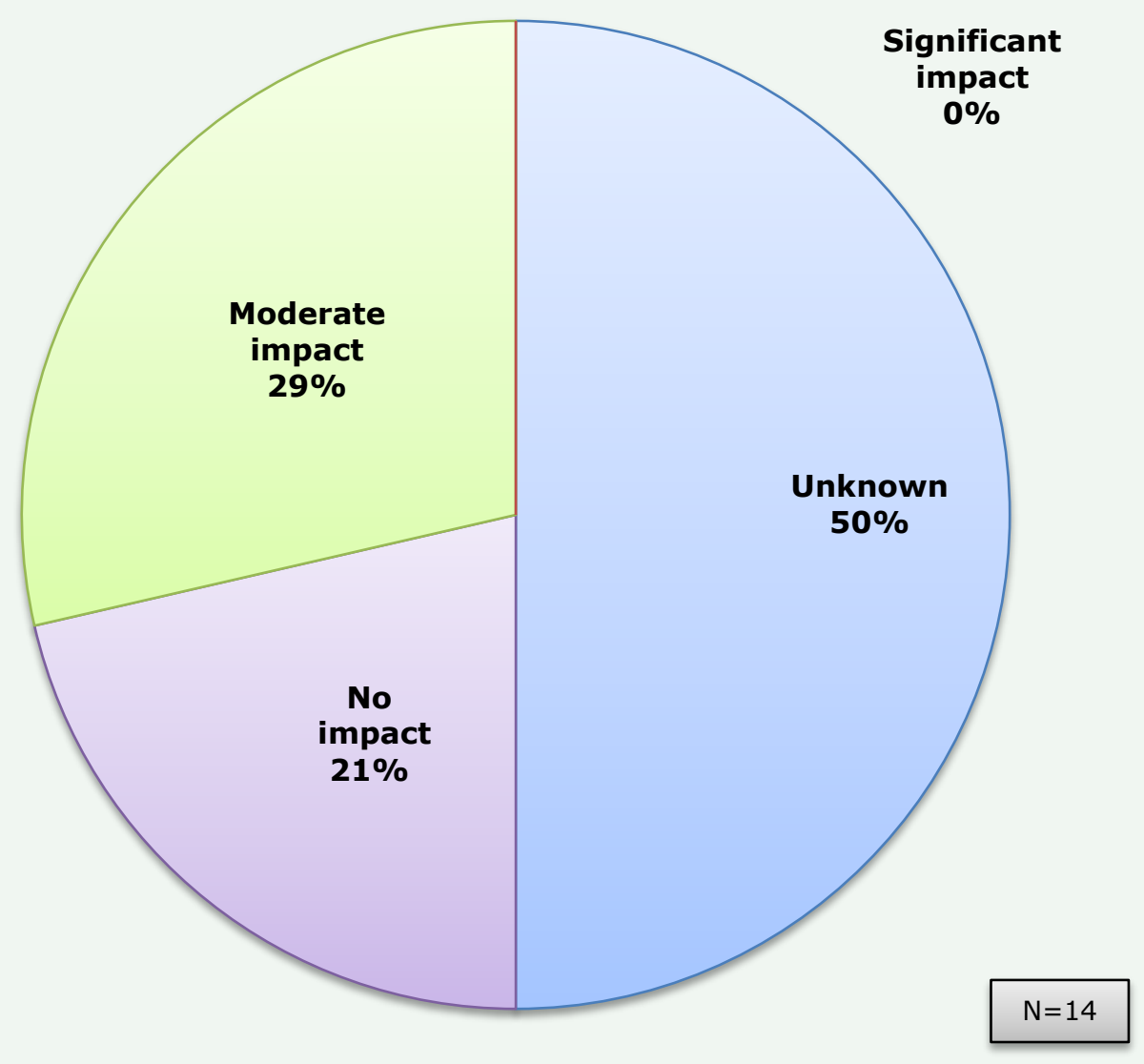

Figure 3-22: Impacts of AVL Deployment on System Productivity 


\section{Impacts of AVL Deployment on Customer Satisfaction}

One of the agencies that noted significant impacts on customer satisfaction cited a decreased number of complaints related to dialysis trips. Further comment was not provided, but it can be concluded that better same-day rescheduling and timeliness of return trips contributed to the decreased number of complaints. The main reason emphasized for experiencing moderate to significant impacts was the accuracy of the information passed to the customer about the location of his/her ride and when it would arrive to pick them up.

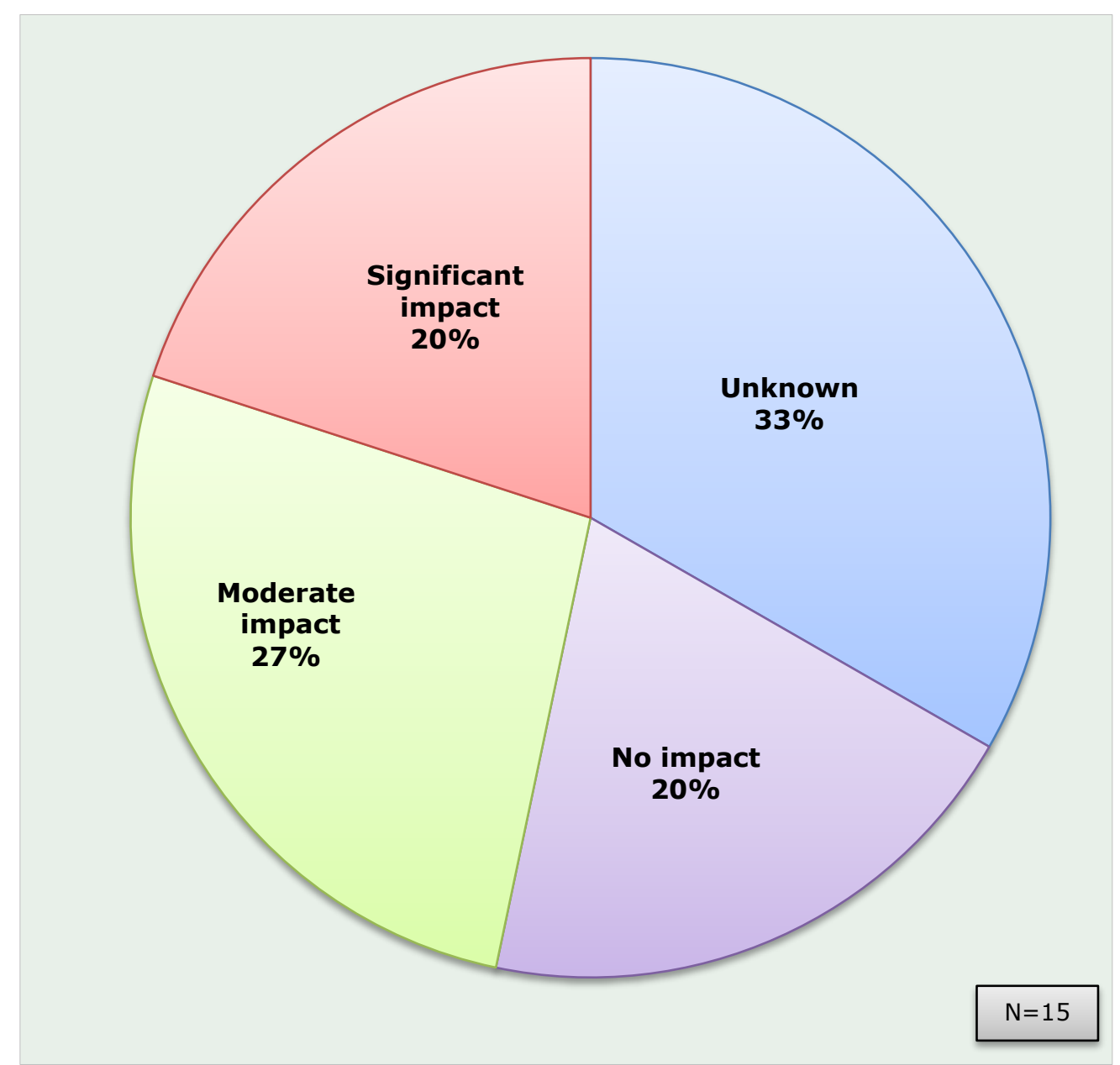

Figure 3-23: Impacts of AVL Deployment on Customer Satisfaction 


\section{Impacts of AVL Deployment on Driver Performance}

As shown in Figure 3-24, 53\% of responders experienced moderate to significant impacts after AVL deployment. One agency experiencing significant impacts indicated that drivers are more efficient, which helps to improve their customer service skills. Also indicated was that the ability to track drivers prompted agency staff to address issues with the drivers when necessary.

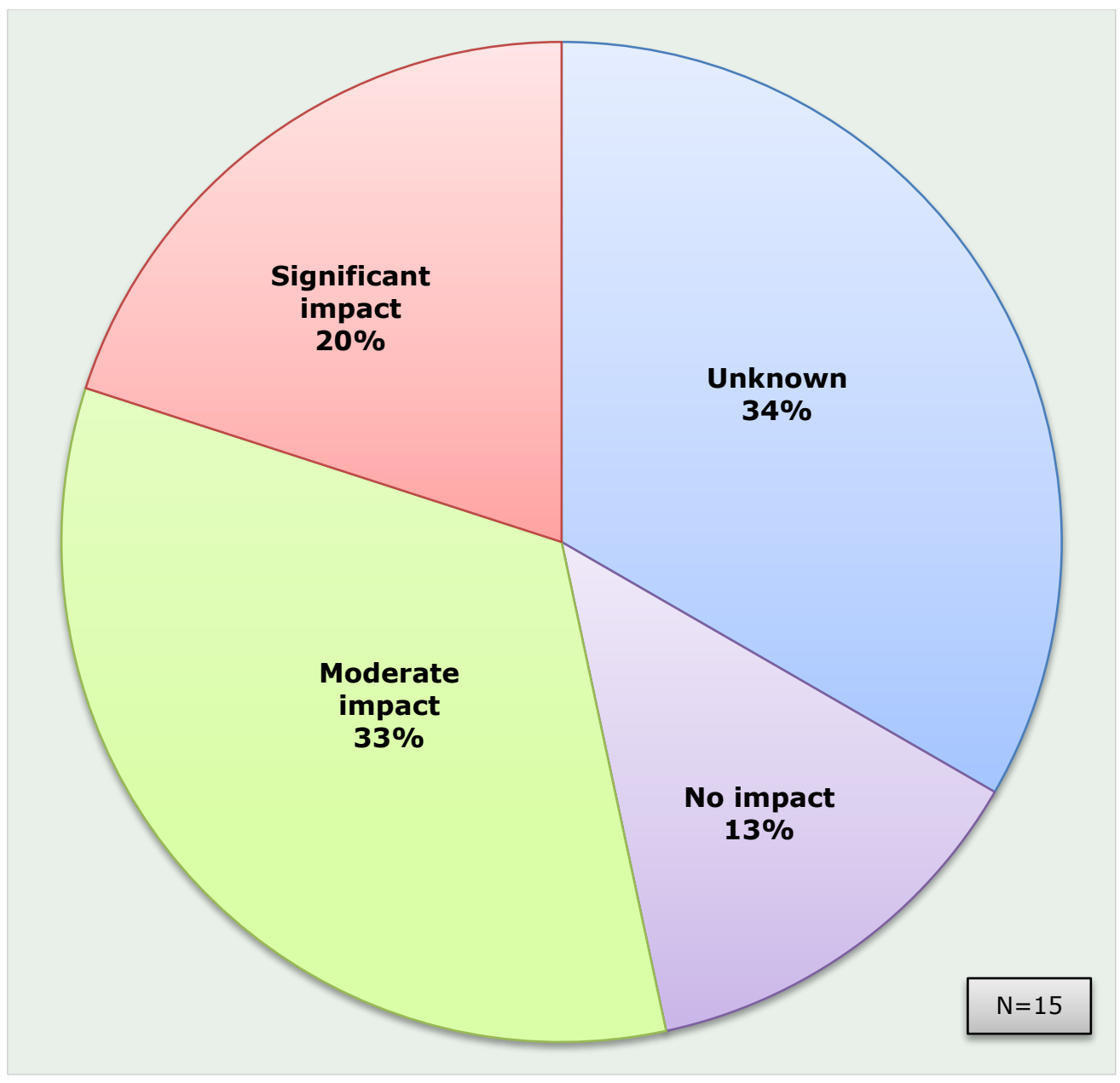

Figure 3-24: Impacts of AVL Deployment on Driver Performance 


\section{Advanced Telephone Systems}

Advanced telephone systems with automated service, call forwarding, voice-mail, and call hold were used by $43 \%$ of agencies surveyed. Brands used included Avaya, ESI, Nortel, Polycom, Cisco, NEC, AT\&T, CSI, AltiGen Communications, Max Agent, Nortel Networks, and RouteMatch.

As shown in Figure 3-25, only 55\% of agencies elected to include a warranty for the package they purchased and $64 \%$ included training. In total, $55 \%$ of respondents indicated that warranty information was unknown to them, $30 \%$ indicated a warranty of one year, and $20 \%$ indicated that a three-year warranty was included with their package. In total, $40 \%$ indicated that their systems were installed within the past two years, and $50 \%$ indicated they were installed in 2011 or 2012. Half of agencies responding indicated that they had updated their system within the past two years. 'Other' in the chart refers to comments by respondents that the system was purchased and/or utilized by others in the agency, therefore, details of the package was unknown to them.

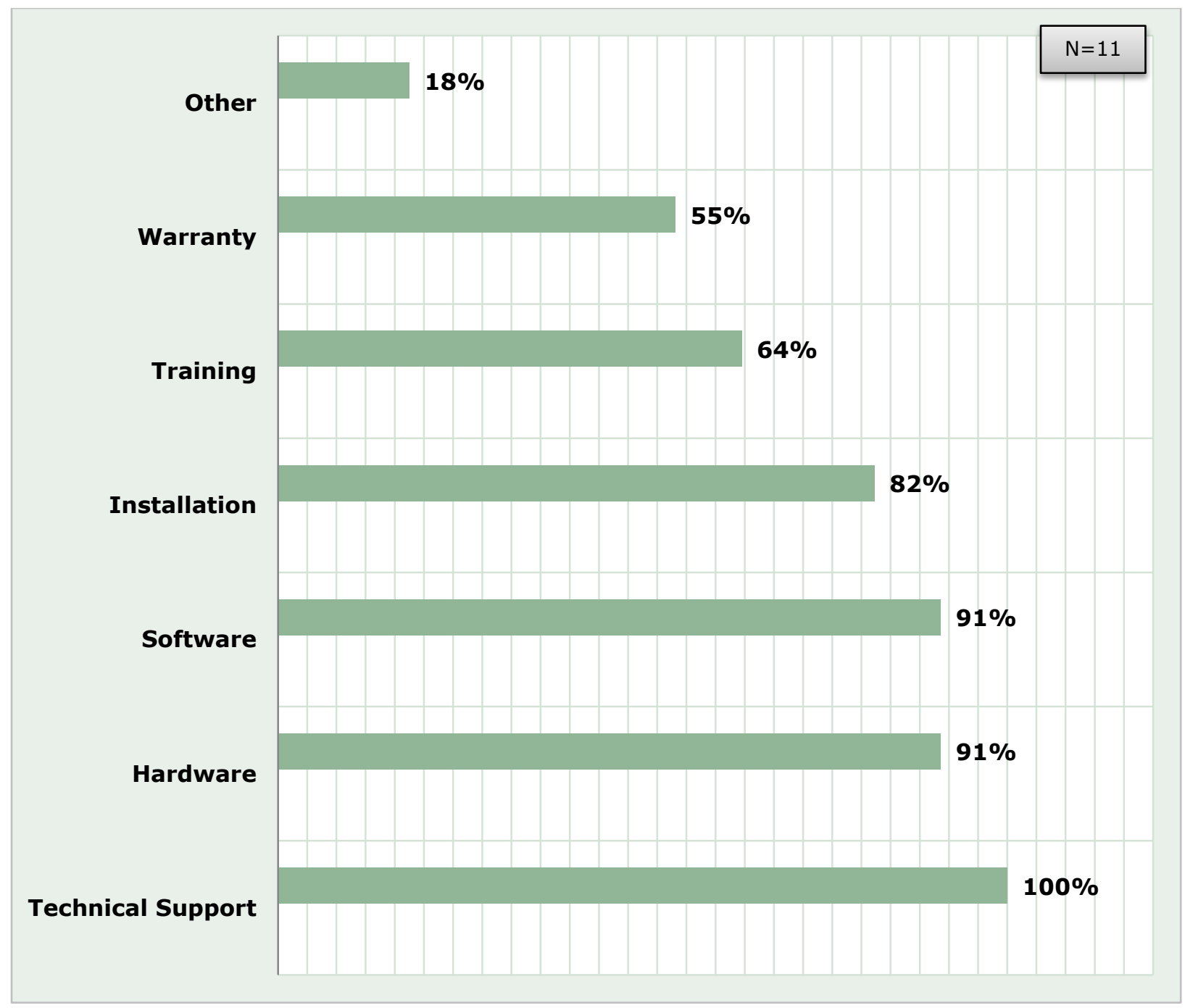

Figure 3-25: Advanced Telephone System Package Selection Considerations 


\section{Impacts of Using Advanced Telephone System on Productivity}

As many as $64 \%$ of respondents experienced moderate to significant impacts from using advanced telephone systems. Reasons provided included the availability of an automated reminder system that calls riders the day before the trip. One agency indicated that two staff members and an advanced telephone system could handle 5,000-6,000 calls per month.

Among the benefits of the system is the capability of receiving reports that can be generated for a specific time to indicate call volume, on-hold time, number of dropped calls, and how long a call lasted. Agencies also stated that the reporting tools allowed for the assessment of call volumes and determination of whether additional personnel are needed or retraining is required.

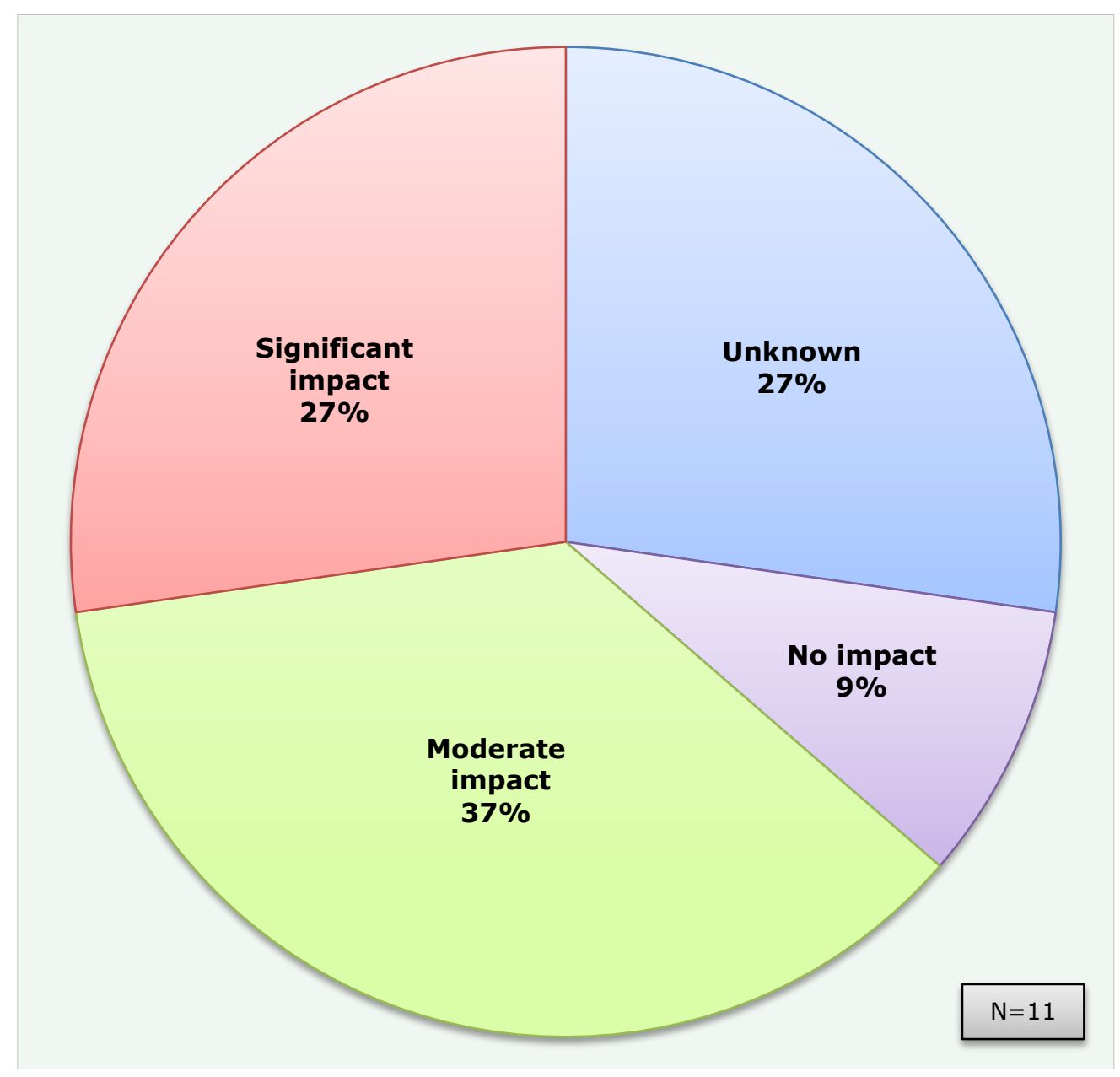

Figure 3-26: Impacts of Using Advanced Telephone System on Productivity 


\section{Impacts of Using Advanced Telephone System on the Reduction of "No-Shows"}

As shown in Figure 3-27, 45\% of agencies indicated experiencing moderate to significant impacts in the reduction of "no-shows" after using advanced telephone systems and attributed it to their customers' ability to leave a message requesting trip cancellation, even after hours.

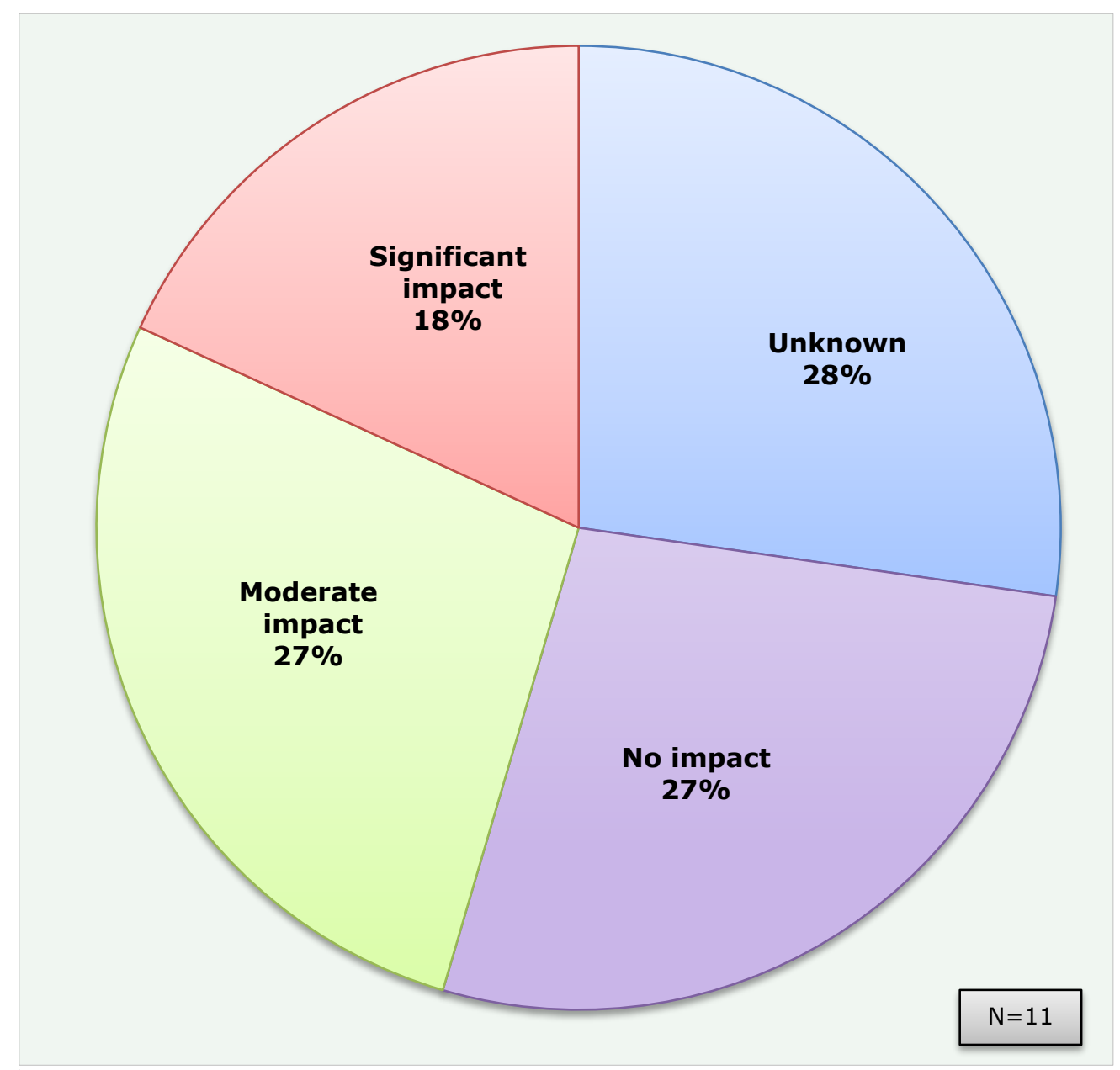

Figure 3-27: Impacts of Using Advanced Telephone System on Reduction of "NoShows" 


\section{Impacts of Using Advanced Telephone System on Customer Satisfaction}

Some of the reasons given for experiencing moderate to significant impacts on customer satisfaction with advanced telephone systems included the ability of passengers to select the person with whom they want to talk or to leave a message for in case they cannot reach that person immediately. Also, with an advanced telephone system, calls are answered immediately, wait times are shorter if put on hold, and messages may be left for individuals after hours.

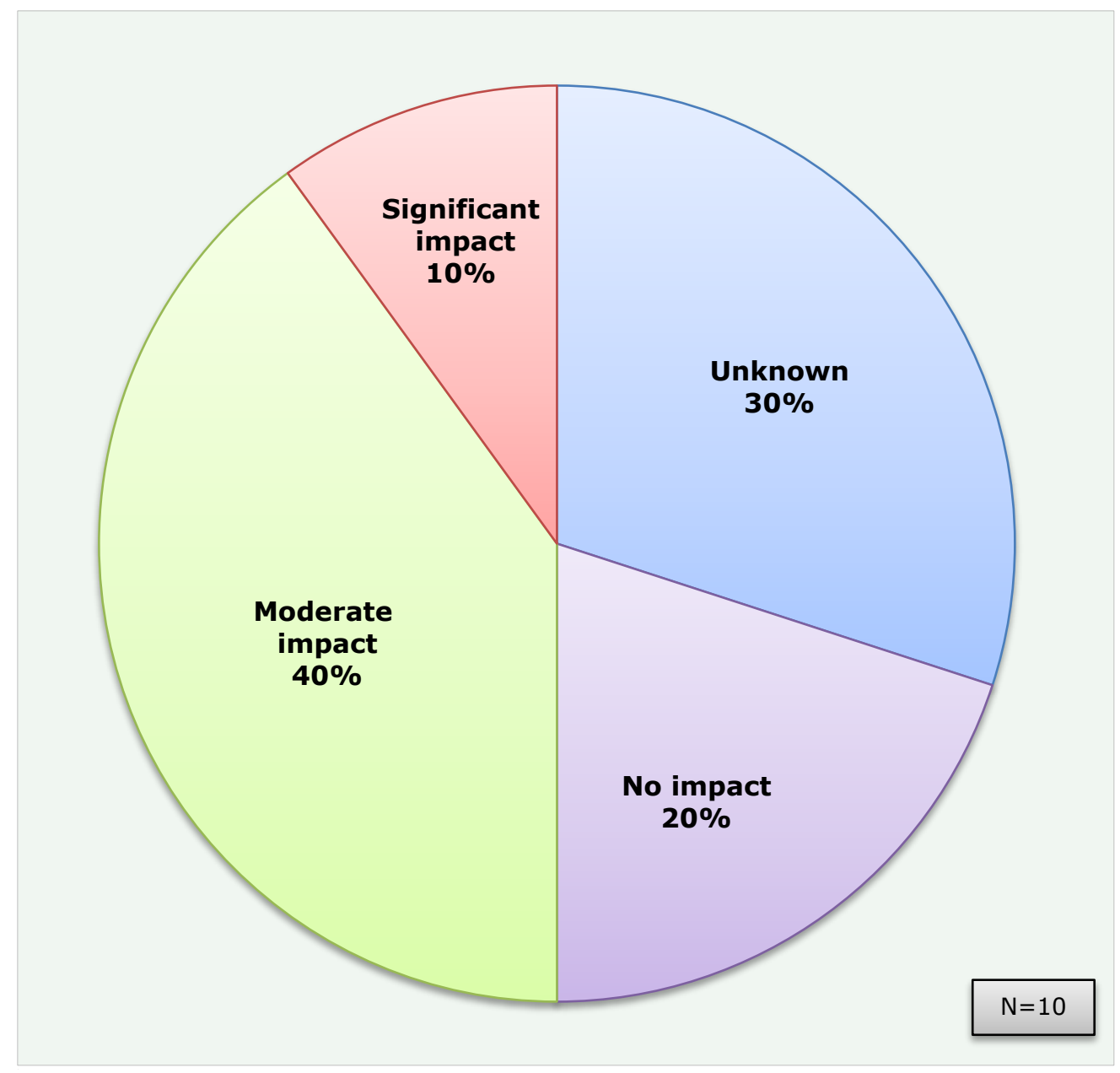

Figure 3-28: Impacts of Using Advanced Telephone System on Customer Satisfaction 


\section{Impacts of Using Advanced Telephone System on Labor Costs}

One agency that expressed achieving significant impacts (10\%) in labor costs attributed it to one less full-time staff required to handle the current call volume. Among the $40 \%$ experiencing moderate to significant impacts, some cited the capability of the system to report call volumes, which allows the adjustment of personnel needed to handle the required workload. Senior Resource Association in Indian River County (Florida) programmed its telephone system to route extra calls to the dispatcher only if the system is experiencing a spike in call volumes; otherwise, the dispatcher does not answer calls.

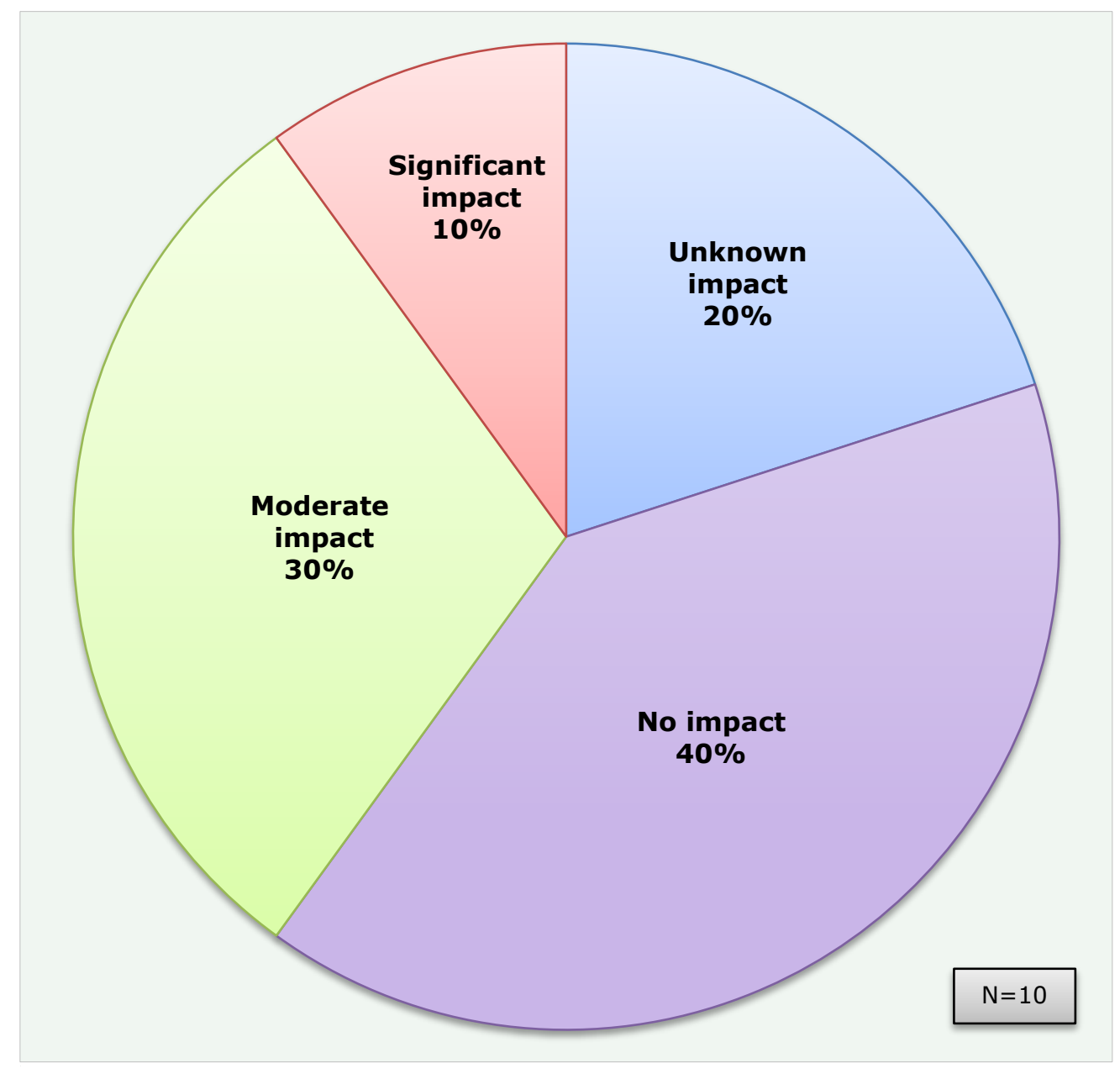

Figure 3-29: Impacts of Using Advanced Telephone System on Labor Costs 


\section{Advanced Telephone Systems with IVR}

When asked if they use advanced telephone systems with IVR, 10\% of agencies responding indicated that they do; however, for the next series of questions, only two respondents provided answers. Related to the packages purchased, both agencies indicated that their packages included:

- Hardware

- Software

- Installation

- Training

- Technical support

- Warranty

The two respondents indicated that vendors used were Computer Instruments (installed in 2011 with a three-year warranty and updated in 2014) and Unified Dispatch, Inc. (installed in 2013 with a one-year warranty and updated in 2014). Only one agency indicated moderate impacts on customer satisfaction, citing better access to information all day versus during call center hours; this agency also cited an $11 \%$ reduction in "no-shows" since using the arrival reminder notification call system. 


\section{Vehicle Security Camera Systems}

Of the 29 agencies that responded, only 11 (38\%) indicated not having vehicle security cameras installed on their fleet vehicles. Brands used included:

- Angel Trak/Hybrid Quest

- Apollo

- Seon

- Provision

- Scion

- REI

- 247Security, Inc.

- Gatekeepers

Packages of video camera systems chosen by participating agencies are shown in Figure 3-30. For warranties included in the packages, $40 \%$ had a five-year warranty and $40 \%$ had a oneyear warranty. Some respondents indicated that they were purchasing vehicles with preinstalled cameras (24\%); $18 \%$ installed cameras in 2013, and 29\% installed them on their fleet vehicles as recently as 2014 and 2015.

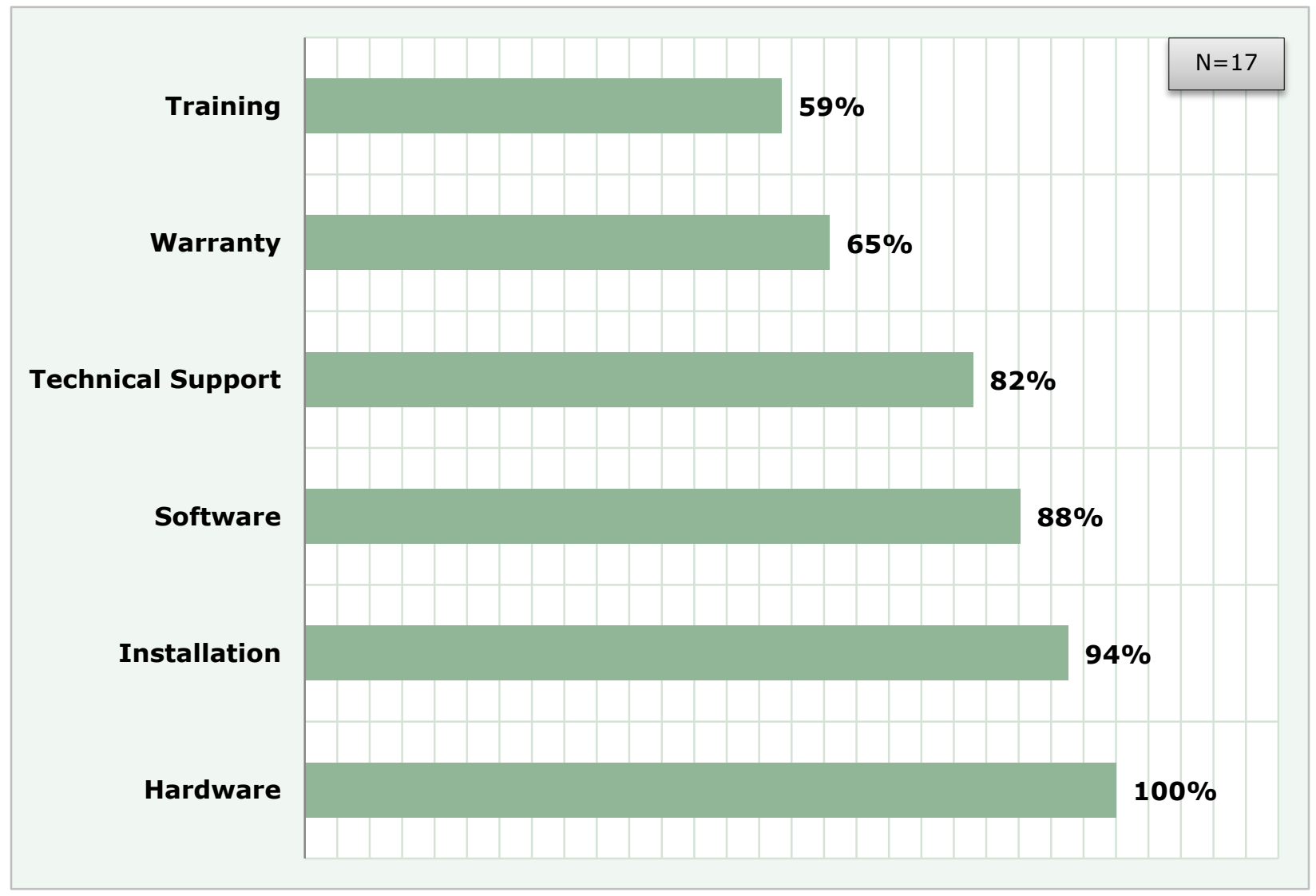

Figure 3-30: Vehicle Security Camera Package Selection Consideration 
Impacts of Using Vehicle Security Camera Systems on Productivity or Performance

One of the reasons indicated by respondents experiencing moderate to significant impacts from using vehicle security cameras (44\%) was the ability of the agency to resolve complaints in an efficient and timely manner. Security cameras also help make both passengers and drivers feel safe and protect them from any false accusations in case of incidents inside or outside the vehicle.

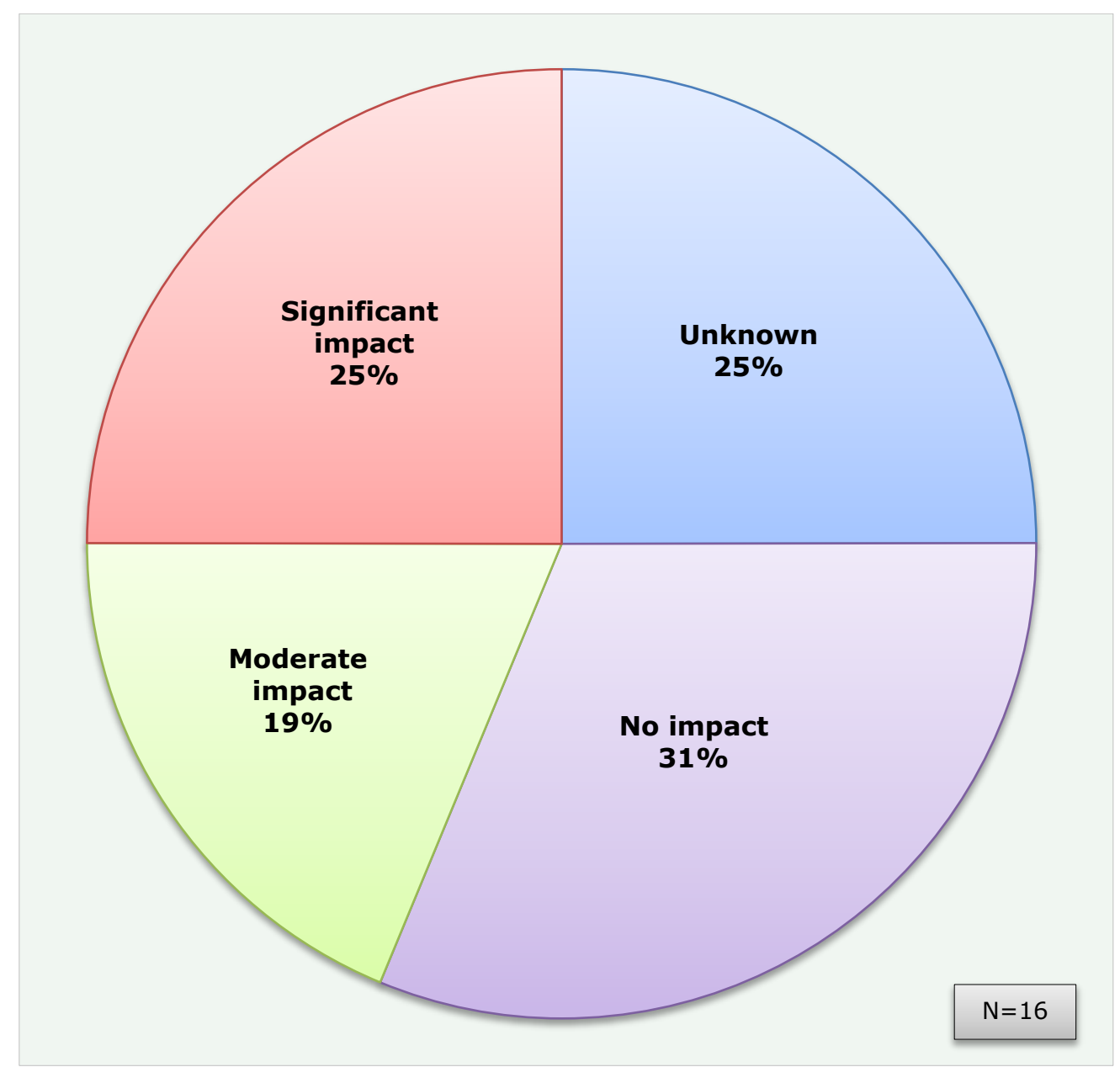

Figure 3-31: Impacts of using Vehicle Security Camera Systems on Productivity or Performance 


\section{Impacts of Using Vehicle Security Camera Systems on Customer Satisfaction}

As shown in Figure 3-32, 63\% of survey participants believe that their agencies have experienced moderate to significant impacts on customer satisfaction from using security cameras. Customers feel safe and seem to appreciate the added security. Because the videos helped in reducing the time of investigating complaints, customers are more satisfied that their complaints are resolved in a timely and effective manner.

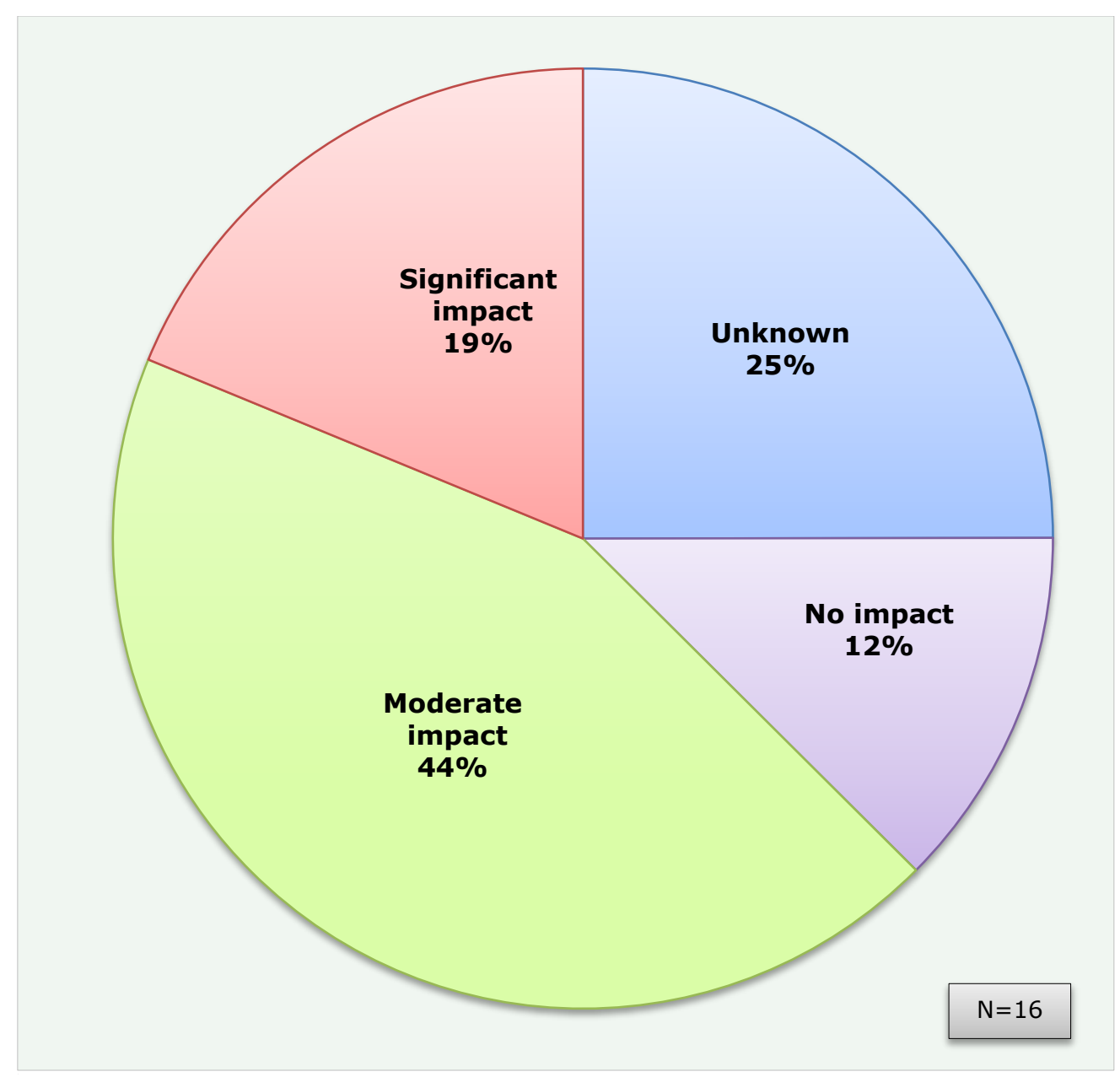

Figure 3-32: Impacts of Using Vehicle Security Camera Systems on Customer Satisfaction 


\section{Impacts of Using Vehicle Security Camera Systems on Driver Performance}

In total, $69 \%$ of agencies indicated that they believe that driver performance has been improved by using vehicle security cameras. The drivers seem to recognize that their time, locations, and passengers are all tracked by audio and video. This technology has helped drivers feel protected from any false claims against their performance, which boosted a sense that the agency "has my back."

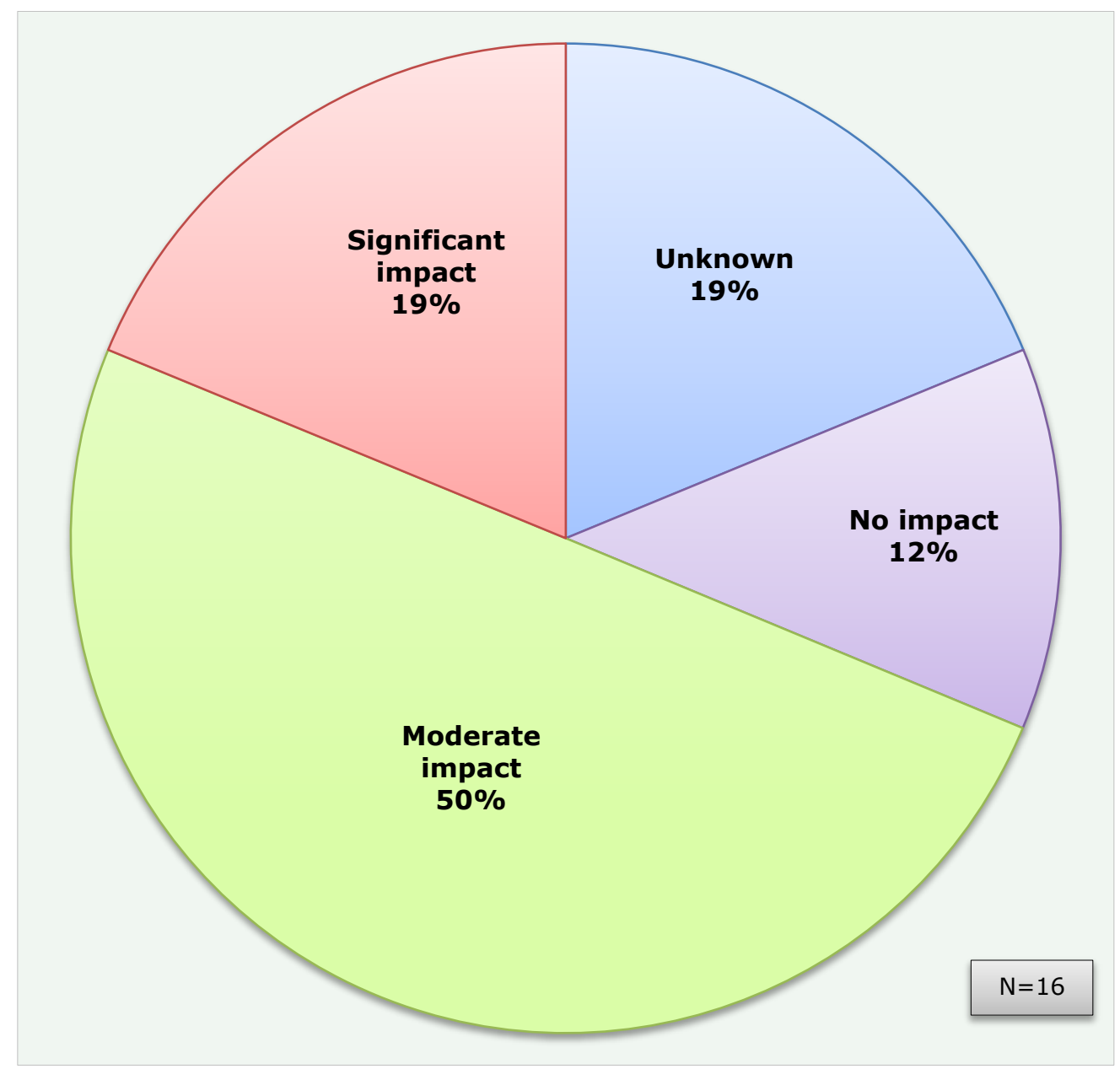

Figure 3-33: Impacts of Using Vehicle Security Camera Systems on Driver Performance 


\section{Chapter 4 - Case Examples and Lessons Learned}

To document helpful practices and lessons learned, seven Florida CTCs were selected for site visits at which in-person interviews were conducted.

\section{Agencies Selected for Site Visits}

The methodology used to select agencies was based on distilling the survey responses from all responding agencies and tabulating those that experienced moderate and/or significant impacts from deploying each technology. Information for each of the technologies was developed that included the impacts on agency performance measures, as shown in Table 4-1.

Some technologies marked as "unknown" in the table were deployed after the survey was completed in February 2015. Site visits were conducted May 12-27, 2015; therefore, comments from the site visits may reflect changes in the impacts noted in the survey. For example, Levy County Transit indicated the impact of vehicle security cameras as "unknown" in the survey; however, the agency deployed vehicle security cameras after the survey was completed, and the discussion from the site visit reflects the positive impacts gained from that technology deployment.

Performance measures included productivity of the system, on-time performance, driver performance, labor costs, and customer service. The research team selected agencies that indicated a minimum of three moderate to significant impacts on performance measures to justify the site visit. Some agencies had more than three relevant performance measures, making the justification for a visit more compelling. The following systems were visited and are listed in the order of visits conducted:

- Pasco County Public Transportation

- Collier Area Transit

- Liberty County Transit

- Levy County Transit

- Lake County Public Transportation

- Senior Resource Association, Indian River County

- Council on Aging of St. Lucie County, Inc.

The remainder of this chapter provides a summary of each of the seven transit agencies that were visited. Each section reports on the following topics:

- System information to facilitate peer comparison: agency information as reported to the Florida CTD and excerpted from the 2014 Annual Performance Report of the Florida Commission for the Transportation Disadvantaged [28].

- Description of technology, costs, and funding sources

- Agency-specific practices

- Technology benefits as experienced by the agency

- Lessons learned and tips for other agencies as recommended by responding agencies 
Table 4-1: Agencies Selected for Further Documentation of Impacts

\begin{tabular}{|c|c|c|c|c|c|c|c|}
\hline $\begin{array}{l}\text { Significant Impacts } \\
\text { of Deployment }\end{array}$ & $\begin{array}{c}\text { Collier } \\
\text { Area } \\
\text { Transit }\end{array}$ & $\begin{array}{c}\text { Pasco } \\
\text { County } \\
\text { Public } \\
\text { Trans- } \\
\text { portation }\end{array}$ & $\begin{array}{l}\text { Liberty } \\
\text { County } \\
\text { Transit }\end{array}$ & $\begin{array}{c}\text { Senior } \\
\text { Resource } \\
\text { Assn., } \\
\text { Indian } \\
\text { River } \\
\text { County }\end{array}$ & $\begin{array}{l}\text { Council } \\
\text { on } \\
\text { Aging } \\
\text { of St. } \\
\text { Lucie, } \\
\text { Inc. }\end{array}$ & $\begin{array}{c}\text { Levy } \\
\text { County } \\
\text { Transit }\end{array}$ & $\begin{array}{c}\text { Lake } \\
\text { County } \\
\text { Public } \\
\text { Trans- } \\
\text { portation }\end{array}$ \\
\hline \multicolumn{8}{|c|}{ Reservation, Scheduling, and Dispatching Software } \\
\hline Customer satisfaction & $\mathrm{S}$ & $U$ & $\mathrm{~S}$ & $\mathrm{U}$ & $\mathrm{S}$ & $\mathrm{S}$ & M \\
\hline Reduction of no shows & M & $U$ & $\mathrm{~N}$ & M & $\mathrm{N}$ & $\mathrm{N}$ & M \\
\hline Driver performance & $\mathrm{S}$ & $\mathrm{S}$ & M & $\mathrm{S}$ & M & $\mathrm{S}$ & M \\
\hline On-time performance & $\mathrm{S}$ & $\mathrm{S}$ & $\mathrm{S}$ & $\mathrm{S}$ & M & $\mathrm{S}$ & M \\
\hline Agency labor costs & $\mathrm{S}$ & $\mathrm{N}$ & M & $\mathrm{U}$ & $\mathrm{N}$ & $\mathrm{S}$ & M \\
\hline \multicolumn{8}{|c|}{ Mobile Data Terminals } \\
\hline Customer satisfaction & $\mathrm{U}$ & U & $\mathrm{S}$ & $\mathrm{U}$ & $\mathrm{S}$ & $\mathrm{S}$ & $\mathrm{N}$ \\
\hline Reduction of no shows & $U$ & U & $\mathrm{N}$ & $\mathrm{U}$ & $\mathrm{N}$ & $\mathrm{N}$ & $\mathrm{N}$ \\
\hline Driver performance & $\mathrm{S}$ & $\mathrm{S}$ & $\mathrm{S}$ & M & M & M & M \\
\hline On-time performance & $\mathrm{S}$ & $\mathrm{S}$ & $\mathrm{S}$ & M & $\mathrm{N}$ & $\mathrm{S}$ & $\mathrm{S}$ \\
\hline Driver satisfaction & $\mathrm{S}$ & $\mathrm{S}$ & M & $\mathrm{S}$ & M & $\mathrm{S}$ & M \\
\hline \multicolumn{8}{|c|}{ Global Positioning System } \\
\hline Customer satisfaction & $\mathrm{S}$ & $U$ & $U$ & NR & NA & NR & NA \\
\hline Driver performance & $\mathrm{S}$ & $\mathrm{S}$ & M & NR & NA & NR & NA \\
\hline On-time performance & $\mathrm{S}$ & $U$ & M & NR & NA & NR & NA \\
\hline System productivity & $\mathrm{N}$ & $\mathrm{S}$ & $U$ & NR & NA & NR & NA \\
\hline \multicolumn{8}{|c|}{ Automatic Vehicle Location } \\
\hline Customer satisfaction & $\mathrm{S}$ & $U$ & U & $\mathrm{S}$ & $\mathrm{S}$ & $\mathrm{N}$ & M \\
\hline Driver performance & $\mathrm{S}$ & $U$ & NR & $\mathrm{S}$ & M & M & $\mathrm{S}$ \\
\hline On-time performance & $\mathrm{S}$ & $U$ & NR & $\mathrm{S}$ & $\mathrm{N}$ & $\mathrm{S}$ & M \\
\hline System productivity & $U$ & $U$ & NR & $U$ & $U$ & M & M \\
\hline \multicolumn{8}{|c|}{ Advanced Telephone Systems } \\
\hline Customer satisfaction & $\mathrm{S}$ & NR & NR & NR & NA & M & NA \\
\hline Reduction of no shows & $\mathrm{S}$ & NR & NR & NR & NA & M & NA \\
\hline System's productivity & $\mathrm{S}$ & NR & NR & NR & NA & $U$ & NA \\
\hline \multicolumn{8}{|c|}{ Vehicle security cameras } \\
\hline Customer satisfaction & M & $\mathrm{S}$ & NA & M & M & U & $\mathrm{S}$ \\
\hline Driver performance & M & $\mathrm{S}$ & NA & M & $\mathrm{S}$ & U & M \\
\hline System productivity & $\mathrm{S}$ & $\mathrm{S}$ & NA & $\mathrm{N}$ & $\mathrm{S}$ & $U$ & $\mathrm{~S}$ \\
\hline
\end{tabular}

$\mathrm{S}=$ significant impacts, $\mathrm{M}=$ moderate impacts, $\mathrm{N}=$ no impacts, $\mathrm{U}=$ impacts unknown, $\mathrm{NR}=$ no response (skipped question), NA = not applicable (technology is not used by agency) 


\section{Pasco County Public Transportation}

\section{System Information}

Table 4-2: 2014 Pasco County Public Transportation Information as Reported to Florida CTD

\begin{tabular}{|c|c|c|c|}
\hline TOTAL COUNTY POPULATION & 475,502 & POTENTIAL TD POPULATION & 240,148 \\
\hline \multicolumn{2}{|c|}{ Trips by Type of Service } & \multicolumn{2}{|l|}{ Vehicle Data } \\
\hline Fixed Route (FR) & 129,236 & Vehicle Miles & $1,147,734$ \\
\hline Deviated FR & 0 & Revenue Miles & $1,017,731$ \\
\hline Ambulatory & 123,505 & Roadcalls & 14 \\
\hline Non-Ambulatory & 18,902 & Accidents & 4 \\
\hline Stretcher & 343 & Vehicles & 104 \\
\hline School Board & 14,531 & Driver Hours & 72,957 \\
\hline \multicolumn{2}{|c|}{ Passenger Trips by Trip Purpose } & \multicolumn{2}{|c|}{ Financial and General Data } \\
\hline Medical & 152,132 & Expenses & $\$ 3,407,405$ \\
\hline Employment & 18,156 & Revenues & $\$ 3,407,405$ \\
\hline Ed/Train/DayCare & 64,120 & Commendations & 10 \\
\hline Nutritional & 11,584 & Complaints & 26 \\
\hline Life-Sustaining/Other & 40,525 & Passenger No-Shows & 2,392 \\
\hline Total Trips & 286,517 & Unmet Trip Requests & 140 \\
\hline \multicolumn{2}{|c|}{ Passenger Trips by Funding Source } & \multicolumn{2}{|c|}{ Performance Measures } \\
\hline CTD & 104,602 & Accidents per 100,000 Miles & 0.35 \\
\hline AHCA & 27,425 & Miles between Roadcalls & 81,981 \\
\hline APD & 19,202 & Avg. Trips per Driver Hour & 2.16 \\
\hline DOEA & 16,013 & Avg. Trips per Para Pass. & 30.97 \\
\hline DOE & 11,136 & Cost per Trip & 11.89 \\
\hline Other & 108,139 & Cost per Paratransit Trip & 20.00 \\
\hline \multirow{2}{*}{ Total Trips } & \multirow{2}{*}{286,517} & Cost per Driver Hour & 43.12 \\
\hline & & Cost per Total Mile & 2.74 \\
\hline
\end{tabular}

\section{Description of Technology, Costs, and Funding Sources}

Pasco County Public Transportation (PCPT) elected to implement new technologies to address reporting requirements that were consuming labor time. PCPT staff researched the available technologies that would increase the efficiency of their operations. For seven months, the staff conducted visits to other transit properties seeking information and lessons learned from the experiences of other agencies. PCPT staff decided to use RouteMatch as its reservation, scheduling, and dispatching software, with Samsung tablets that function as MDT, GPS, and AVL all-in-one units. PCPT elected to have RouteMatch cloud-host the software to secure the data in case of power outages or computer crashing at PCPT. Cloud-hosting also makes it easier for the vendor to update software versions as necessary.

PCPT used funding available from FTA's Urbanized Area Formula Program (Section 5307). Bidding was conducted in accordance with FTA Circular 4220. 
Reservation, scheduling, and dispatching software costs $\$ 605,000$ for the entire system of software and tablets on 48 vehicles, procured in February 2015.

Vehicle security camera systems from Apollo were installed on the fleet of both fixed-route and paratransit vehicles for $\$ 175,000$ in 2011 in a package that included a one-year warranty in addition to technical support and training.

\section{Agency-Specific Practices}

A vehicle odometer reading is a means of reporting and invoicing for an agency. If the odometer reporting is incorrect, the dispatcher can correct that information with data provided from RouteMatch reports. Mileage is reset every time a driver logs into the MDT. The driver completes the manifest log at each customer drop-off and at the property yard when the driver logs off at the end of a shift.

PCPT riders are familiar with drivers, so it is an agency practice to keep the same drivers on the same routes. There is a community feeling within this agency, and the particular needs of the riders are considered when scheduling and taking their trips.

RouteMatch was deemed to be the appropriate vendor by PCPT because it is equipped to accommodate the future needs of the agency as the county experiences growth.

\section{Technology Benefits as Experienced by the Agency}

Vehicle security cameras are beneficial in conflict mitigation to confirm a customer complaint, correct driver behavior if needed, or substantiate that procedures were followed and a complaint was unfounded. Videos are not a live feed, but they can be obtained from the computer hard drive upon request.

PCPT staff reported being pleasantly surprised that the presence of cameras prompted riders not to litter.

The improved efficiency of scheduling and routing was realized in a relatively short time after deployment of the RouteMatch reservation and scheduling services and MDT tablets. On the demand response side, PCPT reported $25 \%$ more trips being accommodated with the new technology, indicating a $25 \%$ increase in driver productivity. PCPT staff reported a reduction in errors in finding customer locations with the use of the electronic manifest that includes turnby-turn GPS navigation.

PCPT noted the benefits of less paperwork, as updates are received instantly, thus reducing errors between dispatchers and operators. Also, the agency experienced time reductions in creating required reports, as the process of manually retrieving the essential portions of a report from different fields in the old system was labor-intensive.

RouteMatch included a safety feature in its programming of the tablet that locks the screen while a vehicle is in motion; however, a message from the dispatcher can be viewed on the screen while the vehicle is moving. The driver can send messages or provide pick-up/drop-off reporting only when the vehicle is parked.

\section{Lessons Learned and Tips for Other Agencies}

PCPT recommended the following:

- Take time to involve all staff before selecting the specifications of a proposed system. In many instances, although upper management is aware of the nature of tasks conducted by employees on a daily basis, the intricate details of these tasks are familiar mostly to 
those who are performing them. Some reporting tasks are comprehensive and require an exhaustive amount of data. Make sure these data needs and the fields needed to develop the reports are described in the specifications.

- Take time to describe the agency's data needs to the vendor before it develops the agency package rather than customize the needed requirements after the system is in place, which also can incur additional costs for the agency.

- Training is vital to the success of the transition between old and new systems. Transitioning to a new system can be challenging, so do not rush the system "going live" after deployment. Make sure the vendor is readily available as the transition occurs to work out any glitches. Even if the system seems ready to go live as soon as installation is complete, be sure that all staff members are comfortable with the new technology and that all glitches occurring in the pilot phase of the deployment are worked out. PCPT piloted the new system with 10 vehicles to work out any problems before going live.

- PCPT staff strongly recommend that the old and new systems work simultaneously for at least a month before disconnecting the old system to ensure that no reporting or billing are missed during the transitioning phase.

- Emphasize the long-term benefits that will be realized after the system is smoothly running and all the bugs are worked out. Efficiency and on-time performance will be realized when route schedules are maximized; the productivity of operators may even double when all are on-board with the new system in place. 


\section{Collier Area Transit}

\section{System Information}

Table 4-3: 2014 Collier Area Transit Information as Reported to Florida CTD

\begin{tabular}{|c|c|c|c|}
\hline TOTAL COUNTY POPULATION & 339,642 & POTENTIAL TD POPULATION & 145,829 \\
\hline \multicolumn{2}{|c|}{ Trips by Type of Service } & \multicolumn{2}{|l|}{ Vehicle Data } \\
\hline Fixed Route (FR) & 0 & Vehicle Miles & $1,150,405$ \\
\hline Deviated FR & 0 & Revenue Miles & 986,938 \\
\hline Ambulatory & 65,840 & Roadcalls & 38 \\
\hline Non-Ambulatory & 18,625 & Accidents & 10 \\
\hline Stretcher & 0 & Vehicles & 23 \\
\hline School Board & 0 & Driver Hours & 59,750 \\
\hline \multicolumn{2}{|c|}{ Passenger Trips by Trip Purpose } & \multicolumn{2}{|c|}{ Financial and General Data } \\
\hline Medical & 47,826 & Expenses & $\$ 3,272,256$ \\
\hline Employment & 9,334 & Revenues & $\$ 4,017,827$ \\
\hline Ed/Train/DayCare & 5,049 & Commendations & 12 \\
\hline Nutritional & 11,164 & Complaints & 16 \\
\hline Life-Sustaining/Other & 11,092 & Passenger No-Shows & 2332 \\
\hline Total Trips & 84,465 & Unmet Trip Requests & 29 \\
\hline \multicolumn{2}{|c|}{ Passenger Trips by Funding Source } & \multicolumn{2}{|c|}{ Performance Measures } \\
\hline CTD & 38,426 & Accidents per 100,000 Miles & 0.87 \\
\hline $\mathrm{AHCA}$ & 0 & Miles between Roadcalls & 30,274 \\
\hline APD & 0 & Avg. Trips per Driver Hour & 1.41 \\
\hline DOEA & 1,067 & Avg. Trips per Para Pass. & 90.05 \\
\hline DOE & 0 & Cost per Trip & 38.74 \\
\hline Other & 44,972 & Cost per Paratransit Trip & 38.74 \\
\hline \multirow{2}{*}{ Total Trips } & \multirow{2}{*}{84,465} & Cost per Driver Hour & 54.77 \\
\hline & & Cost per Total Mile & 2.84 \\
\hline
\end{tabular}

\section{Description of Technology, Costs, and Funding Sources}

Collier Area Transit (CAT) has been using reservation and scheduling software from RouteMatch since 2005. The software was last updated in May 2015. The cost of that system with training, technical support, and hosting fees is $\$ 27,472$, with a $2 \%$ increase annually.

CAT vehicles are equipped with an MDT. For the paratransit system, these units are efficient. Rather than picking up a printed manifest, operators log in to the MDT and their manifest is displayed on screen when the vehicle is not in motion. As the operators complete their manifest, their location is transmitted back to Dispatch, which creates more accurate performance information. Also, if a will-call trip is required or there is a cancellation, the manifest can be updated immediately to locate the closest vehicle or to re-schedule the manifest. 
The MDT units and other Intelligent Technology Systems (ITS) are provided by AVAIL and were installed in July 2012 on both the fixed-route ( 23 vehicles) and paratransit ( 21 vehicles) fleets for $\$ 1.6$ million. Funding was from the American Recovery and Reinvestment Act (ARRA) of 2009. A consulting firm was hired to develop a scope and feasibility study for the procurement of the complete ITS system. A Request for Proposals process was used to solicit qualified vendors to provide the desired system. A selection committee ranked AVAIL as the top qualified firm. Additional spare Vector-9000s were purchased from AVAIL in 2013. Driver ID is needed to log on to access the manifest for the day (Figure 4-1).
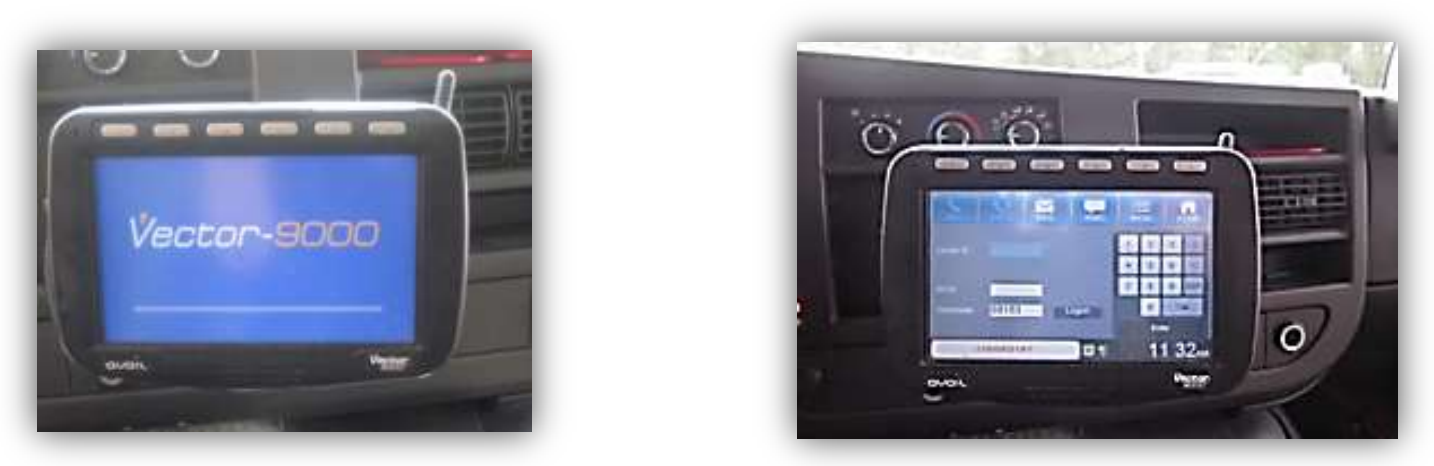

Figure 4-1: MDT (AVAIL Vector 9000) Mounted on Front of Dashboard on Collier Area Transit Vehicles

CAT initially deployed vehicle security cameras from AngelTrax in 2010. The cost for a four- or five-camera system was approximately $\$ 2,800-\$ 3,150$ per vehicle. To replace a single camera costs $\$ 278$ but the agency has never needed to replace the cameras. Currently, cameras are installed as new vehicles are purchased.

The cost of the advanced telephone system installed in 2013 from Avaya CMS was $\$ 10,065$ for design, licenses, setup, installation, and training. The design cost of $\$ 3,000$ was included in the overall cost for the telephone system.

\section{Agency-Specific Practices}

CAT contracts with the Keolis Transit America, Inc., to provide transit and paratransit services for the County. Planning and fleet maintenance are performed by County staff, and Keolis provides workforce operation, administration, dispatching, scheduling, and customer service.

CAT deployed an electronic vehicle inspection reporting system, Zonar, for the required preand post-trip vehicle inspection; including radio, wheelchair lifts, lights, tires, and vehicle body. This deployment accurately tracks records and schedules and timely reports any potential problems early on from daily inspections. The AVAIL dispatch module alerts dispatchers if the wheelchair lift or ramp is not deployed during the pre-trip inspection.

Also unique to CAT is that its cameras are outfitted with GPS; not only is the video timestamped, but it is also location-stamped. Figure 4-3 details the camera system inside each vehicle. The equipment installed on the vehicles takes up space and is generally placed in the compartment above the front window of the vehicle. Newer smaller vehicles may not have that same space available; therefore, other deployed technologies and installation location must be considered for future purchases of vehicles and technology. 

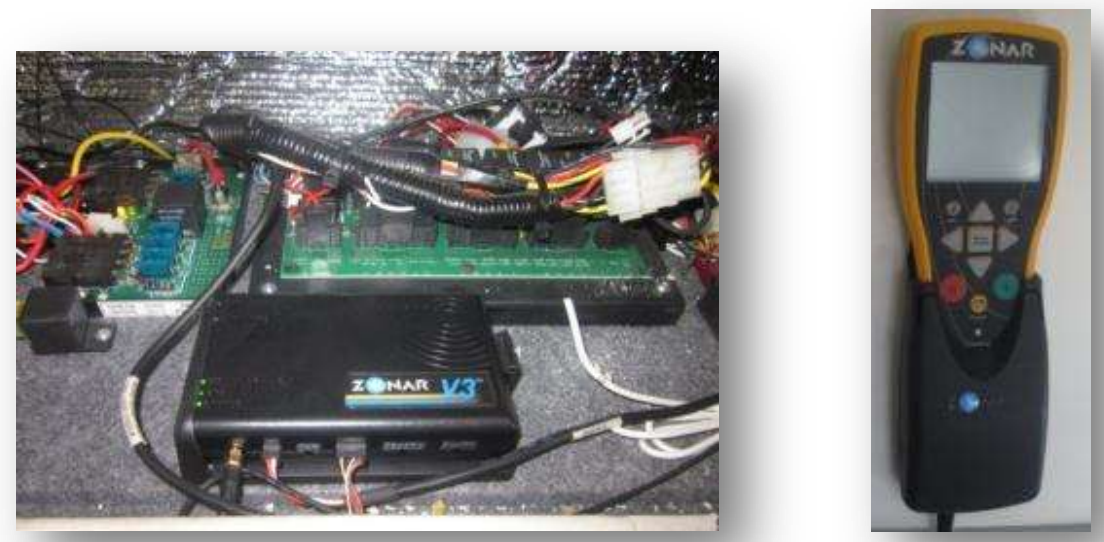

Figure 4-2: Electronic Vehicle Inspection System
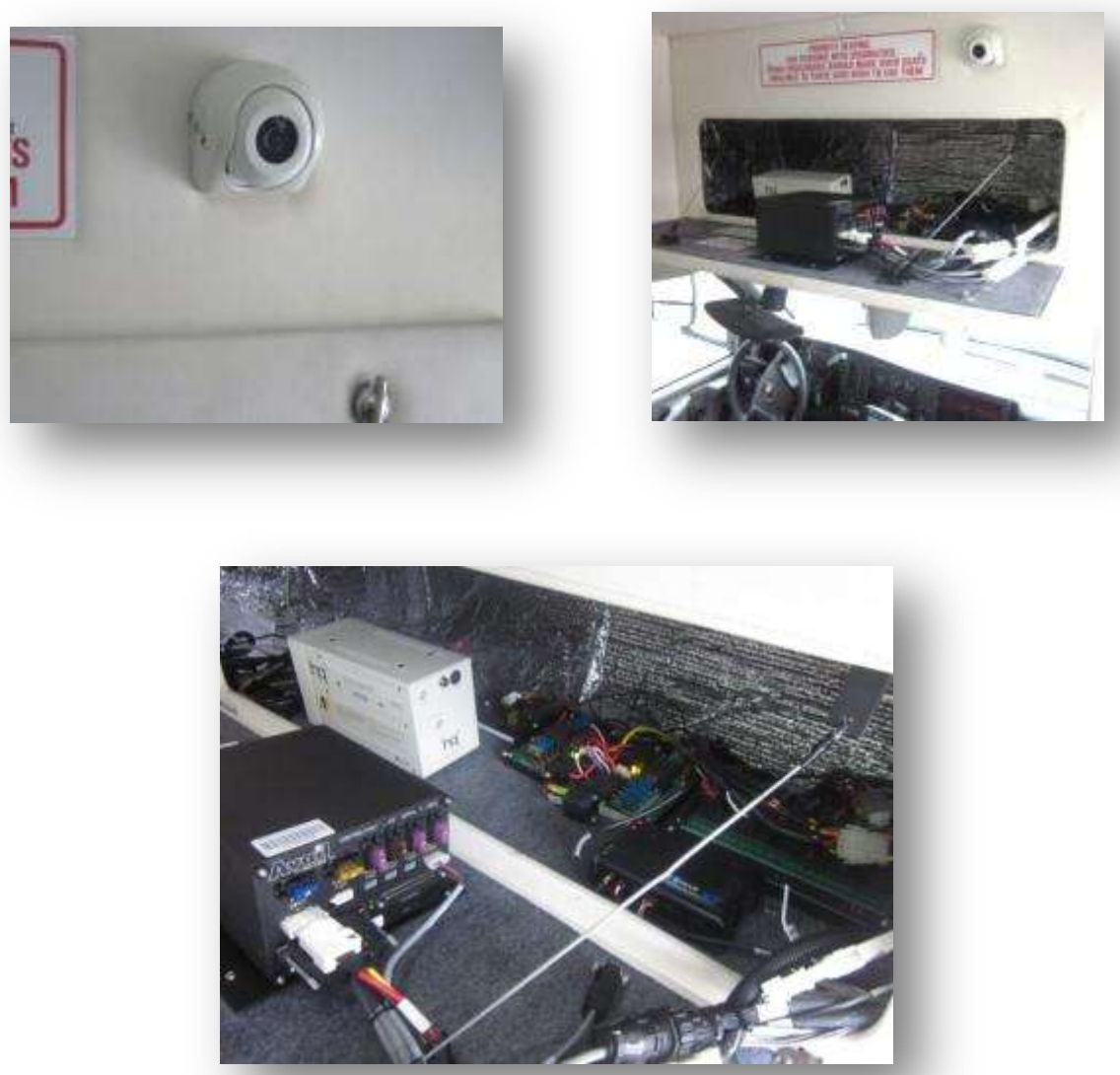

Figure 4-3: Vehicle Security Camera System on Collier Area Transit Fleet Vehicle

A newer AVAIL MDT has been received on a new vehicle purchased by CAT, and the placing of the equipment is pre-planned for the vehicles at the time of purchase, not retrofitted (see Figure 4-4). One drawback of the new MDT is that the wiring is incompatible with older versions of the AVAIL technologies. It is recommended that transit properties inquire about the 
compatibility of existing and future components to ensure extended life expectancy of its technology.

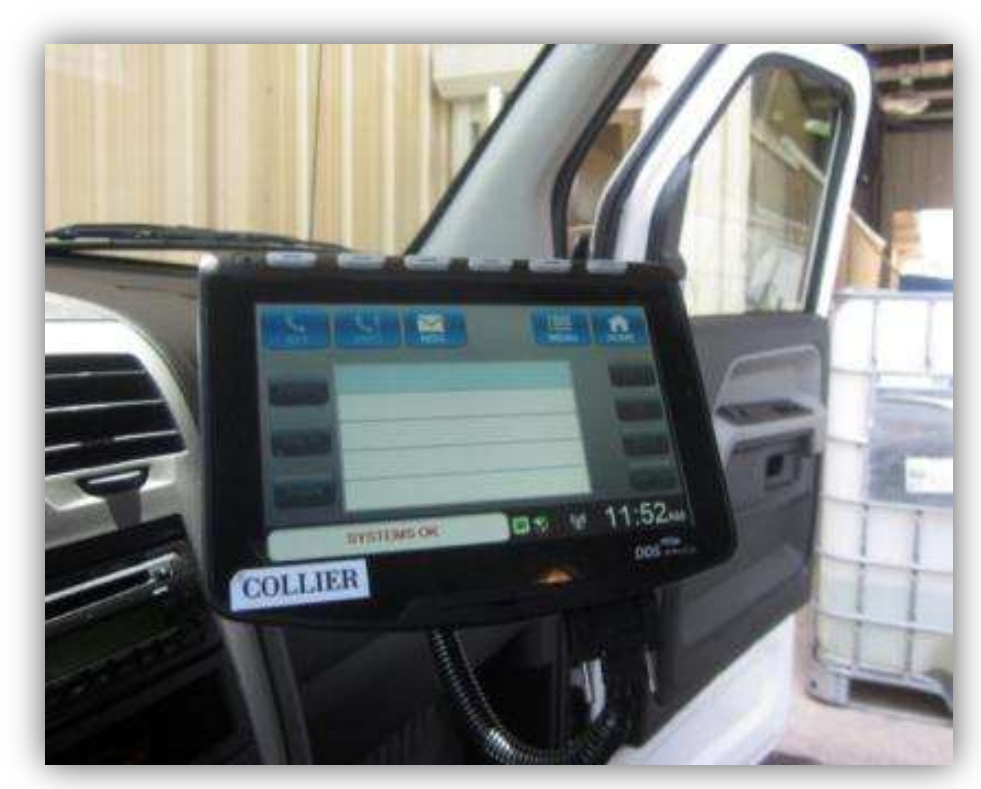

Figure 4-4: New M-Slate MDT from AVAIL on a Collier Area Transit Fleet Vehicle

\section{Technology Benefits as Experienced by the Agency}

RouteMatch is used to increase efficiency of the system by optimizing the route scheduling and accommodating more riders within the schedule by grouping the riders when applicable. The software made report generation more efficient. More efficient routes make for better scheduling, thereby reducing labor costs by improving driver productivity. The scheduling software includes reporting components that allow CAT staff to identify passengers who are repeated "no shows" to allow better implementation of the agency's policies.

Prior to the AVAIL's AVL, the on-time performance reporting was based on $5 \%$ manual sampling of the data from all completed trips and was based on vehicle's time of arrival at the rider's location. With the new technology and reporting capabilities, CAT's staff analyzed 50\% of the data and opted to have this performance indicator based on the requested drop-off time, rather than pick-up time. The agency has a zero-threshold goal with this performance indicator; one second after the requested time of drop-off is considered to be late. The agency performance for this indicator was reported as $70-80 \%$ in 2012 and was $94 \%$ through the month of April 2015.

The call center serves as the customer service center. A reporting tool allows CAT staff to determine if there are call volume issues better accommodated with extra staff dedicated to the call center. Customers receive a confirmation number to use as verification that they reserved or cancelled a trip to minimize a driver showing up unnecessarily or a customer saying they cancelled when they did not.

CAT staff noticed a large reduction in paper and printer ink demands when paper manifests were phased out, which was of significant value to CAT in an effort to become more ecofriendly. 
Vehicle security cameras help to protect the safety of the passengers and drivers and are used to verify when complaints or incidents occur. Corrective actions are taken, if needed, as a result of using the videos.

\section{Lessons Learned and Tips for Other Agencies}

- Training sessions were conducted with management supervisors first, and three sessions were conducted with drivers before and after installing the technology. A refresher training session also was conducted by AVAIL after the system was implemented after the transition was completed.

- Training for schedulers and reservationists ensures that the system is being used to its full capacity. Without training, schedulers might develop shortcuts that may negatively impact productivity and affect customer satisfaction.

- Staff selected key drivers who were eager to learn the new technology to pilot the new system in four vehicles for three months while working the "bugs" out of the new system.

- Transitioning to the AVAIL system and correctly interfacing with the RouteMatch system took approximately six months. The Request for Proposal (RFP) included a detailed description of agency needs from a vendor to interface with its current and future versions of RouteMatch. Although AVAIL and RouteMatch are working adequately for the agency, the agency believes it would have been more convenient to have had the same brand of technology for both the scheduling software and the MDTs. During the transition period, the paper manifest was printed and verified with the electronic manifest until accuracy was achieved. After that, drivers were gradually trained on using only the manifest on the MDT.

- There were some initial issues with the wiring of the AVAIL MDTs on the vehicles as well as errors on MDT modems that required the units to be returned to the vendor for repair and shipped back to CAT to reinstall. Three extra MDT units were included in the original contract with AVAIL. CAT purchased additional spare units in case MDTs needed to be returned to AVAIL for repair.

- The five-year warranty that was part of the initial package purchased from AVAIL was well-used by CAT staff in addressing issues that arose. A recommended practice for other agencies is to make sure the warranty provided by the vendor is comprehensive, e.g., replaces problematic devices or re-installs devices to correct problem wiring. 


\section{Liberty County Transit}

\section{System Information}

Table 4-4: 2014 Liberty County Transit Information as Reported to Florida CTD

\begin{tabular}{|c|c|c|c|}
\hline TOTAL COUNTY POPULATION & 8,349 & POTENTIAL TD POPULATION & 2,889 \\
\hline \multicolumn{2}{|c|}{ Trips by Type of Service } & \multicolumn{2}{|l|}{ Vehicle Data } \\
\hline Fixed Route (FR) & 0 & Vehicle Miles & 383,063 \\
\hline Deviated FR & 0 & Revenue Miles & 363,855 \\
\hline Ambulatory & 31,650 & Roadcalls & 1 \\
\hline Non-Ambulatory & 1,175 & Accidents & 0 \\
\hline Stretcher & 1 & Vehicles & 19 \\
\hline School Board & 0 & Driver Hours & 21,005 \\
\hline \multicolumn{2}{|c|}{ Passenger Trips by Trip Purpose } & \multicolumn{2}{|c|}{ Financial and General Data } \\
\hline Medical & 18,120 & Expenses & $\$ 435,113$ \\
\hline Employment & 184 & Revenues & $\$ 440,399$ \\
\hline Ed/Train/DayCare & 8,029 & Commendations & 4 \\
\hline Nutritional & 2,186 & Complaints & 1 \\
\hline Life-Sustaining/Other & 4,307 & Passenger No-Shows & 25 \\
\hline Total Trips & 32,826 & Unmet Trip Requests & 12 \\
\hline \multicolumn{2}{|c|}{ Passenger Trips by Funding Source } & \multicolumn{2}{|c|}{ Performance Measures } \\
\hline CTD & 11,030 & Accidents per 100,000 Miles & 0 \\
\hline AHCA & 6,157 & Miles between Roadcalls & 383,063 \\
\hline APD & 0 & Avg. Trips per Driver Hour & 1.56 \\
\hline DOEA & 1,184 & Avg. Trips per Para Pass. & 22.18 \\
\hline DOE & 0 & Cost per Trip & 13.26 \\
\hline Other & 14,455 & Cost per Paratransit Trip & 13.26 \\
\hline \multirow{2}{*}{ Total Trips } & \multirow{2}{*}{32,826} & Cost per Driver Hour & 20.71 \\
\hline & & Cost per Total Mile & 1.14 \\
\hline
\end{tabular}

\section{Description of Technology, Costs, and Funding Sources}

Liberty County Transit awarded CTS Software, Inc., the contract for providing reservation, scheduling, and dispatching software and MDT/AVL/GPS services in December 2013. The MDC used by CTS is the Samsung Galaxy Tab 2 purchased from Verizon Wireless. The software used on the MDC (ParaScope) was purchased through CTS Software.

The MDC package provided by CTS Software and Verizon Wireless included the hardware, software, installation, training, technical support, and warranty as well as updates/upgrades to the software application being used on the MDC developed by CTS Software. The total cost in February 2014 for a three-year contract to outfit the 19-vehicle fleet was around $\$ 70,000$ for all hardware (tablets, mounts, chargers, and protective cases), software, training, support, and warranty. CTS Software's latest release of the MDC (ParaScope) was on November 20, 2014. Funding was provided through a service development grant from FDOT. 


\section{Agency-Specific Practices}

Liberty County Transit serves rural residents of the county, and the agency is very familiar with its clients and their needs. There is only one clinic in the county with a registered nurse, so the majority of medical trips are made to other counties and cities.

The dispatcher can check the system remotely after office hours by cell phone if a vehicle is not in the yard by the expected time. Staff shared an instance in which the driver had taken a patient to a hospital in Gainesville where the patient was delayed and eventually retained overnight. The driver stayed with the patient, but since he was not in the vehicle he could not be reached. The dispatcher was able to see that the last "ping" from the tablet was from the parking lot at the hospital and verified that by calling the hospital staff since the driver's cell phone was not responding (dead battery).

The tablets are assigned to drivers. For the longevity of the device, the tablets are not left in the vehicle after hours or during the day when vehicles are not in use. Also, since the tablet is not permanently mounted, the driver can take it to be electronically signed by a rider, which eliminates the need for a rider with a disability to come to the front of the vehicle. Tablets are checked-out with an abbreviated paper manifest and a clipboard every morning (Figure 4-5).

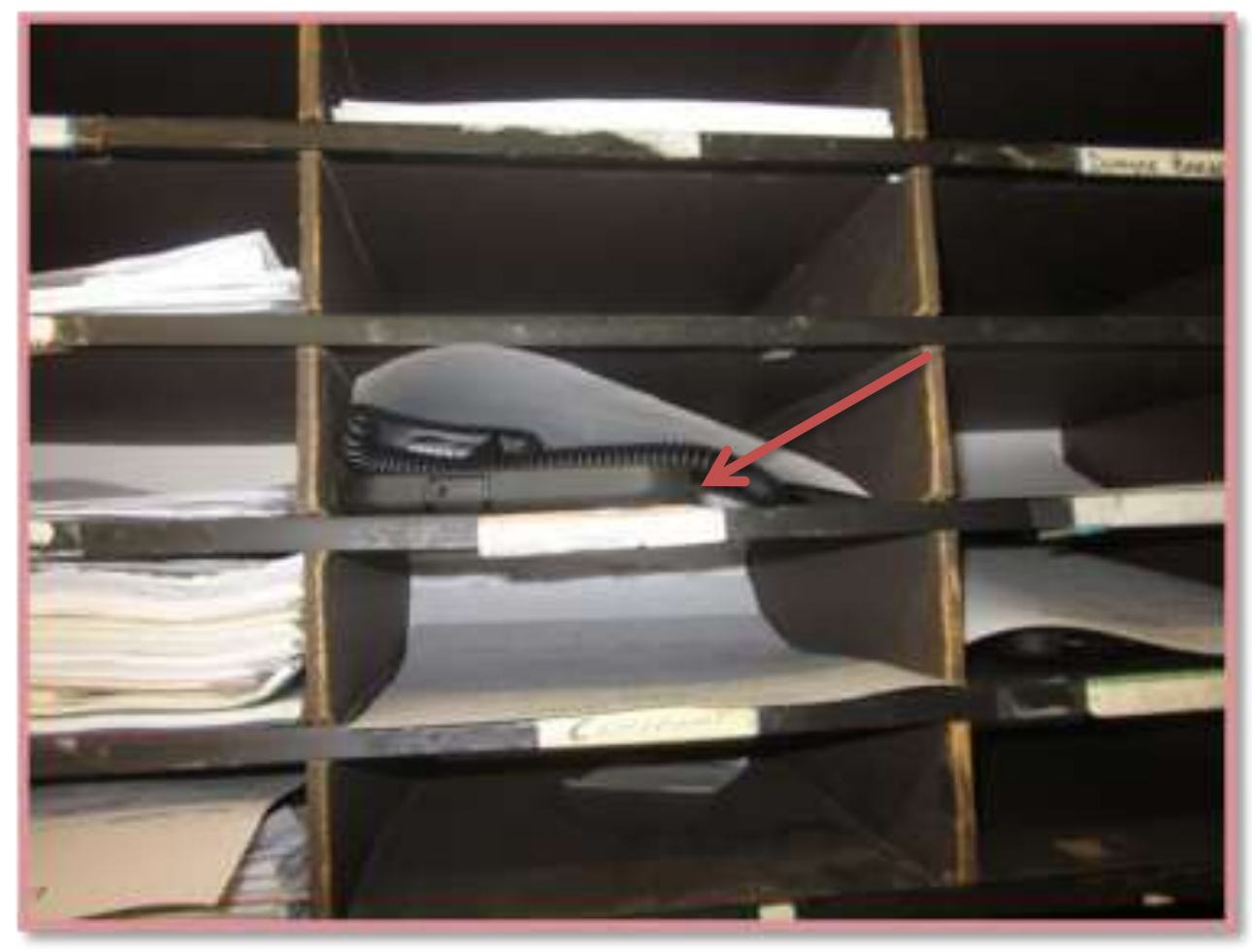

Figure 4-5: Tablets in Liberty County Transit Assigned to Drivers, Not Vehicles 


\section{Technology Benefits as Experienced by the Agency}

Liberty County Transit staff is able to respond to customer requests more quickly by having knowledge of where the drivers are, who is on the vehicle, and when drivers will arrive at their next pick-up/drop-off location.

Results from real-time communication with drivers without the use of radio communication has decreased the time drivers spend pulling over and communicating with the main office. This has impacted customer satisfaction positively because the drivers can focus more on customers and not the radio. A two-way radio is still being used but only as a back-up plan for digital communication.

The MDC plays a big part in driver performance because Liberty County Transit staff can see all vehicles visibly on a map that displays the speed, location, and capacity of each vehicle. Drivers are aware that their performance is being monitored. Also, with the CTS Software program, the history of an actual route can be viewed. This feature has been crucial in monitoring customer complaints and traffic violations. The screen on the right in Figure 4-6 shows the rural nature of the service area. It is not unusual for the Internet and cellular services to be dropped in certain areas, but the system picks up pings after the vehicle leaves these areas so there are continual real-time locations and speeds seen on the screen by the dispatcher.

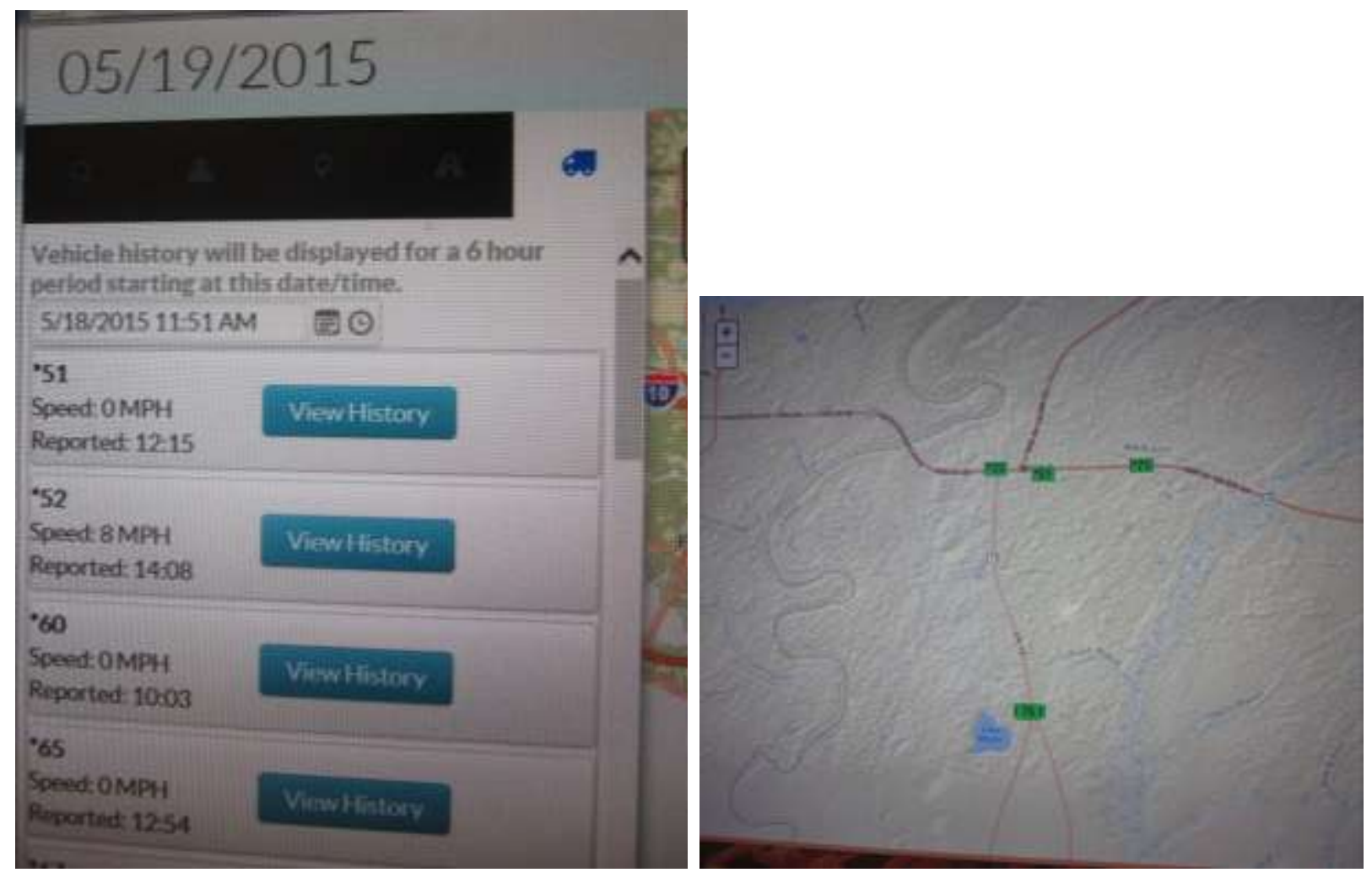

Figure 4-6: Scheduling and Dispatching Staff Can View Real-Time Locations and Speeds of Their Fleet Vehicles

On-time performance has improved mainly because the MDC documents the arrival time as well as the actual time a passenger boarded the vehicle. CTS Software has an on-time performance report that can be generated for any date range to evaluate performance. 
Drivers understand that their activities are tracked, including their location, the speed they are driving, and the status of passengers.

Customers enjoy being able to call in to the office to get an approximate time of arrival. Dispatchers appreciate the efficiency of providing information directly and immediately to drivers, particularly if rerouting is needed.

Liberty County Transit upgraded its software and MDCs just before the new funding source requirements went into effect, and staff reported that, for accounting and billing purposes, the new software offered much-needed help in coping with new requirements.

\section{Lessons Learned and Tips for Other Agencies}

- Training by the vendor before and after deployment is critical to the success of transitioning to the new system. CTS provided adequate training sessions to all agency staff.

- The availability of the vendor to communicate with the agency via phone and/or in person when needed is an important vendor asset to Liberty County Transit. It also helps that all but one neighboring county use the same technology, so collaboration and sharing of shortcuts and practical tips have been beneficial to all agencies involved. Also, the agencies appreciate the initiative that CTS takes to bring them together during national conferences to provide updates on newer features and services. For example, CTS informed these collaborating agencies of a session in the June 2015 Community Transportation Association of America's Annual Expo in Tampa.

- CTS made the software of the MDC very simple to use. At first, the drivers were hesitant about using sophisticated technology on the road, but they adapted to the software program (ParaScope) very well. 


\section{Levy County Transit}

\section{System Information}

Table 4-5: 2014 Levy County Transit Information as Reported to Florida CTD

\begin{tabular}{|c|c|c|c|}
\hline TOTAL COUNTY POPULATION & 39,644 & POTENTIAL TD POPULATION & 20,880 \\
\hline \multicolumn{2}{|l|}{ Trips by Type of Service } & \multicolumn{2}{|l|}{ Vehicle Data } \\
\hline Fixed Route (FR) & 0 & Vehicle Miles & 834,915 \\
\hline Deviated FR & 0 & Revenue Miles & 700,143 \\
\hline Ambulatory & 53,466 & Roadcalls & 15 \\
\hline Non-Ambulatory & 4,006 & Accidents & 2 \\
\hline Stretcher & 8 & Vehicles & 24 \\
\hline School Board & 0 & Driver Hours & 32,213 \\
\hline \multicolumn{2}{|c|}{ Passenger Trips by Trip Purpose } & \multicolumn{2}{|c|}{ Financial and General Data } \\
\hline Medical & 13,010 & Expenses & $\$ 1,634,238$ \\
\hline Employment & 2,809 & Revenues & $\$ 1,643,938$ \\
\hline Ed/Train/DayCare & 37,093 & Commendations & 21 \\
\hline Nutritional & 328 & Complaints & 2 \\
\hline Life-Sustaining/Other & 4,240 & Passenger No-Shows & 1,501 \\
\hline TOTAL TRIPS & 57,480 & Unmet Trip Requests & 56 \\
\hline \multicolumn{2}{|c|}{ Passenger Trips by Funding Source } & \multicolumn{2}{|c|}{ Performance Measures } \\
\hline CTD & 14,962 & Accidents per 100,000 Miles & 0.24 \\
\hline $\mathrm{AHCA}$ & 9,916 & Miles between Roadcalls & 55,661 \\
\hline APD & 10,275 & Avg. Trips per Driver Hour & 1.78 \\
\hline DOEA & 328 & Avg. Trips per Para Pass. & 47.82 \\
\hline DOE & 0 & Cost per Trip & 28.43 \\
\hline Other & 21,999 & Cost per Paratransit Trip & 28.43 \\
\hline \multirow{2}{*}{ Total Trips } & \multirow{2}{*}{57,480} & Cost per Driver Hour & 50.73 \\
\hline & & Cost per Total Mile & 1.96 \\
\hline
\end{tabular}

\section{Description of Technology, Costs, and Funding Sources}

Before deploying the new RouteMatch reservation, scheduling, and dispatching software with MDT/AVL/GPS all-in-one Samsung tablets, Levy County Transit used WillisWare reservation, scheduling, and dispatching software. MDTs were not available from WillisWare, which resulted in some limitations in creating required reports in a time-efficient manner.

RouteMatch 6.1 .12 was purchased in 2007 for $\$ 82,000$, including hardware, software, installation, training, technical support, and warranty. The package included AVL as well. The software was last updated in December 2014. The funding source was FTA through grants available under Sections 5309 and 5310. All procurement processes follow FDOT guidelines. 
The vehicle security camera system from Gatekeepers cost $\$ 58,000$ for 20 vehicles, with the package including hardware, software, training, technical support, and a five-year warranty. The system was installed in February 2015.

Levy County Transit uses a big-screen monitor for a quick overview of real-time fleet location (Figure 4-7).

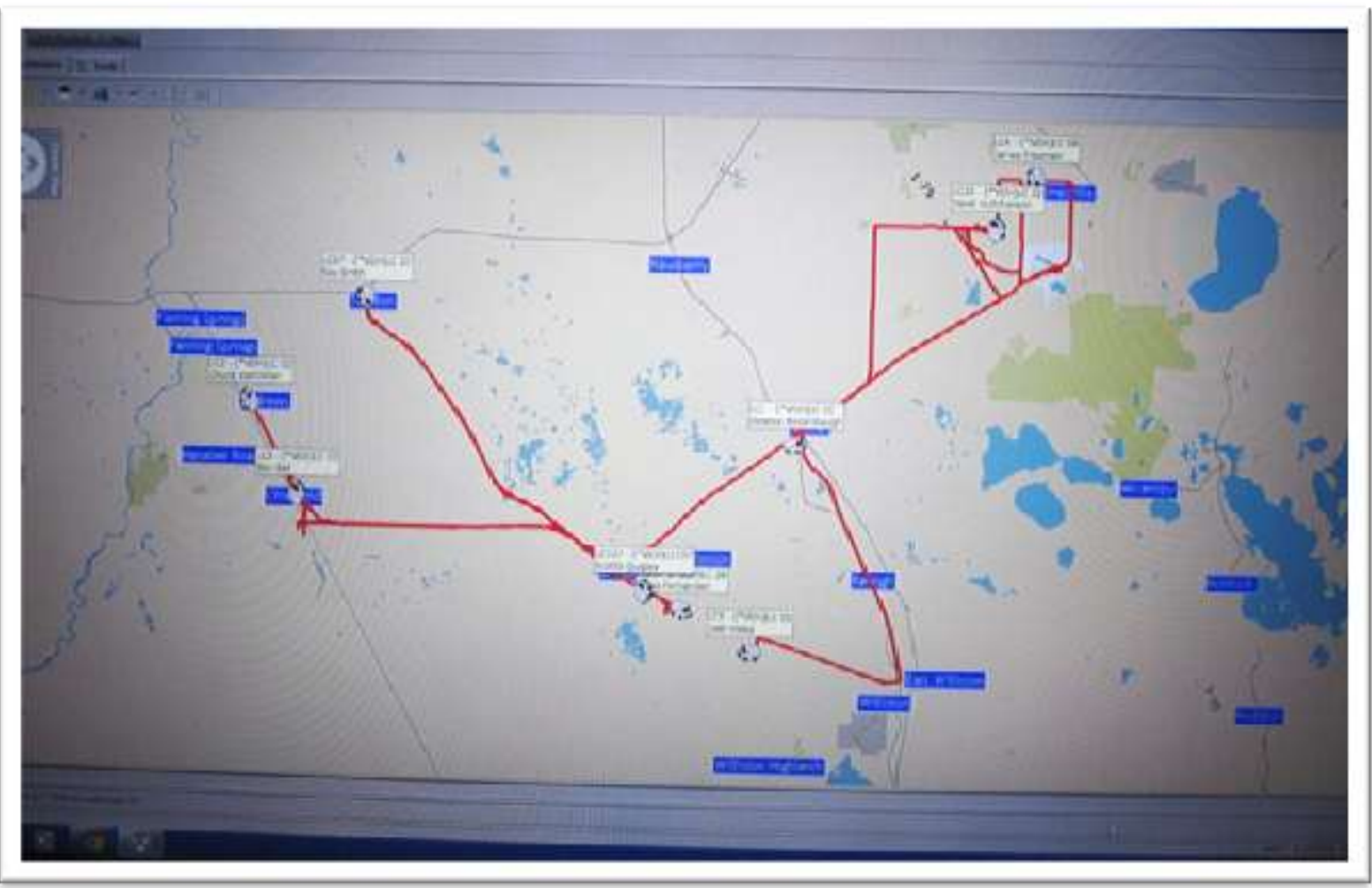

Figure 4-7: Big Screen Displaying Locations of Fleet Vehicles in Real-Time for Ata-Glance Tracking by Schedulers and Dispatchers in Same Office at Levy County Transit

\section{Agency-Specific Practices}

In addition to annual reports, the agency prepares separate reports on passengers who are minors, older adults, low-income, and individuals with disabilities. RouteMatch made these reports less labor-intensive than they were with the previous system.

Since the county is experiencing population growth, demand for paratransit services is growing. The agency is satisfied with the services provided by RouteMatch in meeting its growing needs. RouteMatch's contract with the agency has been in place since 2008 and is currently valid and renewable annually. Levy County Transit elected to use the cloud-hosting service provided by RouteMatch, which takes the risk out of the agency experiencing power outages or computers crashing.

Specific to this agency is that it operates six days a week. On three days per week, a bus leaves the yard at 3:30 am, and all other routes begin between 4:00 and 6:00 am.

Agency management and staff are a close community and interact like a family. The director of the agency has an open-door policy, the objective of which is to keep communications open and ongoing to make sure that the drivers focus on the job at hand and driving passengers 
safely on their runs. Investing the time to make sure drivers are not experiencing unresolved issues is well worth the time for the agency since it takes approximately two months to get a driver hired and trained.

Training and refresher training sessions are conducted throughout the year for all agency staff.

\section{Technology Benefits as Experienced by the Agency}

The reporting functionality of the RouteMatch system has been very effective in meeting the required reporting demands of the agency. Scheduling is more efficient, including adding same-day trips and moving trips to consolidate manifests as trips are cancelled by riders. MDTs help all drivers to become more efficient in locating riders and entering information needed for mileage, times, and breaks. By giving drivers timelines for pick-up, drop-off, and travel, they are able to determine the most efficient routes to travel. Locating new riders and helping new drivers locate riders has noticeably improved with the new technology and mapping/navigation systems.

Customers are given reservation numbers to verify trips, if needed, and can call to get an approximate arrival time of their ride.

Safety features programmed in the RouteMatch system guarantees that the tablet cannot be used while the vehicle is in motion.

\section{Lessons Learned and Tips for Other Agencies}

- Running the old and new reservation, scheduling, and dispatching software in parallel for at least a month will ensure that accurate and timely billing of trips is not missed. The agency director emphasized that it was well worth the investment to pay both vendors for a month to make sure there are no discrepancies between the two systems and that the transition is smooth with no problems before being fully dependent on the new system.

- The use of tablets instead of MDT units was a worthwhile investment for the agency, since an MDT unit costs $\$ 4,000$ and a tablet costs only $\$ 250$.

- The tablets are assigned to drivers. The manifest is available on the tablet, but a hard copy of the manifest is given to the drivers as a back-up in case of a system failure when on a run. Drivers accepted the use of tablets faster than MDTs because the screens are bigger and clearer to read than MDTs.

- Vehicle security cameras are for the protection of the agency and the operators, as well as the clients. Even if the operators may not like being watched, they will eventually understand that the recording is for their protection from any false claims. 


\section{Lake County Public Transportation}

System Information

Table 4-6: 2014 Lake County Public Transportation Information as Reported to Florida CTD

\begin{tabular}{|c|c|c|c|}
\hline TOTAL COUNTY POPULATION & 308,034 & POTENTIAL TD POPULATION & 128,755 \\
\hline \multicolumn{2}{|c|}{ Trips by Type of Service } & \multicolumn{2}{|l|}{ Vehicle Data } \\
\hline Fixed Route (FR) & 0 & Vehicle Miles & $1,907,581$ \\
\hline Deviated FR & 626 & Revenue Miles & $1,587,367$ \\
\hline Ambulatory & 127,548 & Roadcalls & 55 \\
\hline Non-Ambulatory & 37,968 & Accidents & 12 \\
\hline Stretcher & 139 & Vehicles & 94 \\
\hline School Board & 39,407 & Driver Hours & 131,769 \\
\hline \multicolumn{2}{|c|}{ Passenger Trips by Trip Purpose } & \multicolumn{2}{|c|}{ Financial and General Data } \\
\hline Medical & 62,312 & Expenses & $\$ 4,877,440$ \\
\hline Employment & 39,871 & Revenues & $\$ 5,338,015$ \\
\hline Ed/Train/DayCare & 59,047 & Commendations & 50 \\
\hline Nutritional & 22,117 & Complaints & 161 \\
\hline Life-Sustaining/Other & 22,341 & Passenger No-Shows & 5,651 \\
\hline Total Trips & 205,688 & Unmet Trip Requests & 4,659 \\
\hline \multicolumn{2}{|c|}{ Passenger Trips by Funding Source } & \multicolumn{2}{|c|}{ Performance Measures } \\
\hline CTD & 30,926 & Accidents per 100,000 Miles & 0.63 \\
\hline $\mathrm{AHCA}$ & 31,499 & Miles between Roadcalls & 34,683 \\
\hline APD & 53,244 & Avg. Trips per Driver Hour & 1.56 \\
\hline DOEA & 13,671 & Avg. Trips per Para Pass. & 77.82 \\
\hline DOE & 0 & Cost per Trip & 23.71 \\
\hline Other & 76,348 & Cost per Paratransit Trip & 23.71 \\
\hline \multirow{2}{*}{ Total Trips } & \multirow{2}{*}{205,688} & Cost per Driver Hour & 37.02 \\
\hline & & Cost per Total Mile & 2.56 \\
\hline
\end{tabular}

\section{Description of Technology, Costs, and Funding Sources}

Lake County Public Transportation uses RouteMatch reservation and scheduling software system, which was last updated in February 2015. The MDTs with AVL used on agency vehicles are Samsung tablets.

Seon security camera systems are provided as part of the agency's contract with RouteMatch, costing $\$ 233,908$. The security system was installed in 51 paratransit vehicles and 15 fixedroute vehicles in 2014. In 2014, Lake County Public Transportation used FTA 5307 and FDOT 5310 funds in the amount of $\$ 70,952.22$ for the MDTs with AVLs included and installed on 51 vehicles.

The reservation and scheduling software system from RouteMatch (version 6.1) was purchased in January 2010 for $\$ 136,386$. 
A Lake County capital grant provided funding for new buses with MDTs pre-installed in FY 2013/2014.

\section{Agency-Specific Practices}

On October 1, 2013, the Lake County Board of County Commissioners entered into an agreement with Ride Right Transit, LLC, to be the County's transit provider. Ride Right Transit, LLC, provides the paratransit service as the 'Lake County Connection' and subcontracts the fixed-route services to Maruti Transit Group, with the service operating as 'LakeXpress.'

\section{Technology Benefits Experienced by the Agency}

Vehicle security cameras have provided great value in assisting law enforcement and conflict resolution and helping to reduce fraudulent liability claims. Drivers and passengers know they are being videotaped while on the vehicle, and the security system captures some visual and audio outside the vehicle, reducing the number of disputed complaints.

The security system also makes drivers more conscientious about customer service, on time performance, and the safety of the passengers, the public, and the vehicle.

RouteMatch cloud-hosts the software, a good option because the Lake County ITS Department operates from 8:00 am to 5:00 pm on weekdays and transit services extend beyond those hours and days. Thus, RouteMatch provides $24 / 7$ technical services and eliminates the expense of a local server and potential server crashes.

\section{Lessons Learned and Tips for Other Agencies}

- The agency has 70 tablets and contracts with Sprint for data for the tablets. In some areas of the county, Sprint coverage is not as reliable as desired and calls may be dropped; therefore, a paper manifest is used as back-up.

- Because the County contracts with three Medicaid transportation brokers, they requires passengers to sign a hard copy of the manifest; the County is working with those brokers to allow acceptance of an electronic signature. Scheduling for Medicaid passengers requires staff to sign into the Medicaid portal every day to retrieve trips; the County has contracted with RouteMatch to facilitate the County's software system to interface with the brokers systems to allow for the County to download the trips into Route Match electronically. 


\section{Senior Resource Association, Indian River County}

System Information

Table 4-7: 2014 Senior Resource Association, Indian River County, Information as Reported to Florida CTD

\begin{tabular}{|c|c|c|c|}
\hline TOTAL COUNTY POPULATION & 141,994 & POTENTIAL TD POPULATION & 65,699 \\
\hline \multicolumn{2}{|l|}{ Trips by Type of Service } & \multicolumn{2}{|l|}{ Vehicle Data } \\
\hline Fixed Route (FR) & 0 & Vehicle Miles & 358,038 \\
\hline Deviated FR & 0 & Revenue Miles & 300,348 \\
\hline Ambulatory & 25,796 & Roadcalls & 8 \\
\hline Non-Ambulatory & 5,220 & Accidents & 0 \\
\hline Stretcher & 0 & Vehicles & 51 \\
\hline School Board & 0 & Driver Hours & 22,133 \\
\hline \multicolumn{2}{|c|}{ Passenger Trips by Trip Purpose } & \multicolumn{2}{|c|}{ Financial and General Data } \\
\hline Medical & 21,176 & Expenses & $\$ 1,284,337$ \\
\hline Employment & 186 & Revenues & $\$ 1,074,268$ \\
\hline Ed/Train/DayCare & 7,412 & Commendations & 1 \\
\hline Nutritional & 909 & Complaints & 20 \\
\hline Life-Sustaining/Other & 1,333 & Passenger No-Shows & 978 \\
\hline Total Trips & 31,016 & Unmet Trip Requests & 0 \\
\hline \multicolumn{2}{|c|}{ Passenger Trips by Funding Source } & \multicolumn{2}{|c|}{ Performance Measures } \\
\hline CTD & 16,499 & Accidents per 100,000 Miles & 0.00 \\
\hline AHCA & 6,054 & Miles between Roadcalls & 44,755 \\
\hline APD & 0 & Avg. Trips per Driver Hour & 1.40 \\
\hline DOEA & 62 & Avg. Trips per Para Pass. & 22.56 \\
\hline DOE & 0 & Cost per Trip & 41.41 \\
\hline Other & 8,401 & Cost per Paratransit Trip & 41.41 \\
\hline \multirow{2}{*}{ TOTAL TRIPS } & \multirow{2}{*}{31,016} & Cost per Driver Hour & 58.03 \\
\hline & & Cost per Total Mile & 3.59 \\
\hline
\end{tabular}

\section{Description of Technology, Costs, and Funding Sources}

Previously, Senior Resource Association used an outdated access database version of CTS as its reservation, scheduling, and dispatching software and Mentor Ranger MDT units. The agency deployed RouteMatch in 2010, with software and hardware updated in 2014. The entire package, including hardware, software, installation, training, technical support, and a one-year warranty, cost $\$ 100,000+$ with funding from FTA 5307 funds. Procurement was based on Indian River County's "Transportation Procurement Policy." 
A Seon GPS system was installed in 2013 for $\$ 75,000$, and the hardware and software were updated in 2015.

A Seon vehicle security camera system was purchased in 2013 for $\$ 150,000$ for all 24 fleet vehicles. The hardware and software were updated in 2015.

An advanced telephone system with automated service, call forwarding, voice-mail, and call hold, including hardware, software, installation, training, technical support, and a three-year warranty, was purchased from NEC in 2015 for $\$ 10,000$.

\section{Agency-Specific Practices}

Hosted on the agency's server, RouteMatch was deployed in phases; first for paratransit services and then for fixed-route transit services. The agency transitioned from providing service similar to personal taxi service to the multi-loading of passengers to serve more passengers more efficiently and increase driver productivity.

Senior Resource Association's upper management reorganized to achieve total buy-in from employees New job descriptions were drafted and employees had to re-apply for positions. According to the President and CEO of the Association, this was the best management decision to make efficient transit happen.

Tablets are assigned to vehicles rather than drivers, so logging in and out is important for accurate reporting. If a driver overrides the planned trip on the manifest, then the entire data set is inaccurate and office staff must reconcile the manifests. Agency staff organizes a monthly drawing of a $\$ 25$ gift certificate to motivate drivers to follow log-in and log-out procedures accurately.

\section{Technology Benefits as Experienced by the Agency}

The advanced telephone system has been effective in reducing wait time for customers and getting them to a "live" person in a timely manner, which the customers appreciate. The telephone system is used for reporting the number of calls, planning personnel support when high volume occurs, and filtering calls.

The paratransit system has grown substantially with the population growth of the county, but the new RouteMatch system is handling the increase in demand. The labor cost has not decreased because the agency had to employ a scheduler and dispatcher to accommodate the influx of more passengers into the system.

Customers are pleased that shopping trips are now offered more than twice a week, made possible by the increased efficiency of the schedules and increased productivity of the drivers. In addition, customers appreciate that the dispatcher now provides reliable pick-up times.

\section{Lessons Learned and Tips for Other Agencies}

- Before starting the process of developing a package for the agency, the current procedures of how the agency and staff function should be described to the vendor. For example, the agency should note how different departments interact and which fields they pull from to create requested reports.

- Vendors should be asked about plans for phasing out the current technology. The agency was using Mentor Ranger MDTs and was the last agency to purchase those units before the vendor discontinued selling and providing support for them. 
- Drivers must be trained to trust the new GPS-generated route and follow the electronic manifest. If they override the planned manifest, completed trips will be unverified and inaccurate.

- Dispatchers can now negotiate trip times with passengers.

- Senior Resource Association has offered to serve as a partner with other agencies considering the deployment of technology, not only before but during transition. 


\section{Council on Aging of St. Lucie, Inc.}

System Information

Table 4-8: 2014 Council on Aging of St. Lucie, Inc., Information as Reported to Florida CTD

\begin{tabular}{|c|c|c|c|}
\hline TOTAL COUNTY POPULATION & 286,832 & POTENTIAL TD POPULATION & 119,970 \\
\hline \multicolumn{2}{|c|}{ Trips by Type of Service } & \multicolumn{2}{|l|}{ Vehicle Data } \\
\hline Fixed Route (FR) & 29,314 & Vehicle Miles & $1,348,015$ \\
\hline Deviated FR & 0 & Revenue Miles & $1,013,177$ \\
\hline Ambulatory & 124,967 & Roadcalls & 48 \\
\hline Non-Ambulatory & 123,565 & Accidents & 5 \\
\hline Stretcher & 0 & Vehicles & 95 \\
\hline School Board & 0 & Driver Hours & 107,438 \\
\hline \multicolumn{2}{|c|}{ Passenger Trips by Trip Purpose } & \multicolumn{2}{|c|}{ Financial and General Data } \\
\hline Medical & 56,983 & Expenses & $\$ 3,767,646$ \\
\hline Employment & 51,960 & Revenues & $\$ 3,568,295$ \\
\hline Ed/Train/DayCare & 64,924 & Commendations & 7 \\
\hline Nutritional & 12,105 & Complaints & 11 \\
\hline Life-Sustaining/Other & 91,874 & Passenger No-Shows & 1,811 \\
\hline Total Trips & 277,846 & Unmet Trip Requests & 40,851 \\
\hline \multicolumn{2}{|c|}{ Passenger Trips by Funding Source } & \multicolumn{2}{|c|}{ Performance Measures } \\
\hline CTD & 30,289 & Accidents per 100,000 Miles & 0.37 \\
\hline AHCA & 0 & Miles between Roadcalls & 28,084 \\
\hline APD & 64,045 & Avg. Trips per Driver Hour & 2.31 \\
\hline DOEA & 4,090 & Avg. Trips per Para Pass. & 0.00 \\
\hline DOE & 0 & Cost per Trip & 13.56 \\
\hline Other & 179,422 & Cost per Paratransit Trip & 14.94 \\
\hline \multirow{2}{*}{ Total Trips } & \multirow{2}{*}{277,846} & Cost per Driver Hour & 34.56 \\
\hline & & Cost per Total Mile & 2.75 \\
\hline
\end{tabular}

\section{Description of Technology, Costs, and Funding Sources}

In 2002, the Council on Aging of St. Lucie County installed AVL systems made by Radio Satellite Integrators, Inc., called V-Track. The system cost $\$ 169,040$ for 39 vehicles (paratransit and fixed-route). The hardware was updated in 2012, but the software has not been updated.

Veterans Transportation and Community Living Initiative (VTCLI) grant funding was used to develop a call center. 


\section{Agency-Specific Practices}

Transitioning to RouteMatch began in February 2015, and in May 2015, fixed-route vehicles were being linked to work with RouteMatch for real-time monitoring (see Figure 4-8). The agency's "Treasure Coast Connector" (fixed-route) serves St. Lucie County and "Community Transit" (demand-response) serves Fort Pierce.
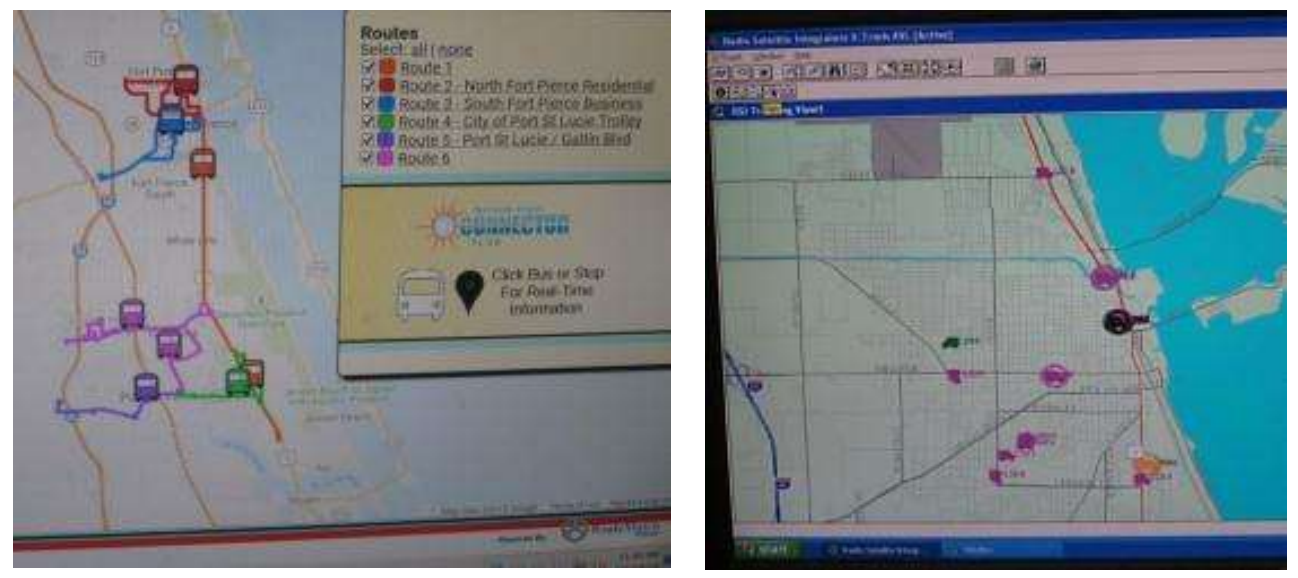

Figure 4-8: Fixed-Route and Demand Response Vehicle Locations and Speeds Monitored by Dispatcher

Drivers reported preferring the tablets to the old Mentor Ranger MDT units because the screen is bigger and is easier to read in daylight (see Figure 4-9).

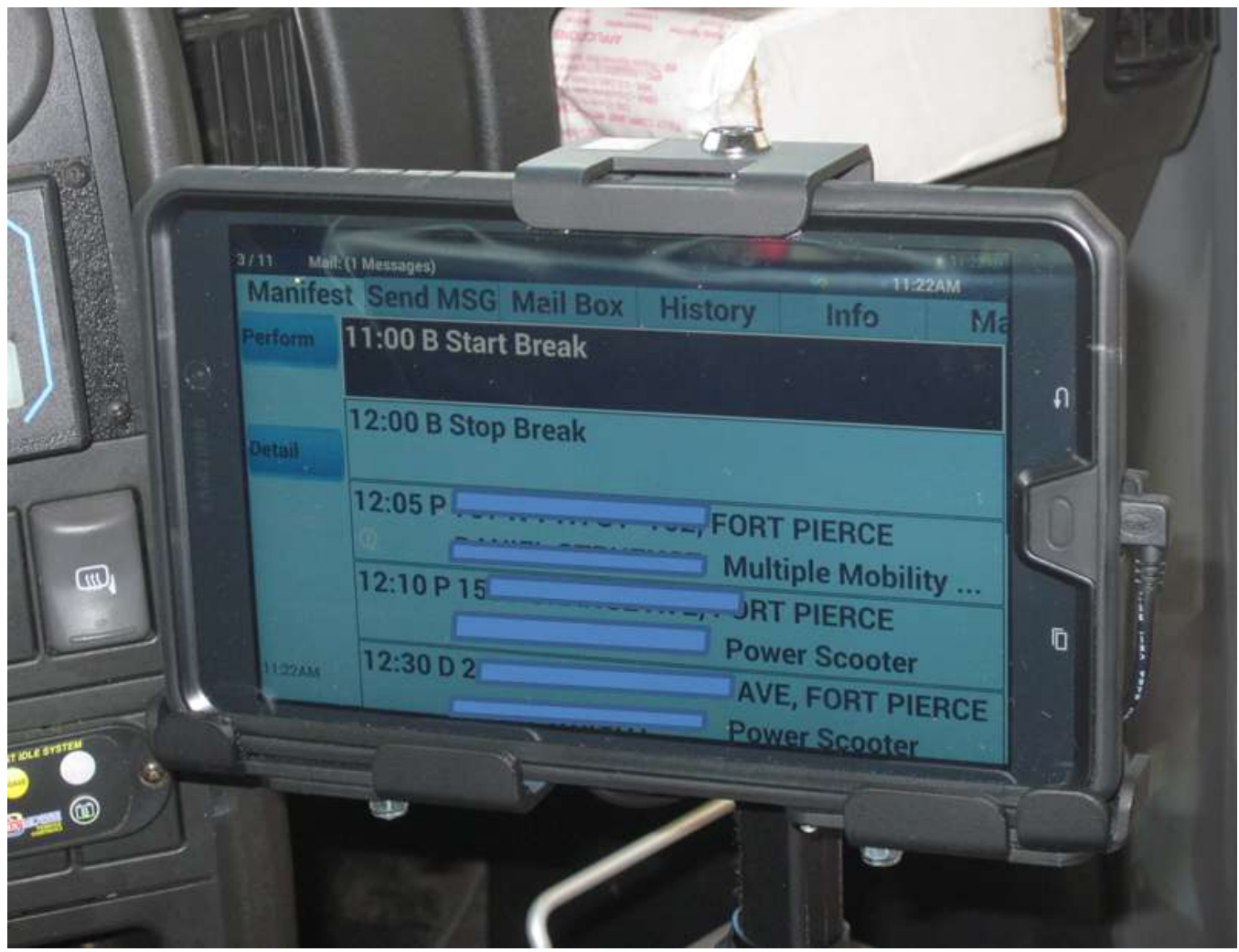

Figure 4-9: Electronic Manifest Displayed on Tablet on Council on Aging of St. Lucie Fleet Vehicle 
The Council on Aging of St. Lucie still has Mentor Ranger MDTs mounted on the dashboards of fleet vehicles, and the new tablets are mounted on stands that are permanently secured to the floor of the vehicle (see Figure 4-10) (it was determined that the dashboard was not sturdy enough to accommodate more weight). The old Ranger units will be removed from the fleet soon. The tablets are interchangeable between vehicles and are not specifically assigned to a driver.
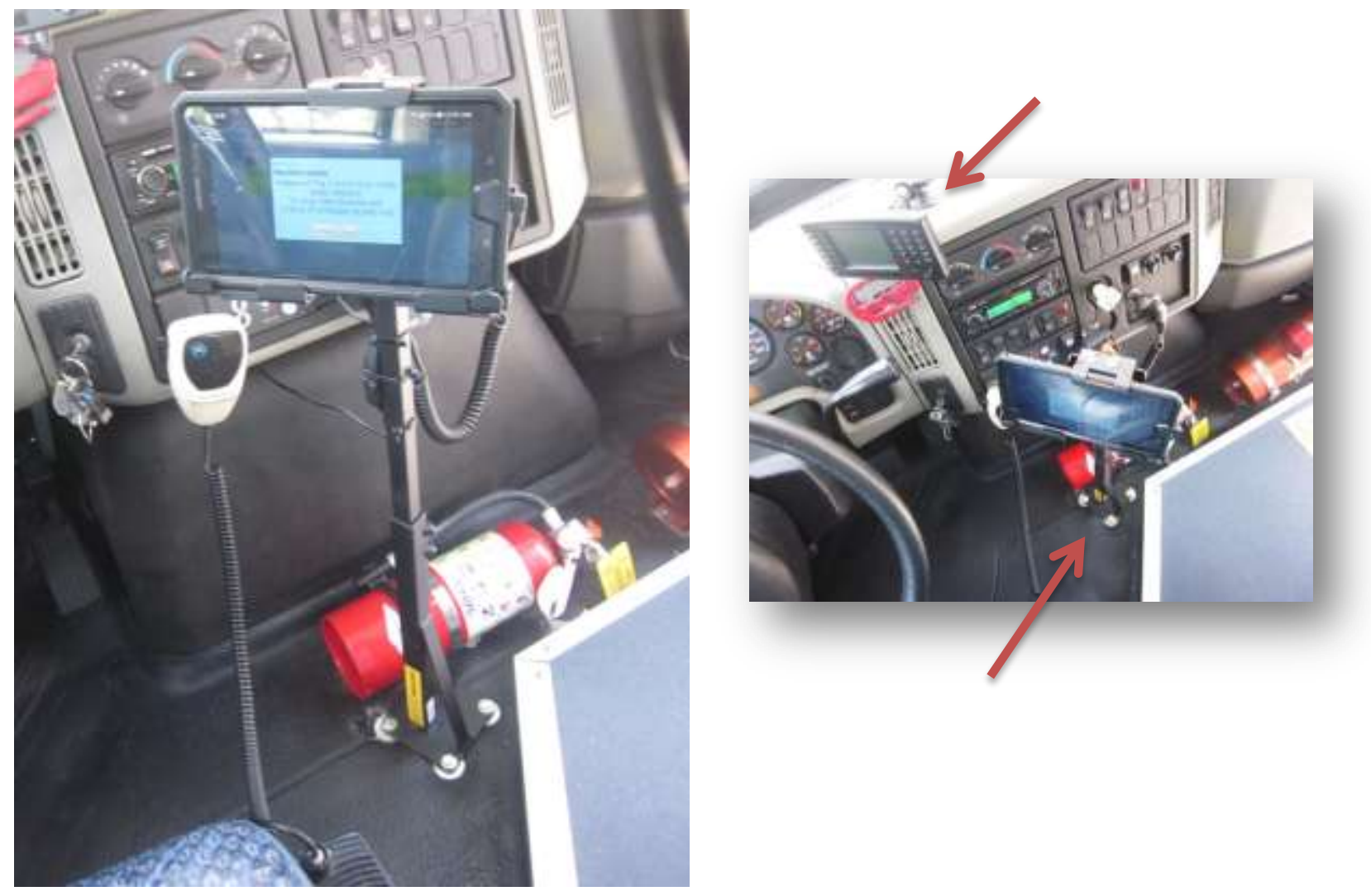

Figure 4-10: New MDT Tablet Mounted on Stand Secured to Floor of Vehicle and Old MDT Ranger Unit Mounted on the Dashboard

The agency does not own a yard/garage; therefore, the vehicles are stored overnight in a parking lot. The need to monitor vehicle locations around the clock is vital to the agency, as previous incidents of vandalism made it necessary to monitor them at night and install security cameras around the parking lot. Tablets do not provide 24/7 monitoring, as the GPS units are turned off when drivers log off at the end of the day. Separate AVL units are installed on vehicles and transmit locations every minute (Figure 4-11). 

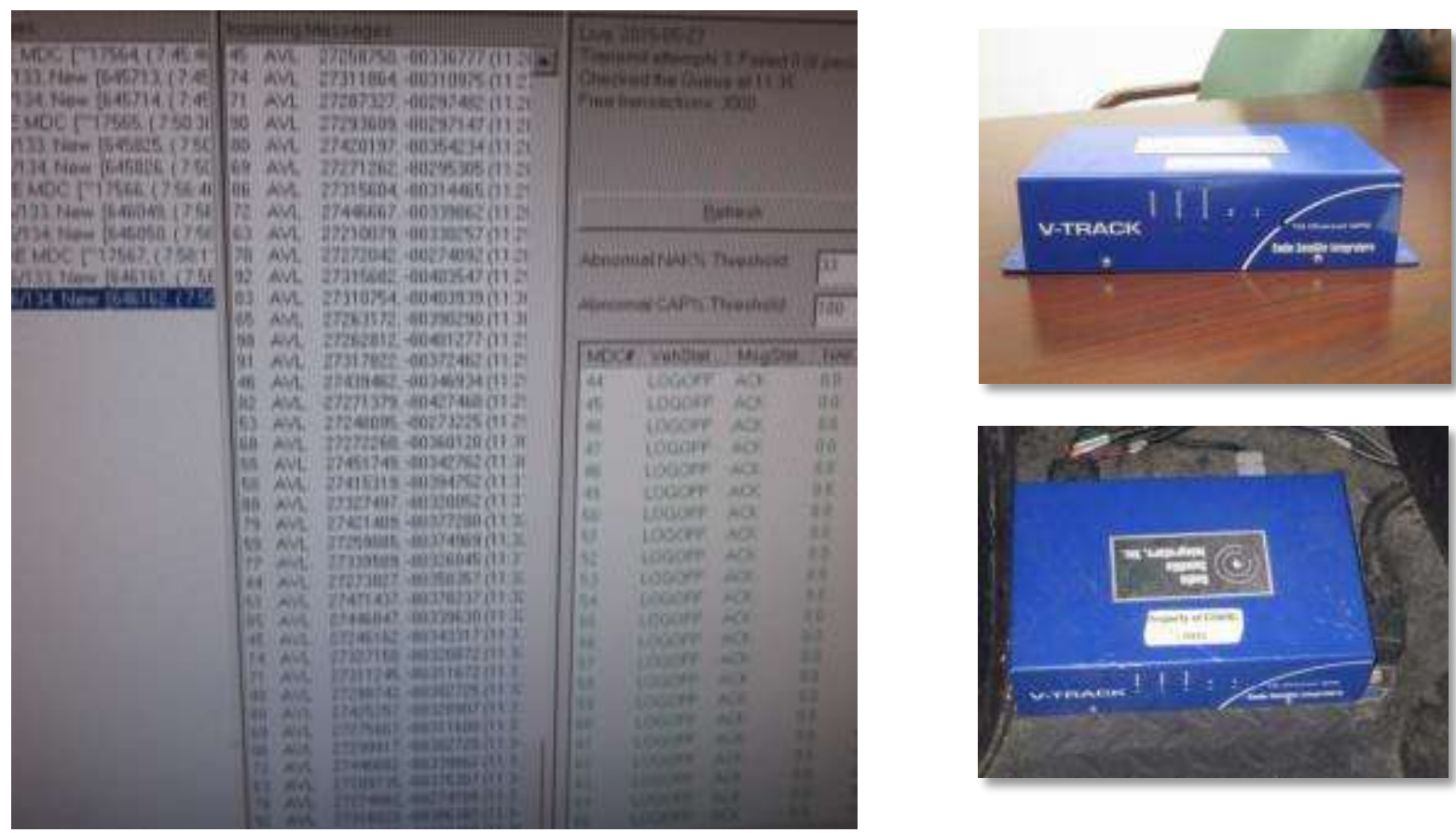

Figure 4-11: V-TRACK AVL System Unit and Screen Output Displaying Location of Vehicles in System

The AVL can track driver routes, which allows the dispatcher to inform riders of the location of the vehicle and provide a more accurate estimated time of arrival. The agency opted to have RouteMatch hosted in-house on its SQL server (Figure 4-12). A dedicated IT analyst monitors the system continuously.

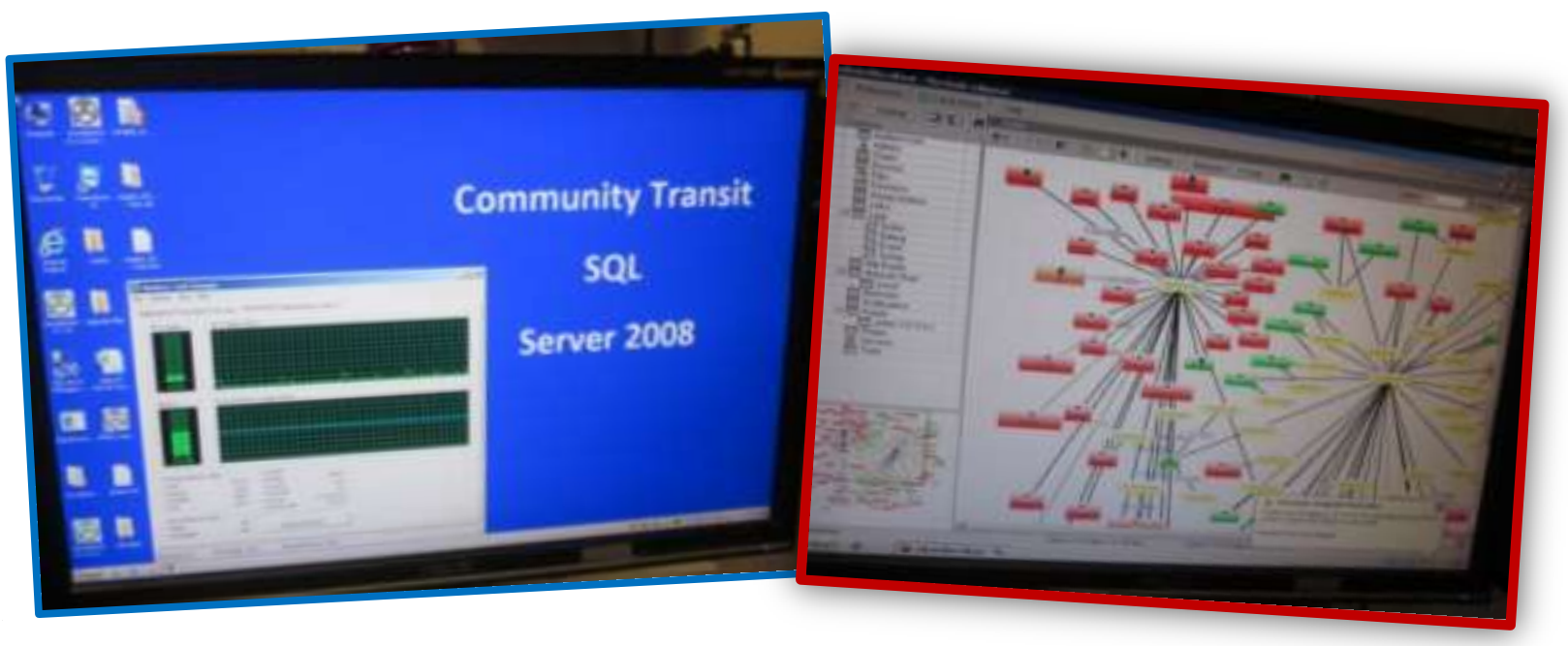

Figure 4-12: Council on Aging of St. Lucie, Inc., Hosts RouteMatch and V-TRACK AVL on its SQL Server 


\section{Technology Benefits as Experienced by the Agency}

The notification module from RouteMatch allows the agency to schedule an electronic call one day before a trip is scheduled to remind a passenger of an upcoming trip. Another reminder call is scheduled 60 minutes before the arrival time in real-time to help passengers get ready for pick-up.

Vehicle security camera systems are considered important assets for this agency. The inside cameras monitor incidents and behaviors inside the vehicle (see Figure 4-13), and the outside camera videotapes at all times in case of accidents (see Figure 4-14). Law enforcement occasionally requires the agency to provide video recordings in case of conflicting stories about incidents.
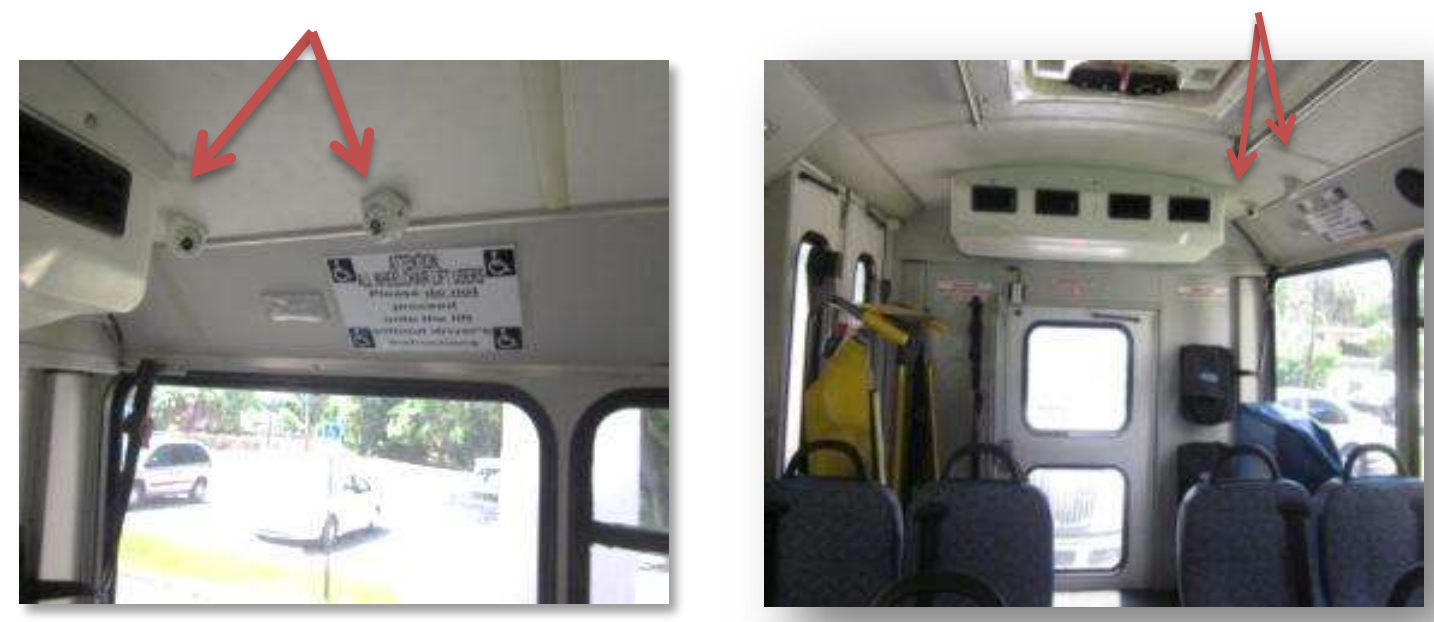

Figure 4-13: Vehicle Security Cameras Mounted Facing Wheelchair Lift

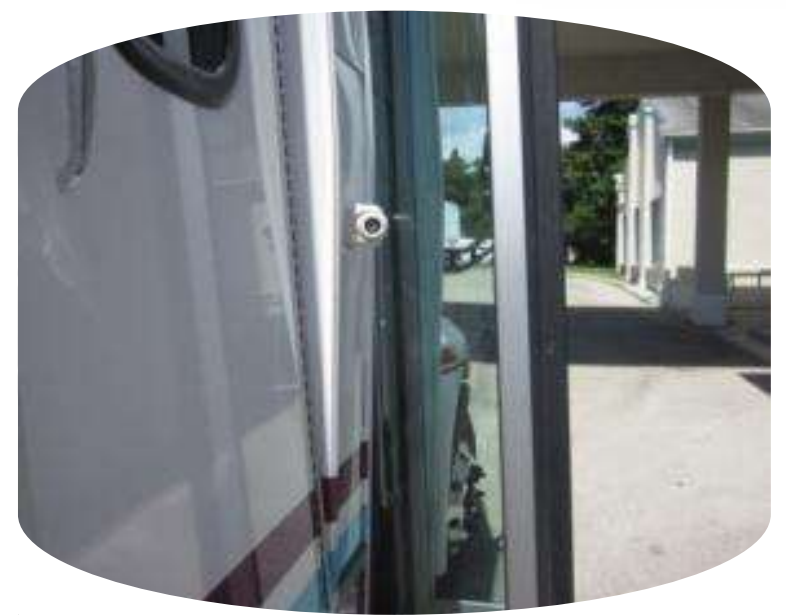

Figure 4-14: Security Camera Mounted on Outside of Transit Vehicle at Council on Aging of St. Lucie, Inc. 


\section{Lessons Learned and Tips for Other Agencies}

- The cameras caused drivers to feel they were being watched, but they became more accepting when considering that the system protects them against incorrect claims by passengers. After a time, the drivers seemed to have forgotten that the cameras were taping their activities. "The customer is always right" was the agency's initial philosophy, but that has evolved as the videos help mitigate conflicting eyewitness accounts.

- Training is very important for all agency staff but particularly for schedulers to optimize routes and the number of passengers transported on the same ride, thus improving performance of the system and driver productivity. RouteMatch makes available online training sessions as part of the package offered to the agency.

- There is less chatter on the two-way radios, and drivers depend more on GPS navigation than asking each other about directions to locate a rider. The dispatcher and driver still communicate through two-way communications in case an alert needs to go out, but they are not as dependent upon it as before the deployment of RouteMatch.

- Prior to RouteMatch and Samsung tablet use, the agency was using Trapeze. Staff were very careful about saying that Trapeze may work for other systems but did not work for their specific needs. Initially, the setup did not accommodate the agency's data needs. Despite many efforts to fix the initial setup, the agency was doing more manual reporting since the software was not extracting data needed to complete the reports. The agency let the two systems (Trapeze and RouteMatch) run side by side for two days before terminating the old system. 


\section{Chapter 5 - Conclusions and Recommendations}

As described in this chapter, many practical lessons are documented based on the interviews conducted with staff of the seven selected Florida agencies. The fact that most of the technologies discussed in this report were recently deployed affected the investigation of one of the study research questions, "What was the return on investment (ROI)?" As previously stated, some agencies deployed the technologies in late 2014 or early 2015 when the survey was sent out. As a result, it was too early for most agencies surveyed and those interviewed to assess the ROI for the acquired technologies. Their assessment of the effectiveness of the technologies in increasing productivity and performance prior to the survey indicates that positive impacts were evident to the staff even in a short time.

It would be beneficial to follow up with the agencies in 1-2 years to see if the ROI can be assessed. It is recommended that a module for this assessment be developed by the Florida CTD to help the agencies follow the same protocol for assessment.

\section{Survey Findings}

Table 5-1 presents the findings of the survey in which participants were asked how each technology impacted the performance of their system. The participants were given the opportunity to justify why they picked significant, moderate, none, or unknown impacts.

To keep some of the statistics of Table 5-1 in perspective, two items of interest need to be kept in mind. First, several of these technologies were implemented in late 2014 or early 2015, and the CTCs remarked that it was too early to assess any impacts. For example, the majority of the respondents ( $83 \%$ ) updated their reservation, scheduling, and dispatching software in late 2014 or early 2015.

Second, several agencies have recently deployed the Samsung Tablet as their MDT/AVL/GPS all-in-one unit; therefore, separating the impacts of one unit that functions as three is not easily expressed. Six of the seven agencies interviewed during site visits use the Samsung Tablet as their MDT unit.

Notable from Table 5-1 are the following:

- The on-time performance measure was most impacted by deploying MDTs (64\%), followed by reservation, scheduling, and dispatching software (63\%). These two technologies work in sync to track important times such as pick-up, leaving the stop after the customer boards, and drop-off at destination. Knowledge of these times is beneficial in generating reports and pinpointing staff improvement or training needs.

- Deploying MDTs scored the highest in moderate to significant improvements on driver performance, with $83 \%$ of the agencies recognizing that improvement. The improved driver performance was tied to the use of tablets, which are easier to read than previous MDTs that had smaller screens. Also, an electronic manifest replacing a paper manifest was an added time-saver for drivers.

- The second most-cited improvement in driver performance was deploying vehicle security cameras (69\%). Some agencies expressed that the drivers initially were uncomfortable with being video- and audio-recorded but soon realized that cameras protected them in case of an incident or false complaint. Drivers generally forgot they were being recorded all the time.

- The most cited technologies affecting customer satisfaction were MDTs (60\%) and vehicle security cameras (59\%). MDTs made the system more efficient, as electronic 
manifests made it possible for dispatchers to communicate changes with drivers, which made return trips more efficient. In addition to feeling more secure with cameras on board, customers experienced faster complaint resolution since the recordings show the agency exactly what happened.

\section{Table 5-1: Impacts of Deploying Different Technologies on Selected Performance Measures}

\section{Performance Measures of Selected Technologies}

\begin{tabular}{llll}
\multicolumn{4}{c}{ Impacts } \\
Significant & Moderate & No Impacts & Unknown \\
Impacts (\%) & Impacts (\%) & $(\%)$ & $(\%)$
\end{tabular}

\section{Reservation, Scheduling, and Dispatching Software}

Customer satisfaction

Reduction of "no shows"

Driver performance

22

\begin{tabular}{|c|}
\hline 3 \\
\hline \\
\hline
\end{tabular}

On-time performance

8

30

37

Agency's labor costs

14

33
19
33
29

\begin{tabular}{|l|l|}
\hline 15 & 30 \\
\hline & 31 \\
\hline 15 & 22 \\
\hline & 22 \\
\hline 25 & 32 \\
\hline
\end{tabular}

\section{Mobile Data Terminals}

Customer satisfaction

16

44

12

28

Reduction of "no shows"

Driver performance

12

On-time performance

29

Driver satisfaction

28

54

28

Global Positioning System

\begin{tabular}{|c|c|c|c|c|}
\hline Customer satisfaction & 11 & 16 & 26 & 47 \\
\hline Driver performance & 26 & & & 32 \\
\hline On-time performance & 5 & 42 & 16 & 37 \\
\hline System productivity & 16 & & & 42 \\
\hline \multicolumn{5}{|c|}{ Automatic Vehicle Location } \\
\hline Customer satisfaction & 20 & 27 & 20 & 33 \\
\hline Driver performance & 20 & 33 & 13 & 34 \\
\hline On-time performance & 25 & & & 44 \\
\hline System productivity & 0 & 29 & 21 & 50 \\
\hline \multicolumn{5}{|c|}{ Advanced Telephone System } \\
\hline Customer satisfaction & 10 & 40 & 20 & 30 \\
\hline Reduction of "no shows" & 18 & & & 28 \\
\hline System productivity & 27 & 37 & 9 & 27 \\
\hline Labor costs & 10 & & & 20 \\
\hline \multicolumn{5}{|c|}{ Vehicle Security Cameras } \\
\hline Customer satisfaction & 19 & 44 & 25 & 12 \\
\hline Driver performance & 19 & 50 & 12 & 19 \\
\hline System productivity & 25 & 19 & 31 & 25 \\
\hline
\end{tabular}




\section{Lessons Learned}

This section summarizes lessons learned by agencies as reported by staff interviewed during site visits. The interviewees all agreed that the 'best bang for the buck' was attained by deploying vehicle security cameras. The benefits of cameras, as shared by all agencies interviewed, was protection of drivers and passengers, incident management, risk reduction, conflict mitigation, and eliminating unfounded liability payouts. Some agencies are pulling video recordings for random inspection to make sure all processes are properly followed by operators. This procedure has the potential to reduce the tasks of field inspectors.

\section{Lessons Learned for Vendor Selection}

- Vendors should be able to provide references, and agencies should take the time to interview these references. Building upon the research presented in this report, peer agencies should be asked about their experiences with vendor technical support, training, availability via phone or in person, timely responsiveness to issues/challenges that come up during transition from old to new system, updates, and customer service beyond the transition. A vendor's timely response to peer agencies is a good indication of its availability.

- Hands-on training provided by a vendor is key in the success of transitioning to new systems. Agencies should make sure ample opportunities are provided for training the staff as well as the operators. In addition, agencies should set up train-the-trainer sessions so staffs are confident in training new operators on the system even after transitioning is completed. Agencies should make sure that contracts include training sessions and/or online educational sessions for their staff.

\section{Lessons Learned for System Selection}

- Before specifications of a new system are decided upon, agencies should seek the input of all agency staff involved in the paratransit operation. Upper management may know in general what all the staff jobs entail, but they may not be as familiar with the intricate data needs required for performing day-to-day tasks, particularly that of report generation.

- Agencies should understand the uniqueness of their system including their specific needs. Since the software is usually standardized, it is recommended that an agency makes sure to explain its specific needs in the planning process before the package for the agency is developed. Data fields that have been used for years in old software may not correspond to the new, and adjustments or customizations may be needed. An agency is better off making this customization upfront than trying to retrofit changes in the software. This task relates to the previous bullet in that all agency staff should describe how they use the current software and how it can be improved to increase the efficiency of their day-to-day tasks.

\section{Lessons Learned for Transitioning to New Technologies}

- New and old systems should be run in parallel for at least a month until all glitches are worked out. Even if this means that the agency will be paying two vendors simultaneously, it is well worth it so as not to fall behind in reporting and billing of trips. One interviewee recalled another agency falling weeks behind in invoicing and billing, resulting in a labor-intensive catch-up process.

- Some resistance to new technology should be expected from staff and operators, but with training attitudes towards change will be more positive once benefits are realized and trust is built. This lesson can be mitigated using the following examples: 
- Collier Area Transit piloted its new technology with key selected vehicle operators who were more technology-enthusiastic than others.

- Pasco County piloted its new technology with 10 operators and deployed the full system after bugs were worked out so the transition was as smooth as possible.

\section{Other Tips}

- Investing in a vehicle security camera system was cited by several agencies as providing the "best bang for the buck." The benefits of video cameras included protection of drivers and passengers, incident management, risk reduction, conflict mitigation, and eliminating unfounded liability payouts.

- Some agencies pull videos for random inspection to make sure operators properly follow all procedures. This policy could reduce the tasks of field inspectors.

- Agencies must have a backup plan in case of Internet or cellular data communications failure such as paper manifests, two-way radio communications, and cell phone access to the software system, etc.

- The deployments have shown that the technologies are helping in increasing overall system efficiency. The effectiveness of these technologies may take time to be realized in full, but money will be saved in the long run from efficiency and performance improvements. Patience is key. 


\section{References}

[1] U.S. Government Accountability Office (GAO). ADA paratransit services: demand has increased, but little is known about compliance (GAO-13-17, Nov. 15,).

Washington, D.C.: GAO. 2012.. Accessed June 23, 2015, at http://gao.gov/assets/660/650079.pdf

[2] R. Brooks, "Emerging trends in paratransit pose new challenges - Five key points ease the struggle with increasing demand, rising costs and declining revenues," Bus Ride, 2012. Accessed July 14, 2014, at http://www.transdevna.com/Veolia/media/VeoliaNews/busride-comEmerging trends in paratransit pose new challenges.pdf.

[3] J. A. Goodwill and H. Carapella, Creative ways to manage paratransit costs (Florida Department of Transportation Research Report BD549-28). Florida International University, Miami, Florida, 2008. Accessed June 5, 2014, at http://www.nctr.usf.edu/pdf/77606.pdf.

[4] Florida APTS Technologies, scheduling/operational software (demand-response), 2011. Accessed June 2, 2014, at http://floridaapts. Ictr.org/technology fleet dr.html.

[5] Nicole Schlosser, "2013 Paratransit survey: Paratransit operators continue to grapple with funding, demand, retention," Metro Magazine, August 2013. Accessed June 18, 2015, at http://www.metromagazine.com/resources/images/paratransit-1.pdf.

[6] City of Petaluma, California, Paratransit scheduling software RFP \& vendor selection, 2010. Accessed September 11, 2014, at http://petaluma.granicus.com/MetaViewer.php?view id=11\&clip id=1118\&meta id $=214561$.

[7] J. Volinski, TCRP Synthesis 112: Maintaining transit effectiveness under major financial constraints, Transit Cooperative Research Program, Transportation Research Board, Washington DC, 2014. Accessed August 14, 2014, at http://onlinepubs.trb.org/onlinepubs/tcrp/tcrp syn 112.pdf.

[8] Florida APTS Technologies, Mobile data terminal, 2011. Accessed May 28, 2014, at http://floridaapts. Ictr.org/technology comm mob.html.

[9] J. Volinski, A review of the cost benefit of mobile data terminals in paratransit operations, Center for Urban Transportation Research, 2003. White paper.

[10] Transit Cooperative Research Program, TCRP Report 124: Guidebook for measuring, assessing, and improving performance of demand-response transportation, 2008. Accessed September 11, 2014, at http://onlinepubs.trb.org/onlinepubs/tcrp/tcrp rpt 124.pdf.

[11] "How GPS works - Educational poster," www.GPS.gov. National Coordination Office for Space-Based Positioning, Navigation, and Timing, 2013. Accessed at http://www.gps.gov/multimedia/poster/.

[12] F. Cevallos, Q. Yuan, S. Wang, J. Skinner, and A. Gan, Feasibility study on the use of personal GPS devices in paratransit, (Florida Department of Transportation Research Report) May 2009. Accessed May 28, 2014, at http://www.fta.dot.gov/documents/TRANSPO Feasibility GPS Paratransit Final.p df.

[13] Mentor Engineering, Brochure: Mentor Ranger. Accessed July 5, 2014, at http://www.fieldtechnologiesonline.com/doc/mentor-ranger-0001.

[14] Florida APTS Technologies, Automatic vehicle location, 2011. Accessed May 23, 2014, at http://floridaapts. Ictr.org/technology fleet avl.html.

[15] Federal Transit Administration, Automatic vehicle location fact sheet: transit overview, 2014. Accessed June 23, 2015, at https://www.pcb.its.dot.gov/factsheets/avl/avl overview.aspx\#page=tech. 
[16] United States Department of Transportation, undated, Transit management systems, Accessed May 27, 2014, at http://ntl.bts.gov/lib/jpodocs/repts te/14073 files/sec 2 3.htm.

[17] Federal Transit Administration, Automatic vehicle location/human service transit," December 2007. Accessed September 26, 2014, at http://www.pcb.its.dot.gov/factsheets/avl/avlHum.pdf.

[18] D. J. Parker, TranSystems Corporation, TCRP Synthesis 73: AVL systems for bus transit: update, Transit Cooperative Research Program, Transportation Research Board, Washington DC, 2008. Accessed July 14, 2014, at http://www.tcrponline.org/PDFDocuments/tsyn73.pdf.

[19] D. Roos, How Interactive Voice Response (IVR) Works. Accessed September 11, 2014 at http://electronics. howstuffworks.com/interactive-voice-response5.htm.

[20] Rodell Notbohm, How transit video surveillance systems play an important role in security and efficiency, 2013. Accessed June 2, 2014, at http://security-today.com/articles/2013/04/01/how-transit-video-surveillancesystems-play-an-important-role-in-security-and-efficiency.aspS.

[21] "Auditors recommend video surveillance for Milwaukee paratransit," Metro Magazine, January 3, 2014. Accessed June 2, 2014, at http://www.metromagazine.com/news/story/2014/01/auditors-recommend-video-surveillance-formilwaukee-paratransit.aspS.

[22] S. Schultze, "Some Milwaukee County riders reported timeliness problems," Milwakee. Wisconsin Journal Sentinel, January 2014. Accessed June 2, 2014, at http://www.jsonline.com/news/milwaukee/paratransit-riders-like-service-surveyfinds-but-video-cameras-urged-b99171277z1-238390011.html.

[23] DriveCam by Lytx, Case Study - Easton Coach Company, 2013. Accessed June 30, 2014, at http://www.lytx.com/uploads/Easton-Case-

Study 05130038 2.pdf.

[24] Paratransit Inc., Customer Service.Online source. Accessed June 18, 2014, at http://www.paratransit.org/php/customer service.php.

[25] Intelligent Transportation Systems Joint Program Office, U.S.DOT, Benefits Database. Implementation of paratransit software with Automatic Vehicle Location/Mobile Data Terminal (AVT/MDT) technologies leads to increase in trip productivity; reduction in administrative staff; and greater overall confidence in the transportation system. March 2003. St. Johns County, Florida. Accessed October 2, 2015 at http://www.itsbenefits.its.dot.gov/its/benecost.nsf/SummID/B201000637?OpenDocument\&Query=Home

[26] R. G. Mathias, TCRP Synthesis 60: Practices in no-show and late cancellation policies for ADA paratransit, Transit Cooperative Research Program, Transportation Research Board, Washington DC, 2005. Accessed July 11, 2014, at http://onlinepubs.trb.org/onlinepubs/tcrp/tcrp syn 60.pdf.

[27] ADEPT for PACE. July 2013. Accessed July 14, 2014, at http://www.stratagen.com/assets/adeptforpace.pdf.

[28] 2014 Annual Performance Report of the Florida Commission for the Transportation Disadvantaged. Florida Commission for the Transportation Disadvantaged. Accessed October 2, 2015, at http://www.dot.state.fl.us/ctd/docs/AORAPRDocs/Final2014AOR.pdf. 


\section{Appendix A - Survey Instrument}

(The survey questions below were formatted from the online version to fit this document.)

1. Please provide us with agency information:

Your Agency

Agency Address

City/Town

ZIP/Postal Code

2. Which type of paratransit vehicles do you currently use?

Number

(Please check all that apply)

of units

\section{Sedans}

Mini Vans

Light-duty small bus, cutaways, and modified van (length: 16 to $28 \mathrm{ft}$.; seats: 10

to 22)

Medium-duty and purpose built bus (length: $30 \mathrm{ft}$; seats: 22 to 30 )

Heavy-duty small bus (length: $30 \mathrm{ft}$.; seats: 26 to 35 )

Heavy-duty large bus (length: 35 to $48 \mathrm{ft}$. and $60 \mathrm{ft}$.; seats: 27 to 40 )

Other (please specify)

3. Which methods can customers use to reserve a trip? (Please check all that apply)
Telephone
Email
Website
Text
Smart Phone Application
Mail
Other (please specify)

4. Which type of paratransit services does your agency provide? (Please select all that apply).

Transportation Disadvantaged

American with Disabilities Act (ADA) complementary paratransit

Medicaid Non-Emergency Transportation

Agency for Persons with Disabilities

Area Agency on Aging

Other (please specify)

5. Which of the following technologies does your agency currently use on its system? (Please check all that apply)

Global Positioning System (GPS)

Automatic Vehicle Location (AVL)

Mobile Data Computer (MDC) or Mobile Data Terminal (MDT)

Reservation, Scheduling, and Dispatching Software

Advanced Telephone System (automated service, call forwarding, voicemail, call hold)

Advanced Telephone System including Interactive Voice Response (IVR)

Vehicle Security Cameras (internal or external)

Other (please specify)

6. Does your agency use Mobile Data Computers (MDC) or Mobile Data Terminals (MDT)?

Yes

No

7. Which company manufactured your MDC or MDT?

8. When was your MDC or MDT system installed? 
9. Which of the following did your MDC or MDT system (package) include?

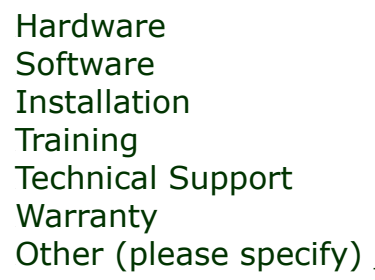

10. How many years does your warranty last?

11. How many fleet vehicles are the MDC or MDT systems installed on?

12. What was the total cost of your MDC or MDT systems to your agency? (Total costs includes all hardware, software, installation, training, technical support, and warranty for all vehicles)

13. When was your MDC or MDT system's software last updated?

14. When was your MDC or MDT system's hardware last updated?

15. How did the use of MDC or MDT impact the reduction of "no shows"?

Unknown

No impact

Moderate impact

Significant impact

Please tell us why you selected this response

16. How did the use of MDC or MDT impact driver performance?
Unknown
No impact
Moderate impact
Significant impact

Please tell us why you selected this response

17. How did the use of MDC or MDT impact your system's on-time performance?
Unknown
No impact
Moderate impact
Significant impact

Please tell us why you selected this response

18. Does your agency use Global Positioning System (GPS) technology?

$$
\begin{aligned}
& \text { Yes } \\
& \text { No }
\end{aligned}
$$

19. Did any of your vehicles come equipped with GPS? If yes, how many?

20. If GPS units were added to your fleet vehicles, which company manufactured your GPS?

21. How many vehicles in your fleet are equipped with a GPS?

22. Which of the following did your GPS (package) include?
Hardware
Software
Installation
Training
Technical Support
Warranty
Other (please specify)

23. How many years does your warranty last?

24. What was the total cost of your GPS system on all vehicles? (Total costs includes all hardware, software, installation, training, technical support, and warranty)

25. When was your GPS system installed? 
26. When was your GPS system's hardware last updated?

27. When was your GPS system's software last updated?

28. How did the use of GPS impact your system's on-time performance?

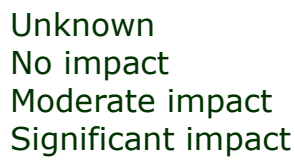

Please tell us why you selected this response

29. How did the use of this technology impact your system's productivity (passengers per revenue hour)?
Unknown
No impact
Moderate impact
Significant impact

Please tell us why you selected this response

30. How did the use of GPS impact your agency's customer satisfaction?
Unknown
No impact
Moderate impact
Significant impact

Please tell us why you selected this response

31. How did the use of GPS impact the reduction of "no shows"?
Unknown
No impact
Moderate impact
Significant impact

Please tell us why you selected this response

32. How did the use of GPS impact driver performance?
Unknown
No impact
Moderate impact
Significant impact

Please tell us why you selected this response

33. Does your agency use Automated Vehicle Location (AVL)?
Yes
No

34. Which company manufactured your AVL system?

35. Is AVL installed on all your fleet vehicles?

Yes

No

How many vehicles in your fleet do not have AVL?

36. Which of the following did your AVL system (package) include?

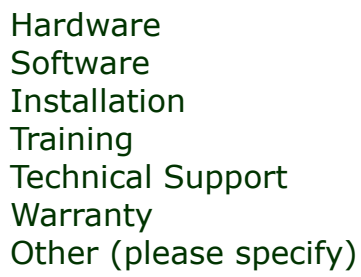

37. How many years does your warranty last? 
38. What was the total cost of your AVL system on all vehicles? (Total costs includes all hardware, software, installation, training, technical support, and warranty)

39. When was your AVL system installed?

40. When was your AVL system's hardware last updated?

41. When was your AVL system's software last updated?

42. How did the use of AVL impact your system's on-time performance?

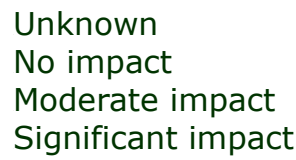

Please tell us why you selected this response

43. How did the use of AVL impact your system's productivity (passengers per revenue hour)?

Unknown

No impact

Moderate impact

Significant impact

Please tell us why you selected this response

44. How did the use of AVL impact your agency's customer satisfaction?

Unknown

No impact

Moderate impact

Significant impact

Please tell us why you selected this response

45. How did the use of AVL impact driver performance?

Unknown

No impact

Moderate impact

Significant impact

Please tell us why you selected this response

46. How did the use of AVL impact the reduction of "no shows"?

Unknown

No impact

Moderate impact

Significant impact

Please tell us why you selected this response

47. Does your agency use reservation, scheduling, and dispatching software?

Yes

No

48. Which company manufactured your reservation, scheduling, and dispatching software system?

49. Your reservation, scheduling, and dispatching software system (package) included which of the following:
Hardware
Software
Installation
Training
Technical Support
Warranty
Other (please specify)

50. How many years does your warranty last? 
51. What was the total cost of your reservation, scheduling, and dispatching software system? (Total costs includes all hardware, software, installation, training, technical support, and warranty)

52. When was your reservation, scheduling, and dispatching software system installed?

53. When was your reservation, scheduling, and dispatching software system last updated?

54. How did the use of the reservation, scheduling, and dispatching software system impact your system's on-time performance?

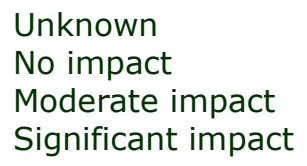

Please tell us why you selected this response

55. How did the use of reservation, scheduling, and dispatching software system impact driver performance?

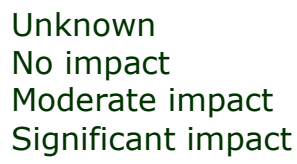

Please tell us why you selected this response

56. How did the use of reservation, scheduling, and dispatching software system impact your agency's labor costs?

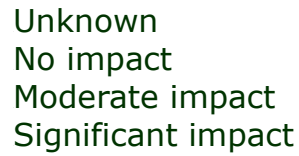

Please tell us why you selected this response

57. How did the use of reservation, scheduling, and dispatching software system impact customer satisfaction?

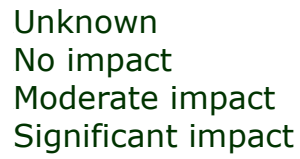

Please tell us why you selected this response

58. How did the use of the reservation, scheduling, and dispatching software system impact your system's on-time performance?
Unknown
No impact
Moderate impact
Significant impact

Please tell us why you selected this response

59. How did the use of reservation, scheduling, and dispatching software system impact the reduction of "no-shows"?

Unknown

No impact

Moderate impact

Significant impact

Please tell us why you selected this response

60 . Does your agency use advanced telephone system with automated service, call forwarding, voice-mail, and call hold?

$$
\begin{aligned}
& \text { Yes } \\
& \text { No }
\end{aligned}
$$

61. Which company manufactured your advanced telephone system with automated service, call forwarding, voice-mail, and call hold? 
62. The purchase of your advanced telephone system with automated service, call forwarding, voice-mail, and call hold included which of the following:

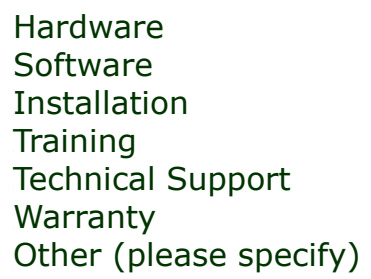

63. How many years does your warranty last?

64. What was the total cost of your advanced telephone system with automated service, call forwarding, voice-mail, and call hold? (Total costs includes all hardware, software, installation, training, technical support, and warranty)

65. When was your advanced telephone system with automated service, call forwarding, voice-mail, and call hold installed?

66. When was your advanced telephone system with automated service, call forwarding, voice-mail, and call hold last updated?

67. How did the use of this technology impact your agency's productivity?

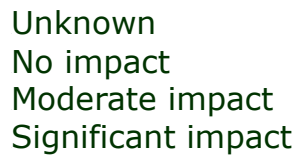

Please tell us why you selected this response

68. How did the use of this technology impact the reduction of "no shows"?

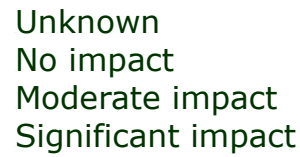

Please tell us why you selected this response

69. How did the use of this technology impact your agency's customer satisfaction?
Hardware
Software
Installation
Training
Technical Support
Warranty
Other (please specify)

70. Does your agency use advanced telephone system including Interactive Voice Response (IVR)?

Yes

No

71. Which company manufactured your advanced telephone system including IVR)?

72. The purchase of your advanced telephone system including IVR included which of the following:
Hardware
Software
Installation
Training
Technical Support
Warranty
Other (please specify)

73. How many years does your warranty last?

74. What was the total cost of your advanced telephone system including IVR? (Total costs includes all hardware, software, installation, training, technical support, and warranty) 
75. When was your advanced telephone system including IVR installed?

76. When was your advanced telephone system including IVR last updated?

77. How did the use of this technology impact driver performance?

Unknown

No impact

Moderate impact

Significant impact

Please tell us why you selected this response

78. How did the use of this technology impact customer satisfaction?

Unknown

No impact

Moderate impact

Significant impact

Please tell us why you selected this response

79. How did the use of this technology impact your system's on-time performance?

Unknown

No impact

Moderate impact

Significant impact

Please tell us why you selected this response

80. How did the use of this technology impact your system's productivity?
Unknown
No impact
Moderate impact
Significant impact

Please tell us why you selected this response

81. How did the use of this technology impact the reduction of "no shows"?
Unknown
No impact
Moderate impact
Significant impact

Please tell us why you selected this response

82. Does your agency use vehicle security cameras (internal and external)?

Yes

No

83. Which company manufactured your vehicle security camera system?

84. How many years does your warranty last?

85. The purchase of your vehicle security cameras system included which of the following:
Hardware
Software
Installation
Training
Technical Support
Warranty
Other (please specify)

86. How many years does your warranty last?

87. What was the total cost of your vehicle security camera system? (Total costs includes all hardware, software, installation, training, technical support, and warranty)

88. How many paratransit vehicles were vehicle security cameras installed on?

89. When were your vehicle security cameras installed? 
90. When was the hardware for your vehicle security camera system last updated?

91. When was the software for your vehicle security camera system last updated?

92. How did the use of this technology impact your system's productivity or performance?
Unknown
No impact
Moderate impact
Significant impact

Please tell us why you selected this response

93. How did the use of vehicle security cameras impact customer satisfaction?
Unknown
No impact
Moderate impact
$\square \quad$ Significant impact

Please tell us why you selected this response

94. How did the use of this technology impact driver performance?
Unknown
No impact
Moderate impact
$\square \quad$ Significant impact

Please tell us why you selected this response

95. Please provide us with your contact information:

Your name

Your title

Email

Phone Number 